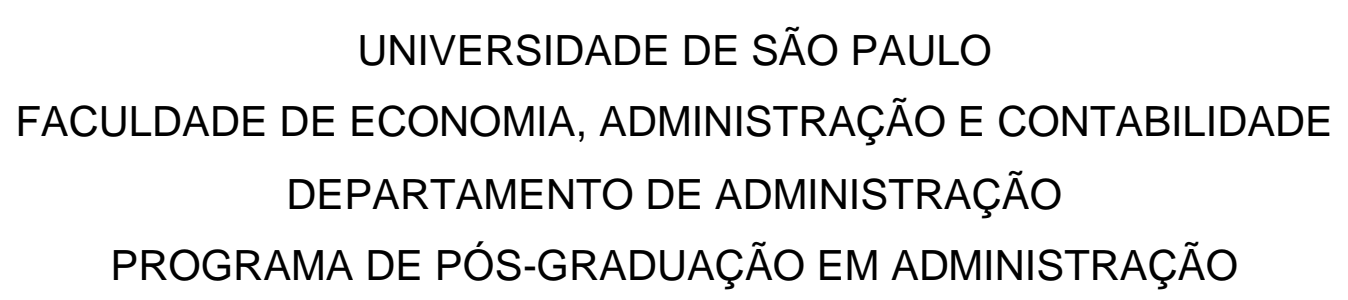

A PRÁTICA DE DESENVOLVIMENTO DE RECURSOS HUMANOS:

APRENDIZAGEM INDIVIDUAL E A INTENÇÃO DE PERMANECER NA ORGANIZAÇÃO.

Carla Almiñana Moreira

Orientador: Prof. Dr. Joel Souza Dutra

São Paulo

2020 
Prof. Dr. Vahan Agopyan

Reitor da Universidade de São Paulo

Prof. Dr. Fábio Frezatti

Diretor da Faculdade de Economia, Administração e Contabilidade

Prof. Dr. Moacir de Miranda Oliveira Júnior

Chefe do Departamento de Administração

Prof. Dr. Eduardo Kazuo Kayo

Coordenador do Programa de Pós-Graduação em Administração 
Carla Almiñana Moreira

\begin{abstract}
A PRÁTICA DE DESENVOLVIMENTO DE RECURSOS HUMANOS: APRENDIZAGEM INDIVIDUAL E A INTENÇÃO DE PERMANECER NA ORGANIZAÇÃO.
\end{abstract}

Dissertação apresentada ao Programa de PósGraduação em Administração do Departamento de Administração da Faculdade de Economia, Administração e Contabilidade da Universidade de São Paulo como requisito parcial para a obtenção do título de Mestre em Ciências.

Orientador: Prof. Dr. Joel Souza Dutra

Versão Corrigida

(versão original disponível na Biblioteca da Faculdade de Economia, Administração e Contabilidade)

São Paulo 
Catalogação na Publicação (CIP)

Ficha Catalográfica com dados inseridos pelo autor

Moreira, Carla Almiñana.

A PRÁTICA DE DESENVOLVIMENTO DE RECURSOS HUMANOS: APRENDIZAGEM INDIVIDUAL E A INTENÇÃO DE PERMANECER NA ORGANIZAÇÃO / Carla Almiñana Moreira. - São Paulo, 2020. $112 \mathrm{p}$.

Dissertação (Mestrado) - Universidade de São Paulo, 2020.

Orientador: Joel de Souza Dutra.

1. Desenvolvimento de Recursos Humanos. 2. Aprendizagem. 3.

Retenção. 4. Práticas de Desenvolvimento. I. Universidade de São Paulo.

Faculdade de Economia, Administração e Contabilidade. II. Título. 
Carla Almiñana Moreira

\section{A PRÁTICA DE DESENVOLVIMENTO DE RECURSOS HUMANOS: APRENDIZAGEM INDIVIDUAL E A INTENÇÃO DE PERMANECER NA ORGANIZAÇÃO.}

Dissertação apresentada ao Programa de PósGraduação em Administração do Departamento de Administração da Faculdade de Economia, Administração e Contabilidade da Universidade de São Paulo como requisito parcial para a obtenção do título de Mestre em Ciências.

Aprovado em:

Banca examinadora:

Prof.(a) Dr.(a):

Instituição:

Julgamento:

Prof.(a) Dr.(a):

Instituição:

Julgamento:

Prof.(a) Dr.(a):

Instituição:

Julgamento: 


\section{DEDICATÓRIA}

Aos meus pais que tanto valorizam o aprendizado e sempre ofereceram todo o apoio para que eu pudesse nutrir uma mente curiosa, investigativa e crítica.

Ao meu marido Maurício e filho Pedro que foram suporte emocional, apoio incondicional e paciência sem fim para todos os momentos de dúvida e ansiedade que acompanham essa jornada. 


\section{AGRADECIMENTOS}

Expresso aqui os meus mais profundos agradecimentos ao professor Joel Dutra por ter acreditado, inspirado e ajudado a dar contorno a este projeto. Agradeço todo o apoio, tranquilidade, sabedoria e direção, tão necessários em tantos momentos.

Ao professor Diógenes Bido que ofereceu um espaço de rico debate sobre a aprendizagem e contribuição imprescindível para a construção do meu conhecimento sobre métodos quantitativos, o que me desafiou a seguir nessa direção.

Aos demais professores da USP, aqui representados pelos professores Wilson Amorin, André Fischer e Marília Martins, meus agradecimentos não só pela contribuição com a minha formação teórica, mas também pelo exemplo e inspiração do que significa a construção científica do conhecimento.

A minha querida amiga Tatiana Dutra que viu em mim uma mestranda, antes até de mim mesma, meu agradecimento pelo apoio, escuta acolhedora e orientações generosas.

À Elaise Rocha Lopes por toda a generosidade, apoio e tenacidade em facilitar o meu navegar por todos os processos que envolveram essa jornada.

À Secretária de Pós Graduação da FEA pelo incansável suporte e orientação para o meu navegar pelos processos dentro da Universidade. 


\section{RESUMO}

Esta dissertação tem por objetivo investigar a percepção dos empregados de empresas alvo sobre a prática de desenvolvimento de recursos humanos (DRH), aprendizagem individual. A pesquisa buscou definições teóricas e modelos de $\mathrm{DRH}$ até chegar nas práticas que foram investigadas por meio da leitura e do levantamento de 75 artigos internacionais relacionados ao tema. Tal levantamento possibilitou compreender a aprendizagem como elemento relevante do campo de investigação do $\mathrm{DRH}$ e definir a aprendizagem individual como foco deste estudo. Assim, com o objetivo de investigar a percepção dos empregados sobre as Práticas de DRH no componente Aprendizagem Individual e sua associação a Intenção de Permanecer em empresas alvo no Brasil, foram utilizados dados secundários, oriundos de pesquisa desenvolvida pelo Programa de Estudos em Gestão de Pessoas (PROGEP), entidade pertencente à Fundação Instituto de Administração (FIA), foram analisados os questionários de 249.783 empregados e utilizados como métodos de análise: tabelas de contingência, teste qui-quadrado e teste de Kruskal-Wallis. A pesquisa encontrou, tanto quando analisadas cada uma das perguntas que compõem a variável Percepção sobre a Prática Aprendizagem Individual de forma independente, quanto avaliando a variável como efeito conjunto, e suas relações com a variável Intenção de Permanecer na Organização, evidências de associação entre as variáveis. Esta associação foi significativa estatisticamente em todos os testes, podendo-se pensar que quanto menos favorável a percepção dos empregados das empresas alvo sobre a Prática de DRH Aprendizagem Individual, menor a intenção dos empregados em permanecer na organização. A pesquisa pode contribuir para a construção do conhecimento de Práticas de $\mathrm{DRH}$ no país e para o aprofundamento do conhecimento sobre a percepção dos empregados sobre a prática aprendizagem individual.

PALAVRAS-CHAVE: Desenvolvimento de Recursos Humanos, Aprendizagem, Retenção, Práticas de Desenvolvimento 


\begin{abstract}
This study aims to investigate the perception of employees from target companies about Individual Learning, a Human Resources Development (HRD) practice. The research moved from theoretical definitions and models of HRD to the practices that were investigated through the analysis of 75 international articles related to the theme. Such investigation made it possible to understand learning as a relevant component in the research field of the HRD and to define individual learning as a focus of the study, as well as its dimensions as guidelines for the construction of the research variable. Thus, with a focus on investigating employees' perception about the HRD Practice of Individual Learning, and its association with the Intention to Stay at the target companies in Brazil, the research used secondary data from a database developed by the Programa de Estudos em Gestão de Pessoas (PROGEP), part of Fundação Instituto de Administração (FIA), this research analyzed 249,783 employees questionnaires, using following methods of analysis: contingency tables, chi-square test and Kruskal-Wallis test.

The research found, both when analyzing each of the questions that make up the variable Perception about Individual Learning Practice independently, and evaluating the variable as a joint effect, and well as its relations with the variable Intention to Stay in the Organization, evidence of association between those variables. This association was statistically significant in all tests, and one can think that the less favorable the perception of employees of the target companies about the Practice of HRD Individual Learning is, the lower the Employees' Intention to Stay in the Organization. The research can contribute to the body knowledge of HRD Practices in the context of Brazil and to the deepening of understanding about the perception of employees regarding individual learning practices.
\end{abstract}

KEYWORDS: Human Resources Development, Learning, Retention, Development Practices 


\section{LISTAS DE GRÁFICOS}

Gráfico 1 - Resultados Esperados sem o Efeito de Associação para o item

Apr_Soc_1 e IPO

Gráfico 2 - Resultados Observados para o item Apr_Soc_1 e IPO 65

Gráfico 3 - Resultados esperados sem o efeito da associação para o gênero e IPO

Gráfico 4 - Resultados Observados para Gênero e IPO................................................... 66

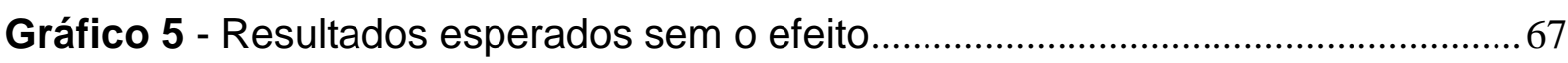

Gráfico 6 - Resultados Observados.

Gráfico 7 - Resultados esperados sem o efeito - Gostaria de me aposentar nesta empresa

Gráfico 8 - Resultados Observados - Gostaria de me aposentar nesta empresa .....69

Gráfico 9 - Box-plot da variável PPAI e IPO.

Gráfico 10 - Quantidade de Respondentes e Outliers da amostra por item da variável IPO 72

Gráfico 11 - Representação gráfica do teste Pos-hoc de Tukey 74

Gráfico 12 - Resultados Esperados sem o Efeito de Associação e Resultados Observados para item Apr_Soc_2 e IPO.

Gráfico 13 - Resultados Esperados sem o Efeito de Associação e Resultados Observados para item Apr_For_1 e IPO

Gráfico 14 - Resultados Esperados sem o Efeito de Associação e Resultados

Observados para item Apr_For_2 e IPO

Gráfico 15 - Resultados Esperados sem o Efeito de Associação e Resultados Observados para item Apr_Inf_1 e IPO

Gráfico 16 - Resultados Esperados sem o Efeito de Associação e Resultados Observados para item Apr_Inf_2 e IPO

Gráfico 17 - Resultados Esperados sem o Efeito de Associação e Resultados

Observados para item Apr_Exp_1 e IPO.

Gráfico 18 - Resultados Esperados sem o Efeito de Associação e Resultados

Observados para item Apr_Exp_2 e IPO. 


\section{LISTA DE QUADROS}

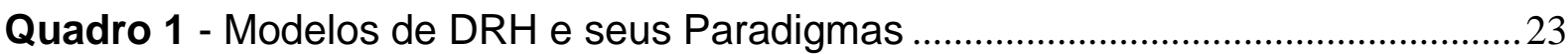

Quadro 2 - Dimensões e Perspectivas dos Modelos de DRH..........................................24

Quadro 3- Análise de artigos sobre Práticas de DRH .................................................... 32

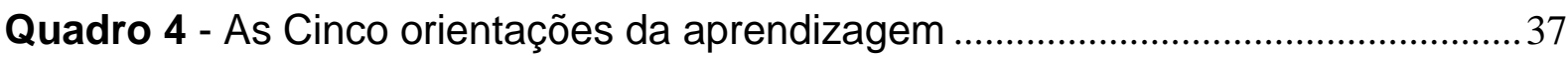

Quadro 5 - Definições de Intenção de Permanecer na Organização.............................. 41

Quadro 6 - Matriz de amarração ..................................................................................4

Quadro 7- Descrição da Variável Percepção sobre Prática de DRH Aprendizagem

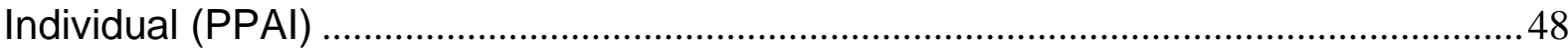

Quadro 8 - Descrição da Variável Intenção em Permanecer na Organização............49

Quadro 9 - Impacto da faixa de variação da correlação..................................................57

Quadro 10 - Análise do alpha padronizado padronizado por item da variável PPAI.58

Quadro 11 - Conjunto de histogramas da variável PPAI por item da variável IPO....73

Quadro 12 - 0 Saída do Testte Tukeyí ........................................................................ 


\section{LISTA DE TABELAS}

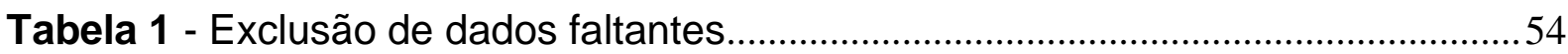

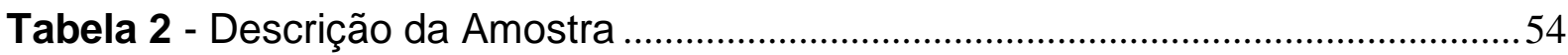

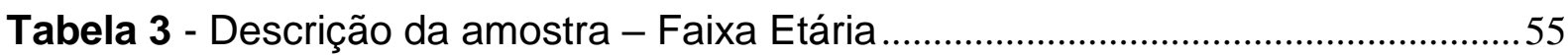

Tabela 4 - Percentual de respostas do item Apr_Soc_1 em relação ao total de respostas presentes na amostra por característica do respondente.

Tabela 5 - Percentual de respostas por item da variável "Intenção de Permanecer na Organização" por característica gênero

Tabela 6 - Percentual de respostas por item da variável "Intenção de Permanecer na Organização" por característica faixa etária

Tabela 7- Matriz de correlação da variável "Percepção Sobre Prática de DRH Aprendizagem Individual" (PPAI)57

Tabela 8 - Frequência de Respostas por item da Escala da variável PPAI 58

Tabela 9 - Percentual de Frequência de Respostas no Item sobre o total de Respostas

Tabela 10 - Frequência de Respostas e Percentual sobre amostra da variável IPO 59

Tabela 11 - Tabela de Contingência Apr_Soc_1 e IPO

Tabela 12 - Tabela de Contingência Apr_Soc_1 e IPO com frequência total de respostas sobre o total de respostas do grupo da variável IPO

Tabela 13 - Contagens Esperadas no cruzamento das variáveis Apr_Soc_1 e IPO.63

Tabela 14 - Outliers

Tabela 15 - Percentual de respostas sobre a amostra de Apr_Soc_1, Apr_Soc_2 por Gênero e Faixa Etária

Tabela 16 - Percentual de respostas sobre a amostra de Apr_For_1, Apr_For_2 por Gênero e Faixa Etária

Tabela 17- Percentual de respostas sobre a amostra de Apr_Inf_1, Apr_Inf_2 por Gênero e Faixa Etária

Tabela 18 - Percentual de respostas sobre a amostra de Apr_Exp_1, Apr_Exp_2 por Gênero e Faixa Etária 
Tabela 19 - Tabela de Contingência Apr_Soc_2 e IPO 103

Tabela 20 - Tabela de Contingência Apr_For_1 e IPO.................................................104

Tabela 21 - Tabela de Contingência Apr_For_2 e IPO................................................104

Tabela 22 - Tabela de Contingência Apr_Inf_1 e IPO .....................................................104

Tabela 23 - Tabela de Contingência Apr_Inf_2 e IPO ……………………………........ 105

Tabela 24 - Tabela de Contingência Apr_Exp_1 e IPO .................................................. 105

Tabela 25 - Tabela de Contingência Apr_Exp_2 e IPO................................................. 105

Tabela 26 - Tabela de Contingência Apr_Soc_2 e IPO com frequência total de respostas sobre o total de respostas do grupo da variável IPO...

Tabela 27 - Tabela de Contingência Apr_For_1 e IPO com frequência total de respostas sobre o total de respostas do grupo da variável IPO.

Tabela 28 - Tabela de Contingência Apr_For_2 e IPO com frequência total de respostas sobre o total de respostas do grupo da variável IPO.

Tabela 29 - Tabela de Contingência Apr_Inf_1 e IPO com frequência total de respostas sobre o total de respostas do grupo da variável IPO.

Tabela 30 - Tabela de Contingência Apr_Inf_2 e IPO com frequência total de respostas sobre o total de respostas do grupo da variável IPO. 108

Tabela 31 - Tabela de Contingência Apr_Exp_1 e IPO com frequência total de respostas sobre o total de respostas do grupo da variável IPO. 108

Tabela 32 - Tabela de Contingência Apr_Exp_2 e IPO com frequência total de respostas sobre o total de respostas do grupo da variável IPO. 


\section{SUMÁRIO}

1 INTRODUÇÃO

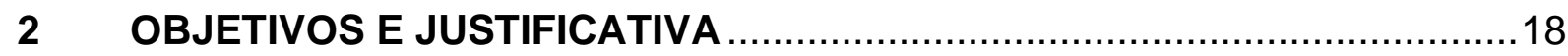

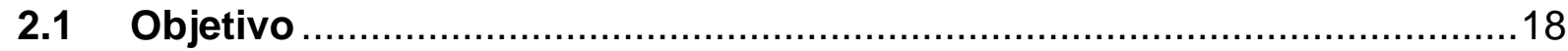

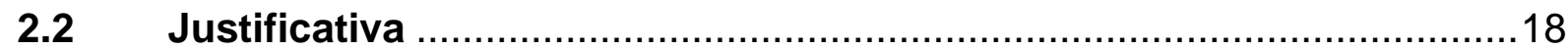

3 REFERENCIAL TEÓRICO

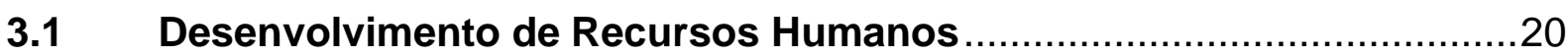

3.1.1 Modelos de Desenvolvimento de Recursos Humanos ........................21

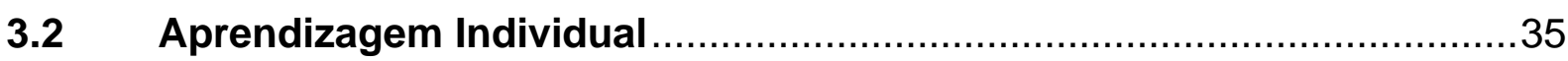

3.2.1 Componentes da Aprendizagem Individual ......................................37

3.2.1.1 Aprendizagem como processo social .............................................

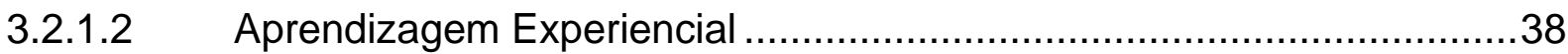

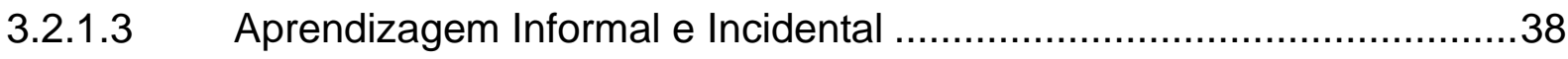

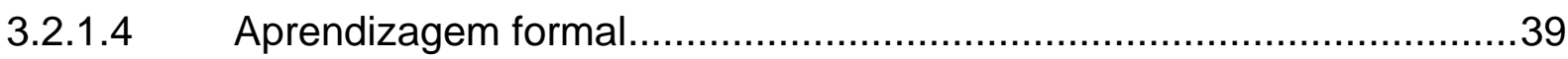

3.3 Intenção em permanecer na organização ……...................................... 40

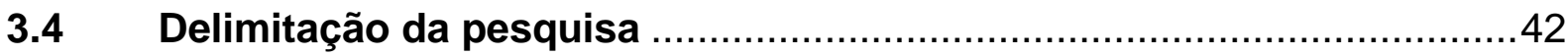

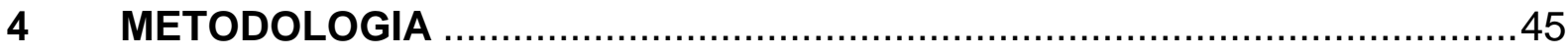

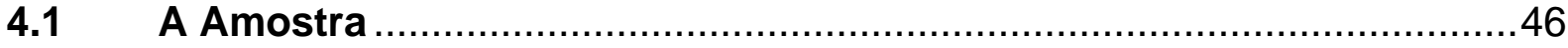

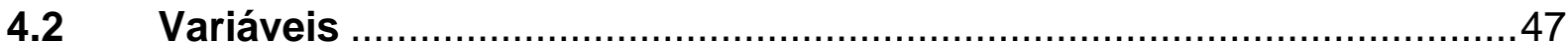

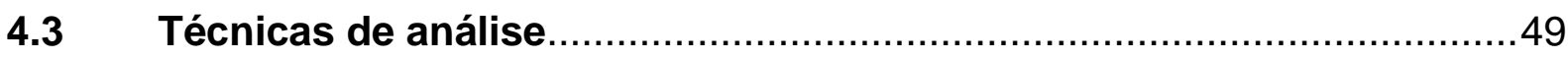

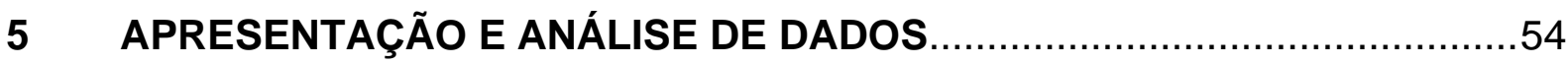

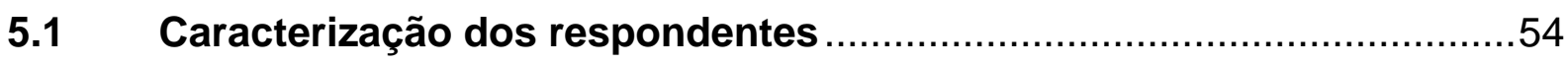

5.2 Análise da variável "Percepção Sobre Prática de DRH Aprendizagem

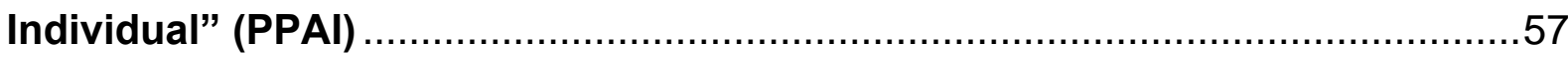

5.3 Análise da variável "Intenção de Permanecer na Organização" (IPO) ..59

5.4 Investigação da Associação entre as variáveis ...................................60

5.5 Associação entre o efeito conjunto da variável (PPAI) e (IPO) …...........70

5.6 Principais aspectos levantados na pesquisa ......................................75

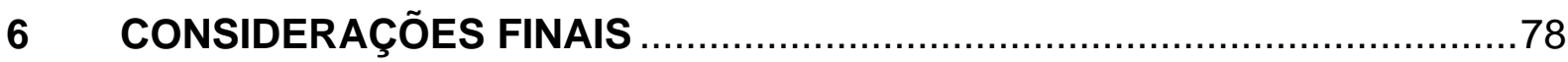

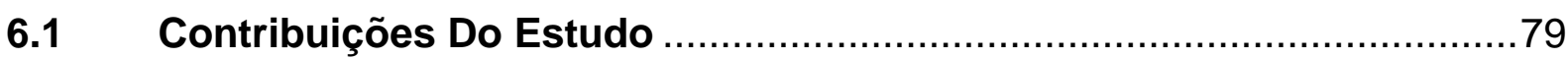

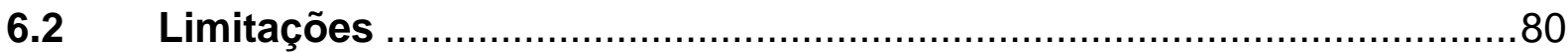


6.3 Recomendações Para Estudos Futuros......................................... 80

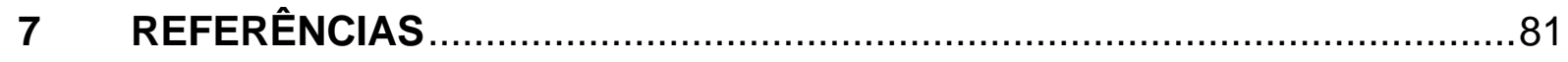

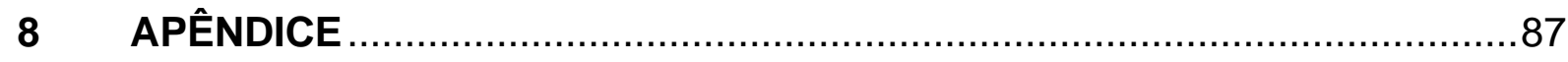

Apêndice A - Análise dos artigos da revisão teórica de Práticas de

Desenvolvimento de Recursos Humanos. ................................................. 87

Apêndice B: Tabelas Desenvolvidas na Análise de Dados ...........................101

Apêndice C: Tabelas de Contingência .................................................. 103

Apêndice D: Tabelas de contingência com percentual de respondentes ........106

Apêndice E: Gráfico de Resultados....................................................109 


\section{INTRODUÇÃO}

O tema Desenvolvimento de Recursos Humanos (DRH) continua sendo um tema relevante para as organizações. É um assunto tanto de interesse teórico, quanto um dilema prático no campo da Administração de Empresas, e mais especificamente, no âmbito da Gestão de Recursos Humanos. Pode-se considerar isso, seja por conta do impacto que o $\mathrm{DRH}$ possa ter no desempenho dos indivíduos, e consequentemente no desempenho da organização (Wickramasinghe, 2015; Otoo et al., 2018a; Otoo et al., 2018b; Otoo et al. 2019), ou porque, é por meio do desenvolvimento das pessoas que as condições para lidar com maior complexidade serão construídas, garantindo sua condição para competir em contexto de constante mudança (Lee, 2007; Garavan, 2007).

Não é possível prever quais os contextos futuros uma organização enfrentará, mas invariavelmente necessitará de pessoas que estejam preparadas para lidar com crescente complexidade. Na medida que a organização investe no desenvolvimento das pessoas, ela também se coloca em contínuo processo de desenvolvimento, condição para que seja bem-sucedida em lidar com as demandas do contexto. (Dutra, 2017)

Este trabalho iniciou buscando compreender as definições e modelos de DRH e ao se deparar com as inúmeras definições e ausência de consenso, investiga modelos de DRH a partir de seus paradigmas, utilizando as definições de Swanson e Holton (2009), mesmo entendendo que esta análise não esgota o campo de possibilidades de modelos de $\mathrm{DRH}$, já aponta para distância entre os modelos e as práticas de $\mathrm{DRH}$. Ainda que entendam as práticas como elementos que organizam os esforços em processos para a ação do $\mathrm{DRH}$, os modelos não são unanimes em tocar a intersecção da perspectiva organizacional e individual onde a prática emerge como o elemento que organiza a atividade humana.

O levantamento das Práticas de DRH realizado por este estudo evidencia um campo, organizado como Práticas de $\mathrm{DRH}$, ainda pouco explorado nacionalmente, no qual não foi encontrada produção sobre esta temática nos últimos 10 anos. Por outro lado, ainda que aproximadamente metade dos artigos levantados em bases internacionais considere seus achados e investigações implicações importantes na prática de $\mathrm{DRH}$, vários artigos investigam relações da prática do $\mathrm{DRH}$ com aprendizagem e na grande maioria das situações, investigando o caráter individual da 
aprendizagem. Assim, considerando que organizações como organismos cada vez mais descentralizados e fragmentados, compostas por uma força de trabalho mais diversificada e socialmente complexa e sujeitas a um ritmo de mudança mais rápido, a aprendizagem e a criação do conhecimento são elementos centrais para pessoas possam resolver problemas mais complexos e reais. (Korte \& Mercurio, 2017)

Por outro lado, o estudo evidência também ausência de consistência do que constitui o campo da prática de $\mathrm{DRH}$ onde, se por um lado há mais homogeneidade no entendimento do componente denominado aprendizagem, os componentes intitulados: desenvolvimento organizacional e desenvolvimento de carreira, apontam para maiores divergências. Observa-se que uma das limitações para a compreensão das práticas de DRH como um conjunto integrado e um campo de estudo é a própria maturidade do campo teórico de cada um dos componentes das Práticas de DRH (Wang, Werner, Sun, Gilley, \& Gilley, 2017).

Entre os artigos investigados a pesquisa encontrou artigos que apontavam para uma relação das práticas de $\mathrm{DRH}$, prolongando a vida profissional de empregados (Veth et al. 2015), ou reduzindo sua intenção de turnover (Shuck et al. 2014).

Em meio à discussão sobre as práticas de $\mathrm{DRH}$, a relevância do paradigma da aprendizagem, o indivíduo e sua percepção sobre as práticas e considerando a influência que as práticas de DRH podem ter na intenção dos empregados de permanecer na organização, surgiu a questão que orientou a pesquisa:

"A percepção dos empregados sobre as práticas de Desenvolvimento de Recursos Humanos no componente Aprendizagem Individual está associada à sua Intenção de Permanecer na Empresa?".

Esta pergunta e o desejo de explorar o contexto brasileiro e contribuir para a construção deste campo teórico no contexto nacional, além de aprofundar a compreensão da aprendizagem individual como prática de $\mathrm{DRH}$, oferecendo uma perspectiva tanto teórica quanto prática sobre o tema, orientaram este estudo. 


\section{OBJETIVOS E JUSTIFICATIVA}

\subsection{Objetivo}

O objetivo geral deste trabalho é Investigar a Percepção dos Empregados sobre as Práticas de DRH no componente Aprendizagem Individual e sua associação a Intenção de Permanecer na Empresa em Empresas Alvo no Brasil.

Os objetivos específicos são:

- Investigar a Percepção dos empregados das empresas alvo, sobre a Prática de DRH Aprendizagem Individual.

- Investigar a Intenção dos Empregados em Permanecer na Organização nas empresas Alvo.

- Investigar a associação da Percepção do efeito conjunto das

Práticas de DRH Aprendizagem individual e a intenção de Permanecer na Empresa.

\subsection{Justificativa}

O Desenvolvimento dos Recursos Humanos vem sendo considerado elemento crítico para a perenidade e sustentabilidade das organizações (Dutra, 2017; Garavan, 2007; Garavan, McGuire, \& Lee, 2015; Lee, 2007; Mankin, 2001), no entanto suas práticas são menos estudadas, boa parte da literatura identificada refere-se a estudos que podem gerar implicações nas práticas de $\mathrm{DRH}$, não se dirigindo diretamente a elas. Se consideradas como a relação mais objetiva e concreta que os empregados têm com os modelos e construções teóricas, as práticas de DRH deveriam ser protagonistas de estudos e na revisão teórica nacional, têm sido mais negligenciadas ainda como um campo sob esta organização.

A definição das práticas de DRH ainda é incompleta e inconclusiva (Wang et al., 2017) e considerando que a aprendizagem é o componente das práticas mais estudadas, esta pesquisa se propôs a não só revisitar e aprofundar a compreensão das práticas de $\mathrm{DRH}$, como também investigar como a aprendizagem se desenvolve 
na percepção de empregados de empresas alvo, relacionando essa percepção à sua intenção em permanecer na organização.

Ainda que o estudo não tenha desconsiderado que existem inúmeros motivos pelos quais os empregados têm intenção de permanecer na organização que atuam, as oportunidades de aprendizado e crescimento na carreira foram compreendidas como um fator importante de retenção na organização, segundo Mello (2014) e pesquisas sobre as Práticas do $\mathrm{DRH}$ relacionaram a percepção dos indivíduos sobre essas práticas e a intenção de ficar na organização ou a intenção de turnover (Shuck, Twyford, Reio Jr., \& Shuck, 2014; Uraon, 2018), oferecendo a possibilidade de explorar este tema no contexto de empresas alvo no Brasil. 


\section{REFERENCIAL TEÓRICO}

\subsection{Desenvolvimento de Recursos Humanos}

O Desenvolvimento de Recursos Humanos (DRH) pode ser visto como um conceito fluido, adaptativo e em evolução que contribui para a mudança organizacional. Existem inúmeras definições sobre o que constitui DRH e muita controvérsia. É notável que suas definições mudam ou são superadas e isso pode ser visto como uma oportunidade dinâmica a ser abraçada e não criticada como contraditória. (Lee, 2007; Mankin, 2001)

O DRH é apresentado como um sistema composto pelas dimensões de "Desenvolvimento Organizacional", "Desenvolvimento de Carreira" e "Treinamento e Desenvolvimento". (Dias, 2017; Mankin, 2001; Sablok, Stanton, Bartram, Burgess, \& Boyle, 2017). Muito embora essa definição não seja unânime pois $\mathrm{DRH}$ e "Treinamento e Desenvolvimento" podem ser percebidos como termos simplesmente intercambiáveis, uma vez que se percebe em algumas posições, uma transição de treinamento e desenvolvimento para aprendizado, com as organizações reconhecendo a natureza penetrante da aprendizagem informal, no local de trabalho e em seus diferentes níveis de agregação (Garavan, 2007; Hubner \& Baum, 2018; Mankin, 2001).

Assim, ao considerar que em um mundo, onde as mudanças são a constante, e são vivenciados fenômenos como alterações em fronteiras, na natureza das organizações, nos padrões de flexibilização do trabalho e migrações virtuais, o $\mathrm{DRH}$ deve ser parte central da estratégia das organizações, fazendo o papel crucial de balancear as necessidades organizacionais e de seus empregados (Lee, 2007).

O desenvolvimento tem papel crucial para dar suporte a perpetuidade e sucesso organizacional, é o processo pelo qual o potencial individual é expandido (Garavan, 1997; Garavan et al., 2015). O desenvolvimento se constitui por processos de aprendizagem conscientes e inconscientes, bem como por meio de processos formais e informais, com vista a capacitar o indivíduo a assumir um papel futuro dentro da organização (Garavan et al., 2015; Hubner \& Baum, 2018). O desenvolvimento não se preocupa com a uniformidade dos resultados da aprendizagem, e concentra-se na 
premissa que ao melhorar os empregados, melhora a organização (Garavan, 1997). Dutra (2017) ressalta que a complexidade permitiu estabelecer uma definição operacional de desenvolvimento: a pessoa se desenvolve quando é capaz de realizar atribuições e assumir responsabilidades mais complexas e o mesmo vale para as organizações que também se desenvolvem na medida que são capazes de lidar com contextos mais complexos.

Ainda que consciente das inúmeras definições de $\mathrm{DRH}$ e da ausência de consenso, esta pesquisa não nega a importância da definição como algo que possa orientar e assim sendo, dar suporte à operacionalização dos contornos nos quais a pesquisa se desenvolve.

São as definições que orientam os modelos e assim como definições, existem inúmeros modelos de DRH. Não é o intuito aqui esgotar os modelos propostos para $\mathrm{DRH}$, mas observar como eles articulam conceitos e definições para a $\mathrm{DRH}$.

\subsubsection{Modelos de Desenvolvimento de Recursos Humanos}

Modelos teóricos são modos de explicação que servem para a análise ou esclarecimento de uma realidade concreta (Gouveia Jr, 1999). Segundo o autor, um modelo se caracteriza pela redutividade, pontualidade e contemporaneidade. A redutividade diz respeito a que, ao construir um modelo, são sempre feitas escolhas de um número finito de elementos do objeto que serão representados. A pontualidade diz respeito ao fato de um modelo representar um determinado fenômeno, e assim, ao representar este fenômeno e não representar outro. $E$, finalmente a contemporaneidade, diz respeito ao fato de que modelos são também coisas que se modificam segundo o lugar, momento histórico e posição social que são usadas. Um modelo é sempre reflexo do momento histórico e das crenças que aqueles que o concebem detém (Gouveia Jr, 1999).

Fischer (1998) considera que o uso da palavra modelo, quando se refere à modelos de gestão de pessoas, significa incluir em uma explicação não apenas os elementos de estrutura, instrumentos e práticas normatizadas, mas também incluir aquilo que interfere significativamente sobre as relações entre os indivíduos e a organização, gerando assim, um determinado padrão de comportamento característico daquela empresa. O autor considera que modelos são abstrações que 
nos ajudam a compreender e ao mesmo tempo agir sobre a realidade. $O$ autor considera que um modelo é uma simplificação, porque a complexidade do fenômeno real nunca pode ser retratada com total fidelidade e em todas as suas dimensões pelo modelo e que, além disso, um modelo também é uma abstração porque modelos emergem de representações, explicações a respeito do fenômeno real (Fischer, 1998).

Foram analisados 3 modelos sob o ponto de vista dos paradigmas apresentados por Swanson e Holton (2009). Os autores distinguem dois paradigmas de análise do $\mathrm{DRH}$, o primeiro aponta para foco no suporte ao atingimento dos objetivos estratégicos da organização, ou seja, perspectiva orientada para desempenho e o segundo para foco no suporte a aprendizagem dentro e fora do contexto organizacional, de forma informal ou formal, ou seja, perspectiva orientada para aprendizagem.

Os autores propõem dois objetivos bastante distintos do que seria o $\mathrm{DRH}$ orientado a cada um destes paradigmas. O paradigma de desempenho sustenta que o objetivo do DRH é avançar na missão do sistema de desempenho que patrocina seus esforços, melhorando tanto as capacidades dos indivíduos que trabalham no sistema e quanto os próprios sistemas nos quais eles realizam seu trabalho. Já no paradigma do aprendizado, o objetivo do DRH é o estímulo ao desenvolvimento, no longo prazo, de capacidade de aprendizagem e remoção de barreiras ao aprendizado de temas relacionados ao trabalho, no nível individual, de grupo e organizacional das organizações. (Swanson \& Holton, 2009)

Ainda que os autores encontrem valor em ambas as abordagens e proponham a reconciliação entre ambos paradigmas, é também verdade que de forma geral os caminhos teóricos tenham permanecidos separados. Ainda que o paradigma do desempenho como teoria, não desconsidere a aprendizagem como parte constituinte do sistema e que o paradigma do aprendizado não desconsidere o diálogo com a estratégia, cultura e objetivos da organização, os modelos tendem a se centrar em um dos paradigmas. (Swanson \& Holton, 2009).

Ainda que consciente da interconexão dos paradigmas o quadro 1, trata de apresentar os modelos de DRH e o paradigma no qual pode-se entender o modelo como mais centrado, a partir das lentes Swanson e Holton (2009). Foram trazidas 
aqui, em especial, as definições propostas para $\mathrm{DRH}$ pelos modelos de Bierema e Callahan (2014), Garavan (2007) e Mankin (2001).

Quadro 1 - Modelos de DRH e seus Paradigmas

\begin{tabular}{|l|l|l|l|l|}
\hline Garavan & Ano & \multicolumn{1}{|c|}{ Definição de DRH } & Paradigma & Por quê \\
\hline Mankin & 2007 & $\begin{array}{l}\text { Conjunto coerente, } \\
\text { verticalmente alinhado e } \\
\text { horizontalmente integrado de } \\
\text { atividades de aprendizagem e } \\
\text { desenvolvimento que } \\
\text { contribuem para o atingimento } \\
\text { dos objetivos estratégicos. }\end{array}$ & $\begin{array}{l}\text { Desempenho } \\
\text { Consiste no desenvolvimento } \\
\text { de estratégias e processos de } \\
\text { aprendizagem, nos níveis } \\
\text { individual, de grupo e } \\
\text { organizacional, que facilitam o } \\
\text { desbloqueio do potencial da } \\
\text { organização. }\end{array}$ & $\begin{array}{l}\text { Atingimento de } \\
\text { objetivos } \\
\text { estratégicos }\end{array}$ \\
\hline $\begin{array}{l}\text { Bierema } \\
\text { e } \\
\text { Callahan }\end{array}$ & 2014 & $\begin{array}{l}\text { Aprendizado } \\
\text { humanos e organizacionais que } \\
\text { se relacionam, aprendem, } \\
\text { mudam e se organizam de } \\
\text { maneira a otimizar o interesse } \\
\text { humano, o avanço da } \\
\text { organização e o impacto social }\end{array}$ & Aprendizado & $\begin{array}{l}\text { Desbloqueio de } \\
\text { potencial como: } \\
\text { acesso a maiores } \\
\text { capacidades; } \\
\text { facilidade para } \\
\text { encontrar } \\
\text { alternativas em } \\
\text { meio a } \\
\text { complexidade. }\end{array}$ \\
\hline
\end{tabular}

Fonte: A autora, embasada em Bierema e Callahan (2014); Garavan (2007); Mankin (2001)

Os modelos analisados demonstram orientações a ambos os paradigmas, no entanto o modelo de Garavan (2007) é orientado ao desempenho, consistente com a definição proposta para DRH como caminho para contribuir para atingimento de objetivos estratégicos. Já os modelos propostos por Mankin (2001) e Bierema e Callahan (2014) são orientados para o aprendizado. A definição destes dois últimos modelos orienta o olhar para inter-relação entre os indivíduos e organização, através de contexto, método, processo e stakeholder, gerando pensamento e decisão crítica que afeta a organização. Já Mankin (2001), tem como eixo central, interconectando todos os elementos de seu modelo, o DRH gerando aprendizado e conhecimento.

Quando analisados os elementos que constituem cada um dos modelos é possível distinguir algumas dimensões que estão presentes. Há um contexto, com as perspectivas de interno e externo. Além de contexto, temos as práticas, com as 
perspectivas organização e indivíduos. O modelo pode ou não levar em consideração todos os elementos.

Desta forma, a seguir propõe-se a apresentação do Quadro 2, que apresenta os componentes e perspectivas dos modelos de $\mathrm{DRH}$, ainda com base teórica em Bierema e Callahan (2014); Garavan (2007); Mankin (2001)

Quadro 2 - Componente e Perspectivas dos Modelos de DRH

\begin{tabular}{|l|c|l|l|l|l|}
\hline \multicolumn{1}{|c|}{ AUTOR } & ANO & EXTERNO & \multicolumn{1}{|c|}{ INTERNO } & \multicolumn{1}{c|}{$\begin{array}{c}\text { PERSPECTIVA } \\
\text { ORGANIZAÇÃ́ }\end{array}$} & $\begin{array}{l}\text { PERSPECTIVA DOS } \\
\text { INDIVÍDUOS }\end{array}$ \\
\hline Garavan & 2007 & $\begin{array}{l}\text { ambiente } \\
\text { global }\end{array}$ & $\begin{array}{l}\text { estratégia, } \\
\text { estrutura, cultura } \\
\text { liderança }\end{array}$ & $\begin{array}{l}\text { Estratégias, Sistemas e } \\
\text { Práticas de DRH }\end{array}$ & $\begin{array}{l}\text { Expectativas, } \\
\text { empregabilidade e } \\
\text { carreira }\end{array}$ \\
\hline Mankin & 2001 & ND & $\begin{array}{l}\text { estratégia, } \\
\text { estrutura, cultura }\end{array}$ & Gestão de DRH & \\
\hline $\begin{array}{l}\text { Bierema e } \\
\text { Callahan }\end{array}$ & 2014 & Contexto & $\begin{array}{l}\text { Relacionar } \\
\text { Stakeholder }\end{array}$ & $\begin{array}{l}\text { Organizar e Mudar } \\
\text { Método e Processos }\end{array}$ & $\begin{array}{l}\text { Aprender } \\
\text { Stakeholder }\end{array}$ \\
\hline
\end{tabular}

Fonte: A autora, embasada em Bierema e Callahan (2014); Garavan (2007); Mankin (2001)

Garavan (2007) argumenta que o Desenvolvimento Estratégico de Recursos Humanos (DERH) possibilita que uma organização combine diferentes elementos do conhecimento, conectando tanto conhecimentos novos e antigos quanto os conhecimento interno e externo para obter vantagens competitivas sustentáveis. $O$ DERH encontra links entre as estratégias organizacionais, os sistemas de $\mathrm{DRH}$, políticas e práticas, incorporam a perspectiva de múltiplos stakeholders, e direcionando suas contribuições para múltiplos níveis de análise.

O DERH deve ser sensível para a estratégia planejada e emergente, sendo que na estratégia planejada a contribuição da DERH tem foco na implementação, e na estratégia emergente, a contribuição da $\mathrm{DERH}$ é capturar a estratégia que está entremeada na arquitetura social da organização.

Outra observação diz respeito ao alinhamento, que define a congruência entre os processos e as práticas. $\mathrm{O}$ autor chama a atenção para o alinhamento vertical e horizontal do DERH. A cultura é outro determinante para o desenho do DERH e permite um sistema alinhado e coerente dando consistência às práticas. Finalmente, 
Garavan (2007) ressalta a importância da liderança que não só demanda como legitima o $\mathrm{DERH}$, por outro lado é o $\mathrm{DERH}$ que encoraja líderes a construírem redes sociais internas e externas.

Assim como Garavan (2007), o modelo de Mankin (2001) também enfatiza os elementos estratégia e cultura. Ele posiciona o DRH como elemento presente na interconexão destes dois elementos com a Gestão de Recursos Humanos.

Essa interconexão, expressa por uma dinâmica de sobreposições também é usada para ilustrar a necessidade de romper fronteiras e barreiras, a fim de facilitar a troca de informações e desenvolver processos compartilhados de aprendizagem e colaboração (Mankin, 2001).

Ele ainda reforça que na era do conhecimento, a comunicação, não apenas na forma de histórias ou narrativas, mas também por meio de imagens visuais, são vistas como importantes para o processo de conversão do conhecimento tácito para o explícito. (Mankin, 2001).

$\mathrm{O}$ autor reflete a natureza do DRH como um conceito que compreende uma variedade de atividades e processos (em vez de visualizá-lo apenas como uma função ou departamento dentro de uma organização), bem como reforçar o ponto anterior de que o $\mathrm{DRH}$ e a $\mathrm{GRH}$ são conceitos integrados, cada um com suas próprias características distintas (Mankin, 2001).

Por meio do desenvolvimento de estratégias e processos de aprendizagem, nos níveis individual, de grupo e organizacional, acontece o desbloqueio do potencial da organização, sendo este potencial como toda a capacidade de integrar a aprendizagem em criação de alternativas que englobem cada vez mais complexidade e os meios pelos quais os processos podem ser mais bem alinhados à estratégia da organização (Mankin, 2001). Se o DRH não ocorrer, também não ocorrem aprendizado, melhoria e mudança, pois cada um desses aspectos exige e resulta em uma mudança de mentalidade ou comportamento ou habilidades. Para desenvolver a organização do conhecimento, é necessário criar um ambiente de aprendizagem apropriado. O desafio para as organizações vai além de transformar o conhecimento tácito em explícito, mas consiste também em criar um ambiente onde o fluxo do conhecimento, tanto explícito quanto tácito, seja contínuo e renovável. (Mankin, 2001)

Bierema e Callahan (2014) tecem críticas ao rumo que o campo de conhecimento e prática de DRH tomou, argumentam que a vocação humanística de 
$\mathrm{DRH}$ foi perdendo espaço para os interesses da organização e propõem um modelo que oferece 4 áreas de engajamento que estão inter-relacionadas. As áreas são apresentadas como verbos, o que na visão das autoras, adiciona a visão de Lee (Lee, 2007). Lee argumenta que talvez seja impossível realmente definir $\mathrm{DRH}$, uma vez que é um processo e está continuamente no estado de se tornar, sem nunca ser, visão apoiada na compreensão do significado do desenvolvimento. As áreas de engajamento são: Relacionar, Aprender, Mudar e Organizar, no inglês em gerúndio, adicionando o sentido de movimento contínuo. Cada uma destas áreas é apoiada por questões guias que levam os profissionais a refletirem sobre onde (contexto), para quem (stakeholders), o que (processo) e como (método).

As autoras apontam para o risco que o DRH contemporâneo sofre ao se alinhar com os interesses da gestão e derivar para práticas hegemônicas que contradizem a sua filosofia subjacente de facilitar humanisticamente 0 desenvolvimento e a mudança que produz benefício holístico para todas as partes envolvidas (Bierema \& Callahan, 2014). Elas consideram que, muitas das inovações do ambiente de trabalho podem parecer tratar os trabalhadores de maneira mais humana, mas a administração criou meios de vigilância desses trabalhadores, tais como monitoramento de comunicações, autovigilância, feedback de 360 graus e equipes de trabalho auto direcionadas que podem ser vistas como um meio gentil de controle gerencial. $\mathrm{Na}$ opinião das autoras, $\mathrm{DRH}$ é fortemente influenciado pela racionalidade masculina, privilegiando traços de objetividade, agressividade, foco em desempenho e padronização. Assim como a sociedade em geral, também presos em premissas inquestionáveis que protegem seus criadores e promovem sistemas de iniquidade social e práticas como o sexismo e racismo. (Bierema \& Callahan, 2014)

As autoras fazem uma distinção entre a visão de stockholder e stakeholder. A visão de stockholders (acionista) é alinhada à visão performativa, orientada para valores de obtenção de lucro, enquanto a visão de stakeholders, salienta a organização como sendo responsabilizada por várias partes, sendo estas, indivíduos ou grupos afetados pelo atingimento dos objetivos organizacionais. Quanto mais se alinha a visão de stockholders, mais o $\mathrm{DRH}$ se afasta de engajar aqueles que são influenciados ou afetados por ela e afirmam que, desempenho não é inerentemente ruim, no entanto, precisa ser equilibrada com outras variáveis organizacionais e comunitárias, além de considerada na totalidade da saúde da organização. 
Assim, é oferecido um modelo que define como o HRD Crítico, processo de engajar sistemas humanos e organizacionais que se relacionam, aprendem, mudam e se organizam de maneira a otimizar o interesse humano, o avanço da organização e o impacto social (Bierema \& Callahan, 2014).

Garavan e Bierema e Callahan (2007; 2014) dão ênfase à transição do contexto externo para o interno enquanto Mankin (2001) considera este aspecto contemplado e parte da estratégia. Todos os modelos, por sua vez, enfatizam o papel da cultura, ainda que Bierema e Callahan (2014) não nomeie desta forma, mas tem uma visão crítica sobre o quanto deve-se estar consciente sobre as relações entre pessoas, a reflexão crítica, o pensamento e a ação, destacando a importância das narrativas e da forma como são construídos os significados e também da importância da observação de padrões de poder e política nos espaços organizados.

Ainda que todos os modelos façam o movimento de relacionar o contexto com as práticas e entendem as práticas como elementos que organizam os esforços da organização em processos orientados para a ação do $\mathrm{DRH}$, Garavan e Bierema e Callahan $(2007 ; 2014)$ vão além da perspectiva organizacional e diferente de Mankin (2001), pois que avançam seus modelos para discutir a perspectiva individual bem como relevante, tocando a intersecção da prática com os indivíduos.

Considerando as discussões sobre o que constitui o $\mathrm{DRH}$, seus modelos, definições e paradigmas, este estudo orienta-se pelo paradigma do aprendizado e propõe como definição para DRH a proposta por Bierema e Callahan (2014), onde o DRH é o processo de engajar sistemas humanos e organizacionais que se relacionam, aprendem, mudam e se organizam de maneira a otimizar o interesse humano, 0 avanço da organização e o impacto social, na medida que entende que esta definição melhor expressa o Desenvolvimento pretendido pelos $\mathrm{DRH}$.

\subsubsection{Práticas de Desenvolvimento de Recursos Humanos}

A discussão sobre definições e modelos permite notar o distanciamento da prática, uma vez que há discussões no nível macro que não aprofundam ou orientam os caminhos sobre as práticas. Por outro lado, pode-se dizer que as práticas de DRH materializam o pensamento conceitual e teórico sobre o tema e são o aspecto 
concreto com a qual os indivíduos se relacionam. São elas que constroem a ponte entre a organização e os indivíduos.

Uma prática pode ser compreendida como uma ação que pode ser identificada ou reconhecida repetidamente. Uma prática é a acumulação histórica dentro de um contexto social que é reconhecida por outros agentes, pertencentes ao mesmo contexto social como "a mesma", assim, uma prática se configura como prática quando se constitui como uma atividade socialmente reconhecível. (Jones, Gold, \& Claxton, 2017)

Existem três princípios que fundamentam uma prática. Ela é uma coleção de atividades produzem ou reproduzem uma ordem social ou sistema; pressupõe a rejeição do dualismo em favor das relações entre as coisas; e ela é de natureza emergente e constituição mútua de elementos com fenômenos. (Korte \& Mercurio, 2017)

As práticas organizam atividades humanas em torno de um conjunto de significados, identidades e comportamentos que emergem como mais ou menos organizados. Em vez de reduzir a prática às tarefas que as pessoas realizam, uma perspectiva mais ampla reconhece os efeitos reais e poderosos da situação, do meio ambiente, artefatos, normas, crenças, política, lógicas institucionais e as experiências dos atores interagindo dentro de um sistema. (Korte \& Mercurio, 2017)

É nesta perspectiva, observando o papel crucial do DRH nas organizações que a investigação das práticas de DRH também não deve ser negligenciada.

Cumberland, Alagaraja, Shuck, e Kerrick (2018) definem as práticas de DRH como atividades, programas e iniciativas que são sistematicamente destinados a facilitar os processos de treinamento e desenvolvimento, desenvolvimento de carreira e desenvolvimento de organização e internamente bem alinhados com as estratégias gerais das organizações.

Este estudo também encontrou resultado consistente com o já observado por Dias (2017) em sua tese, a grande maioria dos artigos levantados por ela naquele momento também define os componentes, tais como os apresentados por Cumberland, Alagaraja, Shuck, e Kerrick (2018) em sua definição das Práticas de $\mathrm{DRH}$, mas não os conceituam. Assim, este estudo adota as definições propostas por Dias, em que o Desenvolvimento Organizacional constitui os processos que asseguram relacionamentos saudáveis intra e inter unidades e colabora para que 
grupos iniciem e façam gestão de mudanças. Já o Desenvolvimento de Carreira compreende os processos que asseguram o alinhamento do planejamento individual de carreira com os processos de gestão organizacional buscando o equilíbrio entre ambas perspectivas. (Dias, 2017)

Dias (2017) argumenta que Treinamento e Desenvolvimento são um conjunto de práticas que identificam, avaliam e ajudam a desenvolver, por meio de aprendizagem planejada, as competências-chave que capacitarão os indivíduos a desempenharem seu trabalho atual e futuro.

O estudo amplia a definição de Dias (2017) para Treinamento e Desenvolvimento, incluindo nesta definição aspectos do aprendizado que vão além do planejado. Propõe o termo utilizado por Garavan (2007), aprendizagem organizacional, entendendo que esta definição melhor atende o paradigma do aprendizado escolhido por este estudo.

Segundo Takahashi (2015), aprendizagem organizacional é um fenômeno coletivo que ocorre no dia a dia e se dá com base nas reflexões, ações e experiências das pessoas que compõe a organização. O conceito de aprendizagem organizacional compreende: processo, transformação, grupo, criação/reflexão e ação. A aprendizagem é organizacional não apenas porque muda padrões cognitivos ou comportamentos, mas porque envolve interação e construção social, ação coletiva e compartilhamento de conhecimentos (Takahashi, 2015). Segundo a autora, o resultado é partilhado e consensualmente validado no nível da organização sendo institucionalizado de diversas formas, envolvendo mecanismos formais e informais (Takahashi, 2015).

Definindo como Aprendizagem Organizacional o conjunto de práticas que facilitam a institucionalização de conhecimento oriundos de processos, transformações, criação/reflexão, ações e experiências individuais e coletivas, consensualmente compartilhadas de maneira formal e informal que resultam em novas construções sociais e mudanças (Takahashi, 2015), este estudo revê sua definição de práticas de DRH.

As práticas de DRH são um conjunto de atividades, programas e iniciativas que são sistematicamente destinados a facilitar os processos de aprendizagem organizacional, desenvolvimento de carreira e desenvolvimento de organização e 
internamente bem alinhados com as estratégias gerais das organizações. (Dias, 2017; Garavan, 2007; Takahashi, 2015)

A partir desta definição, fica a indagação de como tem sido articulado o conhecimento científico sobre o que constituem as práticas de DRH e qual a resultante das pesquisas que investigam este campo?

Existem dois tipos de revisão de literatura, no primeiro, autores estão lidando com um tópico maduro onde há extensa produção acumulada que necessita um modelo de conceptualização que possa analisá-lo, sintetizá-lo e então expandir a pesquisa. O segundo, autores observam uma questão que está emergindo e pode beneficiar a pesquisa se questão for exposta (Webster \& Watson, 2002). Esta pesquisa se orienta pelo segundo tipo que tende a ser mais curto e focado.

Esta revisão incluiu o maior número de artigos possíveis para tentar trazer uma pluralidade de precedência sob a ótica de origem. A estrutura da análise levou em consideração conceitos, unidades de análise e tipificação. Webster e Watson apontam para que uma revisão sistemática não esgota o levantamento de todo o conhecimento disponível sobre determinado assunto, mas se ela é abrangente e estruturada, será capaz de levantar um senso relativamente completo do que é relevante para os objetivos do levantamento. (Webster \& Watson, 2002)

A investigação sobre a produção acadêmica sobre as práticas de $\mathrm{DRH}$ revela que, assim como a discussão sobre o que constitui o $\mathrm{DRH}$ ainda é controversa e inconclusiva, também é a investigação de suas práticas.

As bases utilizadas para levantamento de artigos acadêmicos foram: Web of Science (Internacional) e Periódicos Capes, Scielo e Spell (Nacionais). As consultas foram realizadas entre dezembro de 2019.

Os termos de pesquisa utilizados nesta base foram: "Human Resource* Development practice*" ou "HRD practice"” . A pesquisa inicial retornou 100 itens. Após análise mais detalhada, com leitura de abstract, a amostra foi reduzida para 75 artigos. Os parâmetros adotados para a manutenção do artigo e posterior análise profunda foram: ser artigo acadêmico e publicado entre 2009 e 2019. Foram descartados 25 artigos.

\footnotetext{
${ }^{1}$ As "" aqui mostram que os termos foram pesquisados conjuntamente e o * é a forma de busca de singular ou plural.
} 
Em relação às bases nacionais, os termos iniciais de busca utilizados foram: "práticas de desenvolvimento de recursos humanos", "práticas de desenvolvimento de pessoas" ou "práticas de DRH". Não houve nenhum retorno, aplicou-se a busca para os termos: "processos de desenvolvimento de recursos humanos", ou "processos de DRH"; "políticas de desenvolvimento de recursos humanos" ou "políticas de DRH". O retorno foi de 2 artigos que foram descartados após leitura de abstract e ano de publicação pois ambos tinham mais de 10 anos de publicados. Foi feita uma nova tentativa nas mesmas bases, substituindo o termo Recursos Humanos por Pessoas, também não houve retorno. Já pode-se fazer uma reflexão inicial sobre a ausência de discussão e investigação empírica no Brasil sobre o tema Práticas de $\mathrm{DRH}$.

Garavan, Mcguire, \& O'donnell (2004) oferecem uma abordagem com 3 possíveis níveis de análise para $\mathrm{DRH}$, a saber: individual, organizacional e comunidade-sociedade (nação).

No nível individual de análise, os autores afirmam que muitos teóricos do campo consideram que os indivíduos se responsabilizam pelo planejamento e mapeamento de seu próprio desenvolvimento, sendo a organização responsável por garantir que as oportunidades de desenvolvimento estejam disponíveis. Já no nível organizacional os autores consideram que uma análise de nível organizacional entende que o DRH é um conjunto especializado de atividades de desenvolvimento ou intervenções que focam no apoio ao alcance dos objetivos organizacionais. No nível organizacional, o DRH contribuiu para o desenvolvimento do capital intelectual e argumentam que a gestão do conhecimento local é considerada vital para o sucesso do negócio, ressaltam ainda que de forma mais contemporânea, a uma mudança de modelos tradicionais de $\mathrm{DRH}$ que focam em conhecimento explícito, para maior ênfase em aprendizagem tácita e aprendizagem informal. De qualquer modo, os autores salientam que as prioridades do DRH em um nível organizacional de análise são determinadas por tomadores de decisões organizacionais, e não por indivíduos. O nível de análise comunidade-sociedade concentra-se no desenvolvimento e enfatiza, entre outras coisas, o desenvolvimento das comunidades e da sociedade, a competitividade nacional e a facilitação do trabalho em rede (Garavan et al., 2004).

Após leitura dos abstracts identificou-se que parte dos artigos, apesar de associado às práticas de $\mathrm{DRH}$ analisava uma ou mais práticas específicas e não o 
conjunto de práticas de $\mathrm{DRH}$. Foram encontrados artigos que pesquisaram treinamento, coaching, avaliação $360^{\circ}$ e avaliação de desempenho.

A análise dos artigos também diz respeito a quanto o artigo se aproxima da teoria e é distante da prática. Sempre que as práticas de DRH não eram as discussões principais do artigo ele foi destacado como implicações no $\mathrm{DRH}$. Nota-se que alguns dos artigos são ensaios e reflexões teóricas que têm por objetivo contribuir para o amadurecimento do campo, mas oferecem, para fins desta pesquisa que objetiva a investigação das práticas, menor contribuição. Um exemplo disso é o artigo de Kuchinke (2017), o qual descreve os principais princípios da ética no contexto da organização do trabalho e postula que o foco na sabedoria prática deve ser visto como uma preocupação central da prática de DRH e da educação em DRH.

Sempre que identificada a prática de $\mathrm{DRH}$, ela foi apontada (aprendizagem organizacional, desenvolvimento de carreira e desenvolvimento de organização) como tema, se estivesse descrita mais de uma das dimensões, o tema foi apontado como DRH. A tabela que descreve os achados está disponível no Apêndice A. Lá poderão ser observados em detalhes, como as práticas foram definidas e avaliadas toda vez que essas informações estavam disponíveis. Todavia, o quadro 3, a seguir tratará de uma análise consolidada dos artigos sobre as práticas de $\mathrm{DRH}$.

Quadro 3- Análise de artigos sobre Práticas de DRH

\begin{tabular}{|c|c|c|c|c|c|c|}
\hline \multirow{3}{*}{ Tema } & \multirow{3}{*}{ Nação } & \multicolumn{4}{|c|}{ Unidade de Análise } & \multirow{3}{*}{ total } \\
\hline & & \multicolumn{2}{|c|}{ Organizacional } & \multirow{2}{*}{ Individual } & \multirow{2}{*}{ ND } & \\
\hline & & Organização & Time & & & \\
\hline Aprendizagem & 2 & 3 & 1 & 10 & 0 & 16 \\
\hline Aprendizagem e Carreira & 0 & 2 & 0 & 0 & 0 & 2 \\
\hline Carreira & 0 & 0 & 0 & 0 & 0 & 0 \\
\hline $\begin{array}{l}\text { Desenvolvimento } \\
\text { Organizacional }\end{array}$ & 0 & 1 & 0 & 1 & 0 & 2 \\
\hline $\mathrm{DRH}$ & 0 & 2 & 0 & 8 & 0 & 10 \\
\hline implicações em DRH & 6 & 1 & 0 & 20 & 18 & 45 \\
\hline Total & 8 & 9 & 1 & 39 & 18 & 75 \\
\hline
\end{tabular}

${ }^{*} \mathrm{ND}$ - não definido

Fonte: elaborado pela autora

A primeira questão relevante para se notar é que a grande maioria dos artigos levantados, na verdade não trata das práticas de $\mathrm{DRH}$, mas sim estuda variáveis, faz propostas de modelos ou construções teóricas ou ainda, propõe reflexões sobre questões que vão, então, gerar implicações nas Práticas de DRH. 
Outra observação é que a maior parte dos artigos investigam o nível de análise individual. O nível de análise Organização e Nação estão próximos e os ND (não definido) estão de modo geral, relacionados a reflexões teóricas.

A Prática de DRH mais investigada foi a Aprendizagem. Nos artigos com mais um dos componentes presentes, o componente aprendizado estava sempre presente. A maioria dos artigos investiga a Aprendizagem na sua dimensão formal e institucional, consistente com as definições de "Treinamento e Desenvolvimento".

No entanto foram encontrados artigos que levam em consideração aspectos formais e informais do aprendizado, de autores diversos, a saber: Froehlich, Beausaert, e Segers (2017); Lammintakanen, Kivinen, e Kinnunen (2010) e Zavyalova, Kucherov, e Tsybova (2018).

Apenas um artigo tocou o aprendizado em time e tinha por objetivo investigar o fluxo do desenvolvimento do conhecimento dentro de times de trabalho (Akhavan, Shahabipour, \& Hosnavi 2018). Este achado, baixo número de artigos dedicados ao aprendizado em time, é consistente com o já apontado por Bido, Godoy, Ferreira, Kenski, e Scartezini (2011) onde observam que ainda que possa ser encontrada vasta literatura sobre times e grupos, a investigação sobre aprendizagem em grupo ainda é limitada.

Outro aspecto observado na análise dos artigos que tinham como foco a prática de $\mathrm{DRH}$ aprendizagem, foi que foram encontrados artigos que investigaram a prática "on the job training" (Ahadi \& Jacobs, 2017; Chai, Kim, \& Kim, 2018), outros investigaram o "action learning" (C Brook, 2012; Cheryl Brook \& Milner, 2014), ainda que dentro do contexto da aprendizagem formal, ambas práticas ligadas a aprendizagem na ação, onde a transformação acontece na medida que exista compreensão e transformação da experiência. (Yeganeh \& Kolb, 2009)

Os artigos que foram identificados sob a classificação Aprendizagem e Carreira, investigavam no componente aprendizagem, o aprendizado formal e no componente carreira, processos ligados à identificação, gestão e desenvolvimento de talentos, no entanto, um deles também trazia para dentro deste mesmo guarda-chuva, a gestão de desempenho (Sablok et al., 2017; Wickramasinghe, 2015).

Nos artigos identificados sob a classificação $\mathrm{DRH}$, de forma geral a aprendizagem continua sendo representada pelo componente formal do aprendizado com itens de avalição ligados ao "Treinamento e Desenvolvimento". Aparecem 
também outros dois componentes, o primeiro ligado ao desenvolvimento de carreira, este consistente com as definições teóricas aqui propostas, o segundo diz respeito à gestão de desempenho (Otoo, 2019; Otoo \& Mishra, 2018b, 2018a; Otoo, Otoo, Abledu, \& Bhardwaj, 2019; Peretz \& McGraw, 2011; Uraon, 2018; Veth, Emans, der Heijden, Korzilius, \& De Lange, 2015).

Os modelos teóricos fazem referência a três componentes do $\mathrm{DRH}$, aprendizagem, gestão de carreira e desenvolvimento organizacional, sendo o desenvolvimento organizacional, componente ligado a estimular, identificar e dar suporte aos processos de mudança na organização (Dias, 2017; Swanson \& Holton, 2009), no entanto, nota-se que quando desdobrado em práticas, um dos componentes presentes, além da aprendizagem e gestão de carreira, diz respeito a gestão de desempenho, esse é um componente apresentado por Garavan (2007), no entanto para Swanson e Holton (2009) o desempenho é uma parte do Desenvolvimento Organizacional ligada ao suporte e direcionamento da mudança.

Essa análise e discussão possibilitou notar que é ainda inconclusivo propor ou definir quais e como se organizam as práticas de $\mathrm{DRH}$. Embora aparentemente simples, as definições baseadas em componentes enfrentaram dois desafios. Primeiro, os componentes precisavam ser mais e melhor definidos. Segundo, ambos Desenvolvimento de Carreira e o Desenvolvimento Organizacional foram campos de prática estabelecidos muito antes do início do Desenvolvimento de Recursos Humanos, podendo assim ser difícil trazer uma organização teórica destes campos para debaixo do campo DRH (Wang et al., 2017).

Após a análise das Práticas de DRH, este estudo optou por explorar o nível individual e como ele constrói suas percepções sobre sua interação e experiência com o nível da organização, entendendo que é nessa ponte que se encontram as práticas. O estudo também opta pela investigação da Prática de DRH Aprendizagem, compreendendo que a aprendizagem seja ela individual, de grupo ou organizacional é um componente central de inúmeros modelos de Desenvolvimento de Recursos Humanos (Bierema \& Callahan, 2014; Garavan, 2007; Mankin, 2001). É indiscutível a relação da aprendizagem com o próprio desenvolvimento dos indivíduos, dos grupos e da organização (Camillis \& Antonello, 2010). A aprendizagem é mola propulsora de desenvolvimento e mudança e, no contexto organizacional, condição para que a 
organização se perpetue no tempo e encontre alternativas para os desafios do mundo complexo.

Bido et al. (2010) argumentam que muito embora o indivíduo seja o agente da aprendizagem, as organizações não representam uma simples coleção de indivíduos, e ainda que muitos autores defendem que a aprendizagem organizacional (AO) ocorre a partir da aprendizagem individual (AI) de seus membros, o processo não é uma simples ampliação da aprendizagem do indivíduo para a organização. Ainda assim, podemos argumentar que se por um lado, o simples fato de existir aprendizagem individual, não garante aprendizagem de grupo e aprendizagem organizacional, por outro lado, não haverá aprendizagem de grupo e aprendizagem organizacional, se não houver aprendizagem individual. Não negando as demais como fatores importantes para o desenvolvimento da organização, a investigação desta pesquisa foca sua atenção na percepção sobre aprendizagem individual.

\subsection{Aprendizagem Individual}

Em sua dissertação, Mello (2014) analisa os fatores de retenção de indivíduos em organizações e o fator "oportunidades de desenvolvimento" aparece em primeiro lugar. Os indivíduos que citam este como o fator preponderante para que fiquem na organização, fazem referência não só às oportunidades de crescimento na empresa, mas também de oportunidades de aprendizado e desenvolvimento. Mello (2014) ressalta que a retenção de pessoas diz respeito não somente à redução de custos de contratação, mas também diz respeito aos impactos que "perder" que as pessoas têm nos grupos e no ritmo do trabalho, afetando tanto o clima quanto a produtividade.

Aprendizagem e desenvolvimento são termos comumente intercambiáveis, no entanto para alguns autores, o desenvolvimento é o potencial resultante de processos de aprendizagem. Garavan (1997) considera que desenvolvimento é expandir o potencial de alguém através de processos de aprendizagem conscientes e inconscientes, com vista a capacitar o indivíduo a assumir um papel futuro dentro da organização. Cook-Greuter (2004) ressalta que o desenvolvimento ocorre por meio da interação entre pessoa e ambiente, é um potencial que pode ser encorajado e facilitado pelo apoio e desafio adequados. Segundo a autora, a profundidade, a 
complexidade e o escopo do que as pessoas percebem podem se expandir ao longo da vida e, na medida que o desenvolvimento acontece, autonomia, liberdade, tolerância à diferença e ambiguidade, assim como flexibilidade, reflexão e a habilidade de interagir com o ambiente aumentam enquanto as defesas diminuem. A maior parte do aprendizado, alerta Cook-Greuter (2004), é voltada para expandir, aprofundar e enriquecer o modo atual de criação de significado de uma pessoa, mas para se desenvolver, as pessoas precisam transformar seu modo atual de fazer sentido em direção a uma perspectiva mais ampla.

Ainda reconhecendo estas distinções, o aprendizado é condição para que o potencial do desenvolvimento possa ser explorado. Este estudo o aprendizado individual é explorado, reconhecendo suas diferentes formas.

A aprendizagem individual para Didier e Lucena (2008) não é um fim em si ou um produto é um processo que ocorre ao longo do tempo e que implica em mudança, segundo Camillis e Antonello (2010), que descrevem a aprendizagem individual como a permanente revisão de conceitos aprendidos por meio do processo de tensão e conflito que ocorre por meio da interação entre o indivíduo e o ambiente. As autoras observam que o processo de tensão e conflito é organizado no contexto de experiências concretas, observação e reflexão (Camillis \& Antonello, 2010).

Estas definições nos ajudam a fazer a escolha sobre o pressuposto no qual este estudo se apoia ao olhar para a aprendizagem individual. Didier e Lucena (2008) organizam as correntes de pensamento sobre a aprendizagem em 5 grupos: behaviorista, cognitivista, humanista, aprendizagem social e construtivista. Cada uma destas correntes de orientação teórica sobre a aprendizagem tem sua forma particular de perceber o tema e formas sintetizadas no quadro 4, mostrando que este estudo se orienta pelas perspectivas construtivista e de aprendizagem social. 
Quadro 4 - As Cinco orientações da aprendizagem

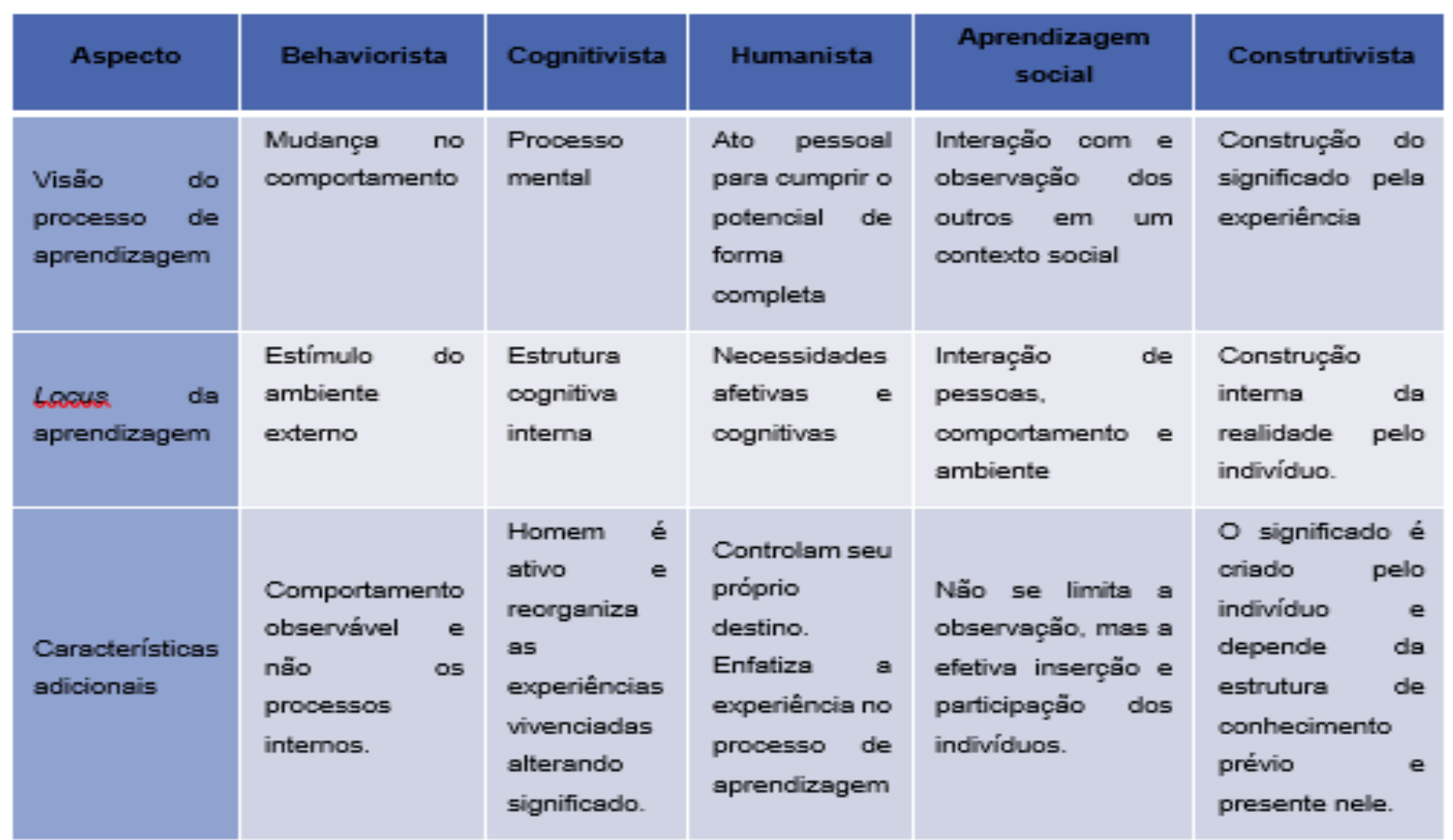

Fonte: adaptado pela autora de Didier e Lucena, 2008.

Após revisão de literatura, foram construídas as categorias da aprendizagem individual e avaliando cada uma delas sob o ponto de vista de sua fundamentação teórica.

\subsubsection{Componentes da Aprendizagem Individual}

\subsubsection{Aprendizagem como processo social}

É em sua essência que a corrente teórica da aprendizagem social, entende que indivíduos aprendem não só por intermédio da execução de atividades e tarefas, mas, também, pelo estabelecimento de relacionamentos sociais com determinados sujeitos, em circunstâncias específicas. A aprendizagem social assume que as pessoas aprendem interagindo com outras pessoas em contextos sociais. (Didier \& Lucena, 2008) 


\subsubsection{Aprendizagem Experiencial}

A abordagem experiencial de pressupostos construtivistas, percebe a aprendizagem como um processo de construção de significados, é o meio pelo qual as pessoas formam sentido de suas experiências (Didier \&Lucena, 2008).

Didier e Lucena (2008) afirmam que ainda que essa corrente reconheça que tais experiências ocorrem em um determinado contexto sociocultural, a construção do significado é realizada internamente, pelo indivíduo. É este indivíduo que ao lidar com uma nova experiência faz uso dos conhecimentos que desenvolveu a partir de suas experiências anteriores dando o sentido de continuidade à interação (Didier \& Lucena, 2008).

Segundo os autores em estudo a experiência pode consistir em um acontecimento, interação com ferramentas ou de pessoa, o desempenho de uma tarefa, ressaltam que o conhecimento é criado fora da experiência por meio da síntese entre o conhecimento prévio e a percepção de suas experiências presentes.

Didier e Lucena (2008) consideram como fundamentos da aprendizagem experiencial o engajamento do aprendiz, a construção ativa por parte do aprendiz de sua própria experiência, ainda que influenciada pelo passado único de cada aprendiz e pelo contexto atual, a existência de continuidade entre as experiências, existência de contexto social particular, com valores econômico-culturais e circunstâncias políticas que podem fundamentar o aprendizado, distorcê-lo ou limitá-lo e que o aprendizado é influenciado pelas emoções e sentimentos, fatores-chave para a criação de possibilidades ou barreiras.

\subsubsection{Aprendizagem Informal e Incidental}

Apoiados nos pressupostos da aprendizagem experiencial, Marsick et al. (2009) definiram aprendizagem informal e incidental como a aprendizagem que ocorre fora de atividades formalmente estruturadas e institucionalmente patrocinadas. Afirmam que esse aprendizado ocorre com frequência em circunstâncias não rotineiras, ou seja, quando os procedimentos e respostas que as pessoas normalmente usam falham. 
Os autores distinguiram ainda a aprendizagem incidental da informal, definindo a aprendizagem incidental como um subproduto de alguma outra atividade, como realização de tarefas, interações interpessoais, percepção da cultura organizacional ou experimentação de tentativa e erro (Marsick et al., 2009). Os autores contrastaram a natureza às vezes intencional e mais possivelmente planejada da aprendizagem informal com a natureza acidental e muitas vezes semiconsciente da aprendizagem incidental.

\subsubsection{Aprendizagem formal}

A aprendizagem formal, pode ou não ser de caráter experiencial, é mais comumente apoiada em abordagens mais tradicionais da aprendizagem como a behaviorista ou cognitivista, mas em organizações com visões mais contemporâneas, observa-se um caráter mais construtivista. Aprendizagem formal é tipicamente patrocinada institucionalmente, baseada na sala de aula e altamente estruturada (Didier \& Lucena, 2008).

As oportunidades de aprendizagem formal aumentam a consciência, mas essa aprendizagem é normalmente dissociada da ação da vida real (Marsick et al., 2009).

O levantamento bibliográfico identificou dois artigos que relacionavam a percepção dos indivíduos sobre as Práticas do $\mathrm{DRH}$ e as associava à intenção de ficar na organização ou à intenção de turnover (Shuck et al., 2014; Uraon, 2018). Considerando toda a reflexão sobre os conceitos, modelos e práticas de DRH que orientaram este estudo, foi feita a opção por investigar esta associação a partir da percepção dos indivíduos sobre a Prática de DRH Aprendizagem Individual, entendendo aqui que sempre que for feita referência a esta percepção, estamos nos referindo a como o indivíduo percebe as oportunidades que a organização oferece para que possa ocorrer a aprendizagem individual, ou seja, como o indivíduo percebe o conjunto de práticas de DRH que são facilitadoras da aprendizagem individual e a Intenção de Permanecer na organização. 


\subsection{Intenção em permanecer na organização}

Os termos intenção em permanecer na organização ou intenção de turnover, ainda que antônimos, são utilizados igualmente por muitos autores pois tanto um quanto o outro expressam a força da conexão do indivíduo com a organização da qual ele faz parte, seja pelo desejo de permanecer ou pelo desejo de sair da mesma.

Uraon (2018) observa que a intenção de permanecer refere-se à força da disposição dos funcionários em permanecer em sua organização no futuro próximo. Esse comportamento ocorre devido à experiência dos funcionários em suas organizações. Já para Emiroğlu et al. (2015), a intenção de turnover é considerada com a vontade consciente e deliberada de deixar a organização, ou seja, representa a estimativa de um indivíduo sair do trabalho em um futuro próximo. As intenções de turnover são divididas em duas categorias: rotatividade voluntária e rotatividade involuntária, onde a voluntária é a decisão de um funcionário de deixar a organização e a involuntária, por outro lado, é a saída de um empregado iniciado pelo empregador (Emiroğlu et al., 2015).

Para Cho et al. (2009), o impacto tanto do turnover voluntário, quanto involuntário na organização são enormes. A saída para os efeitos do trabalho afeta diretamente a percepção dos clientes sobre a degradação da qualidade do serviço, a redução da satisfação e do moral dos funcionários, o aumento dos custos com treinamento de pessoal e o aprimoramento pessoal.

O quadro 5, a seguir, apresenta definições de interação de permanecer na organização e foi realizado com a proposta de ilustrar os estudos realizados aqui. 
Quadro 5 - Definições de Intenção de Permanecer na Organização

\begin{tabular}{|c|c|c|c|}
\hline Artigo & Data & Autor & $\begin{array}{c}\text { A Percepção sobre a Intenção em } \\
\text { Permanecer na organização refere- } \\
\text { se a: }\end{array}$ \\
\hline $\begin{array}{l}\text { Employees intent to leave: A } \\
\text { comparison of determinants } \\
\text { of intent to leave versus } \\
\text { intent to stay }\end{array}$ & 2009 & $\begin{array}{l}\text { Cho, Johanson e } \\
\text { Guchait }\end{array}$ & $\begin{array}{l}\text { Desejo consciente e deliberado do } \\
\text { funcionário em ficar }\end{array}$ \\
\hline $\begin{array}{l}\text { Conflict management style of } \\
\text { Jordanian nurse managers } \\
\text { and its relationship to staff } \\
\text { nurses' intent to stay }\end{array}$ & 2016 & $\begin{array}{l}\text { Al-Hamdan, } \\
\text { Nussera E } \\
\text { Masa'deh }\end{array}$ & $\begin{array}{l}\text { Percepção sobre ficar no trabalho } \\
\text { atual. Envolve pensamentos e } \\
\text { atitudes tendendo a permanecer com } \\
\text { o empregador atual. Deve ser } \\
\text { compreendida como um } \\
\text { comportamento que está sendo } \\
\text { contemplado, mas ainda não } \\
\text { aconteceu. }\end{array}$ \\
\hline $\begin{array}{l}\text { Human resource practices, } \\
\text { organizational commitment } \\
\text { and intention to stay }\end{array}$ & 2007 & $\begin{array}{l}\text { Janet Chew e } \\
\text { Christopher C.A. } \\
\text { Chan }\end{array}$ & Sem definição \\
\hline $\begin{array}{l}\text { Examining the Impact of HRD } \\
\text { Practices on Organizational } \\
\text { Commitment and Intention to } \\
\text { Stay Within Selected } \\
\text { Software Companies in India }\end{array}$ & 2018 & $\begin{array}{l}\text { Ram Shankar } \\
\text { Uraon }\end{array}$ & $\begin{array}{l}\text { Força do desejo do empregado em } \\
\text { ficar na organização no futuro } \\
\text { próximo. Este comportamento ou } \\
\text { percepção é resultantes da } \\
\text { experiência do empregado na } \\
\text { organização. }\end{array}$ \\
\hline $\begin{array}{l}\text { Ethical Leadership as } \\
\text { Antecedent of Job } \\
\text { Satisfaction, Affective } \\
\text { Organizational Commitment } \\
\text { and Intention to Stay Among } \\
\text { Volunteers of Non-profit } \\
\text { Organizations }\end{array}$ & 2018 & $\begin{array}{c}\text { Benevene, Dal } \\
\text { Corso, Carlo, } \\
\text { Falco, Carluccio e } \\
\text { Vecina }\end{array}$ & Sem definição \\
\hline
\end{tabular}

Fonte: elaborado pela autora

Este estudo considerou a definição de Uraon (2018) como orientadora, na qual a intenção em permanecer na organização é a percepção que o empregado tem da força do desejo de permanecer lá em um futuro próximo e é uma percepção resultante da experiência do empregado na organização.

Os artigos investigados durante o levantamento do referencial teórico das práticas de DRH apontam para associação entre a percepção dos indivíduos sobre as 
práticas de $\mathrm{DRH}$ e, tanto a intenção de permanecer na organização quanto a intenção de turnover.

Shuck et al. (2014) não investigou as práticas de DRH diretamente, no entanto, essa pesquisa investigou a percepção dos funcionários ao suporte organizacional ao desenvolvimento. Utilizaram a escala "Perceived Investment in Employee Development - PIED”, desenvolvida por Lee e Bruvold, em 2003. Relacionaram então esta percepção com sua influência em intenção de turnover e possível moderação de nível de engajamento e o estudo encontrou que o apoio à participação nas práticas de $\mathrm{DRH}$ foi significativo e negativamente relacionado à intenção de turnover dos empregados. Já Uraon (2018) examinou o impacto de práticas abrangentes de $\mathrm{DRH}$ no comprometimento organizacional (afetivo, continuidade e comprometimento normativo) e na intenção do funcionário de permanecer. O estudo verificou que as práticas de $\mathrm{DRH}$ tiveram um impacto significativo e positivo na intenção dos empregados em permanecer na organização.

\subsection{Delimitação da pesquisa}

Após a análise das Práticas de DRH, este estudo optou por explorar o nível individual de pesquisa. Investigou as percepções dos empregados sobre sua interação e experiência com o nível da organização, entendendo que é nessa ponte que se encontram as práticas. Ao compreender as práticas como os elementos que organizam atividades humanas em torno de um conjunto de significados, identidades e comportamentos que emergem como mais ou menos organizados (Korte \& Mercurio, 2017) e considerar que os integrantes de uma organização são expostos às mesmas características estruturais que propiciam o entendimento compartilhado entre os membros, pode-se então compreender o formulário do empregado, da pesquisa "Melhores Empresas para se Trabalhar" (MEPT), instrumento nos moldes de diagnóstico de clima organizacional, que é utilizado para compreender as necessidades, as preocupações e as percepções dos empregados, conforme definido no laudo técnico da pesquisa, como um instrumento válido, o qual permite investigar as percepções dos empregados sobre as práticas de DRH e a intenção de permanecer na empresa. 
O referencial teórico orientou a pesquisa e as variáveis foram identificadas a partir da análise do questionário dos empresados da pesquisa das MEPT, tanto a base quanto a pesquisa serão apresentadas no capítulo de metodologia.

A análise do questionário permitiu que itens fossem escolhidos, à luz da teoria, construindo as categorias que então compuseram a variável "Percepção Sobre Prática De DRH Aprendizagem Individual". Também permitiu a escolha da pergunta que representou a variável "Intenção de Permanecer na Organização" que também serão descritas no capítulo metodologia

O problema de pesquisa, objetivos gerais e específicos a luz do referencial teórico possibilitou a escolha das variáveis e a definição das hipóteses representadas na matriz de amarração descrita no quadro 6 a seguir: 
Quadro 6 - Matriz de amarração

Problema de Pesquisa

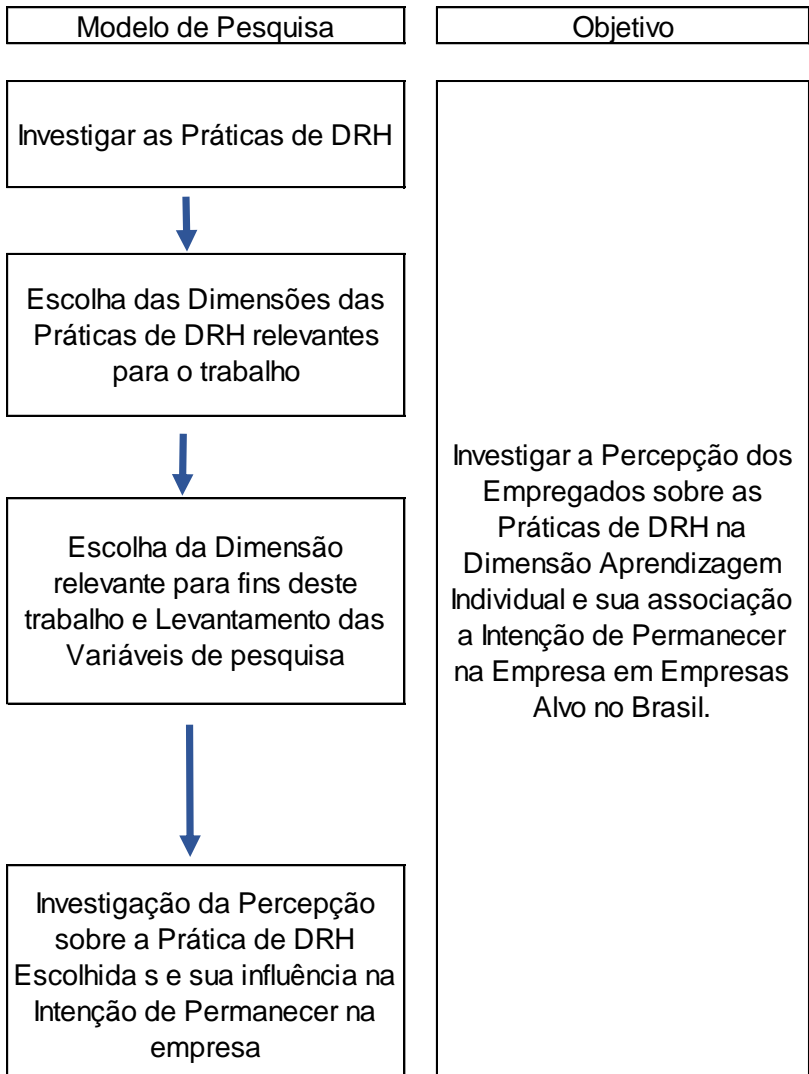

A percepção dos funcionários sobre as práticas de Desenvolvimento de Recursos Humanos na dimensão Aprendizagem Individual está associada a sua Intenção de Permanecer na Empresa?

\begin{tabular}{|c|c|c|}
\hline Objetivos Específicos & Literatura Base & Hipóteses \\
\hline $\begin{array}{l}\text { Investigar a Percepção dos } \\
\text { empregados das empresas alvo } \\
\text { sobre a Prática de DRH } \\
\text { Aprendizagem Individual }\end{array}$ & $\begin{array}{l}\text { O processo de Aprendizagem } \\
\text { Individual } \\
\text { Camillis e Antonello, 2010; Bido et } \\
\text { al., 2010; Didier e Lucena, 2009; } \\
\text { Marsick et al., 2009 }\end{array}$ & $\begin{array}{c}\text { Percepção sobre a Prática de DRH Aprendizagem } \\
\text { Individual é favorável }\end{array}$ \\
\hline $\begin{array}{l}\text { Investigar Intenção dos } \\
\text { Empregados em Permanecer na } \\
\text { Organização nas empresas Alvo }\end{array}$ & $\begin{array}{c}\text { Cho et al, 2009; AL-Hamdan et al, } \\
\text { 2016; Chew e Chan, 2007, Uraon, } \\
\text { 2018; Benevene et al, } 2018\end{array}$ & $\begin{array}{c}\text { Intenção dos Empregados em Permanecer na } \\
\text { Organização é favorável }\end{array}$ \\
\hline $\begin{array}{l}\text { Investigar a associação da } \\
\text { Percepção do efeito conjunto das } \\
\text { Práticas de DRH Aprendizagem } \\
\text { individual e a intenção de } \\
\text { Permanecer na Empresa }\end{array}$ & $\begin{array}{l}\text { Camillis e Antonello, 2010; Bido et } \\
\text { al., 2010; Didier e Lucena, 2009; } \\
\text { Marsick et al., } 2009 \\
\text { Cho et al, 2009; AL-Hamdan et al, } \\
\text { 2016; Chew e Chan, 2007, Uraon, } \\
\text { 2018; Benevene et al, } 2018\end{array}$ & $\begin{array}{c}\text { Quanto menos favorável a Percepção dos } \\
\text { empregados das empresas alvo sobre a Prática } \\
\text { de DRH Aprendizagem Individual, menor A } \\
\text { Intenção dos Empregados em Permanecer na } \\
\text { Organização }\end{array}$ \\
\hline
\end{tabular}

Fonte: elaborado pelo autor 


\section{METODOLOGIA}

Um método é um caminho para se chegar a determinado fim e o método científico é o conjunto de procedimentos intelectuais e técnicos adotados para se atingir o conhecimento (Gil, 2008).

A pesquisa utilizou uma abordagem quantitativa. A pesquisa quantitativa é um meio para testar teorias objetivas, examinando a relação entre variáveis, sendo que essas variáveis podem ser analisadas por procedimentos estatísticos (Richardson, 2017).

O Método estatístico fundamenta-se na aplicação da teoria estatística da probabilidade e constitui importante auxílio para a investigação em ciências sociais. Em virtude do grande número e da complexidade das variáveis que interferem na produção dos fenômenos sociais, de modo geral, as hipóteses elaboradas nas ciências sociais não são rigorosamente causais, apenas indicam a existência de algum tipo de relação entre as variáveis. Segundo Richardson (2017), a relação entre variáveis pode ser de natureza diversa.

Foi desenvolvida com dados secundários, obtidos pela técnica de levantamento de campo, ou survey, o que significa dizer que as pessoas, cujos comportamentos ou fenômenos que se deseja investigar, responderam a perguntas, para em seguida, mediante análise quantitativa, pudessem ser obtidas conclusões correspondentes dos dados coletados (Gil, 2008). Muito embora a survey tenha um propósito descritivo, descrevendo aspectos da realidade e analisando suas distribuições, frequência de atributos e características, os dados também podem permitir análises correlacionais e explicativas (J. F. Hair Jr., Babin, Money, \& Samuel, 2005; Richardson, 2017).

O uso de dados secundários de bancos de pesquisa que estejam disponíveis, obtidos por meio da técnica de levantamento é uma estratégia vantajosa, em especial para pesquisadores individuais, se considerados os custos e tempo (Gil, 2008; Richardson, 2017).

Uma limitação desta técnica é a ênfase na percepção do respondente. Os levantamentos recolhem dados referentes à percepção que as pessoas têm acerca de si mesmas ou do fenômeno perguntado. A percepção é subjetiva, podendo assim influênciar os resultados, uma vez que existe diferença, segundo Gil (2008) entre o que as pessoas fazem ou sentem e o que elas dizem a esse respeito. Essa questão 
foi menos relevante para esta pesquisa pois ela buscou investigar exatamente a percepção dos indivíduos sobre determinadas variáveis.

Uma outra limitação desta técnica é sua dificuldade em apreensão do processo de mudança. Desta forma, o levantamento proporciona uma visão estática do fenômeno estudado, oferecendo uma fotografia, mas não indicando suas tendências à variação, nem possíveis mudanças estruturais, de acordo com Gil (2008). Essa pesquisa reconhece essa limitação e oferece uma perspectiva de corte transversal, já apontando para possíveis estudos futuros com cortes longitudinais.

Os dados secundários, utilizados neste estudo, foram coletados em uma pesquisa pública, de abrangência nacional. A pesquisa, desenvolvida pelo Programa de Estudos em gestão de Pessoas (PROGEP), entidade pertencente à Fundação Instituto de Administração (FIA) que por sua vez foi criada por iniciativa de professores do Departamento de Administração da Faculdade de Economia, Administração e Contabilidade da Universidade de São Paulo (FEA-USP), em uma parceria da Editora Abril. A pesquisa foi criada tanto para para desenvolver projetos de consultoria, pesquisa e educação como também para criar um ranking das melhores organizações para se trabalhar no Brasil. A pesquisa é aplicada anualmente e contêm dois formulários. O primeiro desenvolvido para ser respondido sob a perspectiva da empresa para captar informações sobre as práticas de gestão das organizações. Já o Formulário do Empregado foi elaborado como um instrumento para pesquisa nos moldes de diagnóstico de clima organizacional, que é utilizado para compreender as necessidades, as preocupações e as percepções dos empregados.

Esta pesquisa teve como objeto de estudo a percepção dos empregados, assim utilizou dados capturados pelo Formulário do Empregado.

\subsection{A Amostra}

Pode-se considerar como a população deste estudo os empregados das empresas que atuam no Brasil e buscam o reconhecimento pela gestão da qualidade do ambiente de trabalho, participando da pesquisa pública das melhores empresas para se trabalhar (MEPT), oriunda da parceria da Editora Abril com o Programa de Estudos em gestão de Pessoas (PROGEP), entidade pertencente à Fundação Instituto de Administração (FIA), entidade criada por professores do Departamento de 
Administração da Faculdade de Economia, Administração e Contabilidade da Universidade de São Paulo (FEA-USP).

A população é composta pelos empregados das organizações que se voluntariam a participar da pesquisa. No momento do levantamento que originou os dados utilizados desta, podiam participar as companhias que tivessem no mínimo 100 empregados com vínculo empregatício no momento da inscrição e que operassem no mercado brasileiro há mais de três anos.

Todos os empregados com vínculo empregatício e estagiários com contrato de estágio vigente podiam responder à pesquisa e a empresa recebeu um lote de cartas-senhas de acordo com o número total de empregados.

Neste momento configurou-se uma amostra probabilística estratificada, que é constituída quando a população é subdividida em estratos exaustivos e excludentes de acordo com variáveis consideradas relevantes (Richardson, 2017). Nesta amostra a variável considerada para a estratificação foi o porte da organização.

A amostra coletada representou 258.427 questionários respondidos por empregados de empresas que voluntariamente desejam participar das Pesquisa Melhores Empresas para Trabalhar no ano de 2019, referindo-se à 410 empresas.

\subsection{Variáveis}

A pesquisa proposta explorou duas variáveis e sua associação, a saber:

a) Percepção sobre a prática de DRH aprendizagem individual (PPAI), que é constituída por 8 itens. Todos as assertivas da variável PPAI foram medidas por uma escala categórica ordinal Likert de 1 a 5 e opção NS/NR (Não Sei/Não Quero Responder), sendo que 1 representa "discordo plenamente" e 5 representa "concordo plenamente". Os itens estão agrupados de acordo com os componentes da teoria que originaram sua escolha para compor a categorização da escala proposta e avaliada. A variável PPAI foi investigada como variável constituída por itens, não foram investigadas as dimensões que originaram a escolha das assertivas, já que seriam necessárias mais assertivas por dimensão para que essa análise fosse feita. $O$ quadro 7 apresenta a 
descrição da variável Percepção sobre prática de DRH Aprendizagem Individual.

Quadro 7- Descrição da Variável Percepção sobre Prática de DRH Aprendizagem Individual (PPAl)

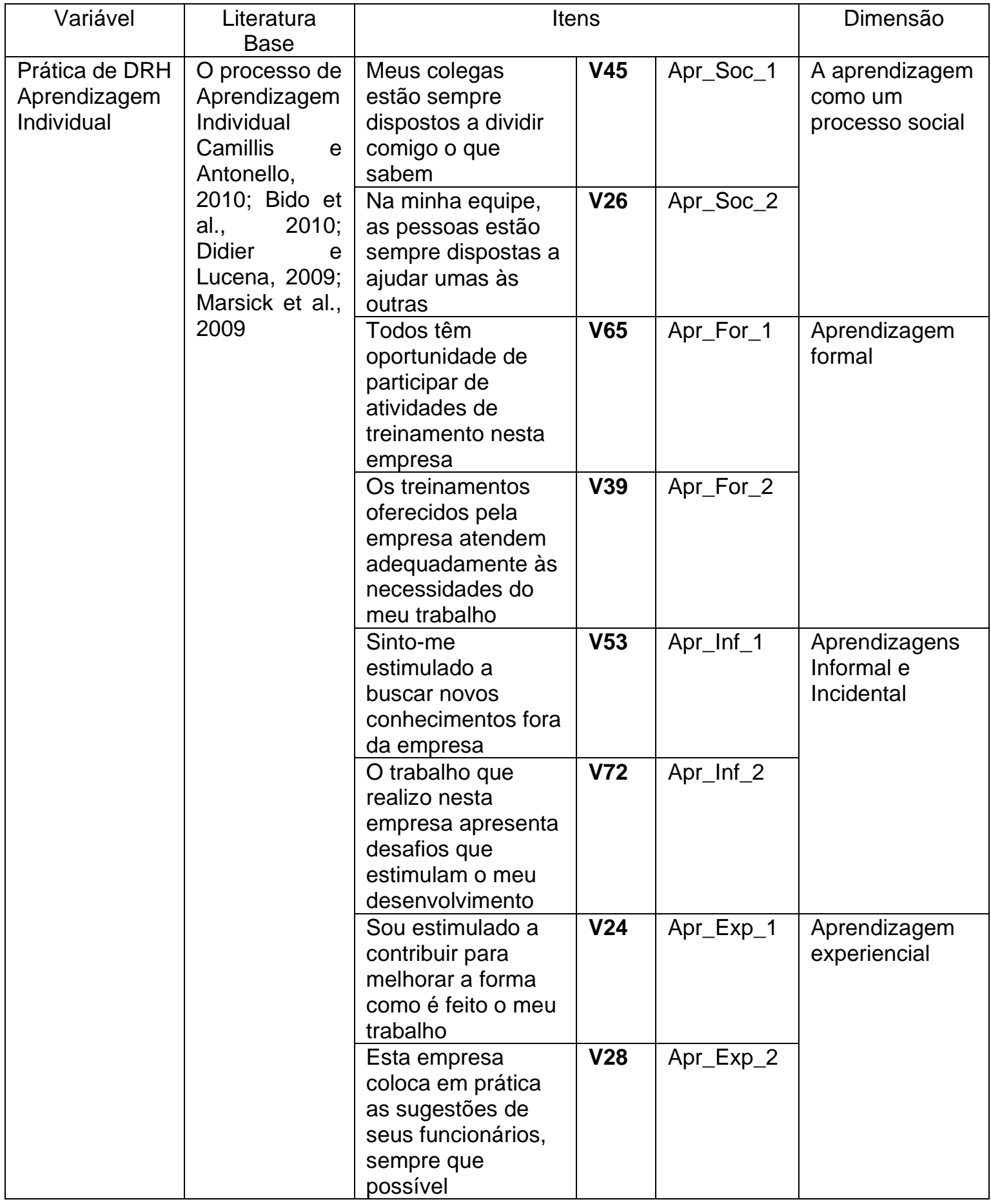

Fonte: elaborado pela autora 
b) Intenção de Permanecer na Organização (IPO), que consiste também é uma variável categórica ordinal. Sua escala foi representada pela afirmação "Estou procurando outra empresa neste momento" como representando a menor intenção de permanecer na organização e "gostaria de me aposentar nesta empresa" como a maior intenção de permanecer na organização.

A adoção destes parâmetros para esta pesquisa está baseada em adaptação das escalas apresentadas por Cho et al. (2009) e Benevene et al., (2018) e resultou no quadro 8, que descreve a variável intenção em permanecer na organização.

Quadro 8 - Descrição da Variável Intenção em Permanecer na Organização

\begin{tabular}{|c|c|c|}
\hline \multirow{7}{*}{$\begin{array}{c}\text { INTENÇÃO DE } \\
\text { PERMANECER } \\
\text { NA } \\
\text { ORGANIZAÇÃO }\end{array}$} & \multirow{7}{*}{$\begin{array}{l}\text { Por quanto tempo mais } \\
\text { você se vê trabalhando } \\
\text { nesta empresa? }\end{array}$} & Estou procurando outra empresa neste momento \\
\hline & & Por menos de 1 ano \\
\hline & & Entre 1 e 3 anos \\
\hline & & Entre 3 e 5 anos \\
\hline & & Entre 5 e 10 anos \\
\hline & & Mais de 10 anos \\
\hline & & Gostaria de me aposentar nesta empresa \\
\hline
\end{tabular}

Fonte: elaborado pela autora

\subsection{Técnicas de análise}

Conforme apresentado na discussão de variáveis da pesquisa, o questionário utilizado na presente pesquisa conta com uma série de questões categóricas ordinais. Em especial, as questões envolvendo a "Percepção Sobre Prática de DRH Aprendizagem Individual” (PPAI) estão em escala Likert de 5 pontos, sendo que o ponto 1 representa o 'Discordo Totalmente' e o 5, 'Concordo Totalmente'. No caso da "Intenção de Permanecer na Organização" (POI), a escala, também ordinal, contempla 7 categorias, indo de 'Estou procurando emprego atualmente', o que corresponde ao nível mais baixo na intenção de permanência, ao 'Pretendo me aposentar nesta empresa', equivalente ao nível mais alto.

A análise natural que deve ser feita quando são considerados cruzamentos de questões categóricas ordinais são as chamadas tabelas de contingência, que são úteis para buscar padrões de associação que eventualmente existam entre as variáveis. A tabela de contingência ou tabulação cruzada, combina as respostas para 
as categorias de duas variáveis simultaneamente (Levine et al, 2016; Sweeney, Williams e Anderson, 2013).

O objetivo desta análise é verificar se há independência entre as variáveis cruzadas nas tabelas de contingência. Essa é uma das aplicações mais importantes da distribuição $\chi^{2}$ (qui quadrado). A estatística $\chi^{2}$ mede o quanto a diferença (ao quadrado) entre a frequência observada (fo) e a frequência esperada (fe) do cruzamento das variáveis em questão, se afasta em relação a frequência esperada, sendo calculada, para cada célula na i-ésima linha e na j-ésima coluna e somada para todas as células:

$$
\chi^{2}=\sum_{i} \sum_{j} \frac{\left(f_{o}-f_{e}\right)^{2}}{f_{e}}
$$

As frequências esperadas são obtidas por:

$$
f_{e}=\frac{\text { total da linha } \times \text { total da coluna }}{\text { Total geral }}
$$

Essa estatística segue uma distribuição qui-quadrada, com gl graus de liberdade. Os graus de liberdade em uma tabela de contingência são dados por (linhas - 1) x (colunas - 1) (Sweeney, Williams e Anderson, 2013). Assim, para 5 categorias de resposta de concordância sobre o aprendizado versus 7 categorias de intenção, chegam-se a $(5-1) \times(7-1)=24$ graus de liberdade.

O cerne da montagem do teste $\chi^{2}$ está em compor uma tabela de frequências esperadas, isto é, qual a contagem de indivíduos se esperaria obter dentro de cada cruzamento da categoria de "Intenção de Permanecer na Organização" (POI) em relação ao nível de concordância na assertiva sobre cada um dos itens que compõe a variável "Percepção Sobre Prática de DRH Aprendizagem Individual" (PPAI) caso não houvesse nenhuma associação entre as variáveis.

Caso exista associação entre as variáveis, observa-se um desvio substancial das frequências observadas em relação às esperadas.

Portanto, olhar para a tabela de frequências esperadas e compará-la às frequências observadas já dá uma percepção inicial sobre a associação ou não das variáveis. Essas diferenças são captadas pela estatística calculada conforme as equações acima. 
O teste estatístico envolvendo o $\chi^{2}$ tem a mesma lógica dos demais testes. Compara-se o valor obtido com um valor crítico ou o p-valor obtido com um nível de significância desejado (em geral $\alpha=0,05$ ), considerando-se que o efeito de associação não existe. Se o valor da estatística for muito elevado em relação ao crítico, o que corresponde a um p-valor abaixo do nível de significância, rejeita-se a hipótese nula de que não existe associação estatística (Levine et al., 2016). Por ser mais fácil de interpretar, neste trabalho será utilizado o p-valor calculado, lembrando-se o que ele significa: a probabilidade de se obter o resultado observado caso o efeito seja inexistente. Ou seja, se essa probabilidade for muito baixa, significa que há evidências de o resultado não ter sido obtido por acaso e, portanto, o efeito ou a associação entre as variáveis possivelmente é real. Para efeitos práticos, será adotado um nível de significância de $\alpha=0,05$. Se o $p$-valor do teste $\chi^{2}$ de independência de variáveis for inferior a esse valor, considera-se que o resultado obtido é estatisticamente significativo. Ou seja, quando $p$-valor $<0,05$, há evidências de que as variáveis estão estatisticamente associadas (Levine et al., 2016).

Cabe ressaltar que muito textos usualmente afirmam que o teste $\chi^{2}$ é bastante sensível ao tamanho da amostra. Quando a amostra é pequena sua premissa de um mínimo de 5 contagens esperadas dificilmente é atendido, de acordo com Sweeney et al (2013). No entanto, uma amostra muito grande aumenta a chance de falsos positivos, isto é, de haver significância estatística por mero acaso. Isso acontece quando os efeitos são pequenos e os modelos são mais complexos. Em comparações simples, como o caso das que estão em questão neste estudo, é um resultado há tempos conhecido de que o teste $\chi^{2}$ é robusto e se comporta adequadamente conforme a distribuição teórica (Bearden, Sharma e Teel, 1982).

O teste estatístico envolvendo o $\chi^{2}$ tem a mesma lógica dos demais testes. Compara-se o valor obtido com um valor crítico ou o p-valor obtido com um nível de significância desejado (em geral $\alpha=0,05)$ (J. F. Hair Jr. et al., 2005).

A fim de ampliar a investigação desta pesquisa, compreende-se que uma forma de avaliar o efeito conjunto das variáveis de aprendizado e sua relação com a intenção é gerar uma escala que pondere todas as respostas aos 8 itens que avaliam o aprendizado e observar como ele se distribui por categoria da variável de intenção. A escala pode ser gerada por uma análise de componentes principais.

Uma análise de componentes principais é um elemento de análise fatorial, 
uma técnica multivariada para análise de interdependência entre variáveis. Apesar de alguns pesquisadores apenas considerarem a análise fatorial sob o ponto de vista exploratório, onde ela busca estrutura em um conjunto de dados ou ajuda a reduzir os dados por meio de agrupamentos, o pesquisador pode, a partir de suporte teórico, testar hipóteses sobre agrupamentos de variáveis, utilizando a análise fatorial em papel confirmatório (J. F. Hair Jr., Black, Babin, Anderson, \& Tatham, 2009). Este foi o uso dado para esta análise nesta pesquisa.

Foi feita a análise de componente principal de construto "Percepção Sobre Prática de DRH Aprendizagem Individual" (PPAl) e o resultado esperado é de um fator com autovalor bem maior que 1 e os demais com autovalor inferior a 1. Já em relação à porcentagem de variância, esperamos o primeiro valor acima de $50 \%$ e os demais bem abaixo disso. (J. Hair Jr, Hult, Ringle, \& Sarstedt, 2014)

Havendo uma escala para a variável "Percepção Sobre Prática de DRH Aprendizagem Individual" (PPAI), pode-se avaliar se há diferenças da distribuição do aprendizado para cada uma das 7 categorias da variável de intenção de permanência na empresa. Usualmente, pode-se executar uma Análise de Variância (ANOVA), um teste de comparação de médias (quando há mais de dois grupos de comparação), que permite concluir se as diferenças observadas numericamente são estatisticamente significativas. Com esse tipo de técnica é possível inferir se os grupos de respondentes, separados em cada uma das categorias de resposta da intenção de permanência, realmente diferem em relação à escala do aprendizado ou se os valores são, do ponto de vista da estatística, um empate técnico, considerando-se o número de pessoas em cada categoria da variável.

A ANOVA apresenta quatro premissas que devem ser cuidadosamente verificadas antes de sua aplicação: (1) Normalidade da distribuição das médias para cada nível; (2) Independência dos erros; (3) Homogeneidade da variância; e (4) Ausência de outliers. Existem testes estatísticos para verificar cada uma das premissas, sendo que alguns deles são obtidos na própria aplicação da técnica (Levine et al, 2016).

Em caso de violação das premissas da ANOVA existem medidas que podem ser adotadas para manter a robustez do teste, como transformações de variáveis e exclusão dos outliers. No entanto, isso pode afetar a distribuição da variável estudada, alterando os efeitos em questão. Assim, a opção mais adequada é 
utilizar o equivalente não paramétrico da ANOVA, o teste de Kruskal-Wallis. Nesse teste, a premissa é de que a escala de medida é seja no mínimo ordinal e que os grupos de comparação sejam independentes (Heiberger \& Holland, 2009).

Uma vez que são feitas as comparações gerais dos grupos (os grupos são cada uma das respostas na variável intenção de permanecer, ou seja, 7 grupos distintos), podem ser feitos os chamados testes pos-hocs para múltiplas comparações, tais como o teste de Tukey ou o de Dunnet. Esses testes permitem verificar quais diferenças entre os grupos são estatisticamente significativas (Heiberger \& Holland, 2009). 


\section{APRESENTAÇÃO E ANÁLISE DE DADOS}

\subsection{Caracterização dos respondentes}

A amostra coletada retornou 258.427 questionários respondidos por empregados de empresas que voluntariamente desejam participar das Pesquisa Melhores Empresas para Trabalhar no ano de 2019, referindo-se à 410 empresas. Os questionários não revelam qual a empresa, mas apresentam a codificação empresa 1 até empresa 410.

Após o recebimento da base de dados foram realizados alguns procedimentos de limpeza de base que eliminaram questionários sem resposta para as perguntas abaixo, na Tabela 1:

Tabela 1 - Exclusão de dados faltantes

\begin{tabular}{|l|l|}
\hline Quantidade Inicial de Questionários & 258.427 \\
\hline & \\
\hline Que tipo de vínculo você tem com a sua empresa atualmente? & 1.415 \\
\hline Você é? (Homem, Mulher, Outro) & 6.102 \\
\hline Por quanto tempo mais você se vê trabalhando nesta empresa? & 1.127 \\
\hline \hline total de questionários com dados faltantes & 8.644 \\
\hline \hline & \\
\hline Questionários válidos & 249.783 \\
\hline
\end{tabular}

Fonte: elaborado pela autora

A amostra se caracterizou por uma predominância de empregado com vínculo empregatício e do sexo masculino e concentrou-se nas faixas etárias entre 20 a 40 anos, a presentadas na Tabela 2(Gênero) e Tabela 3(Faixa Etária):

Tabela 2 - Descrição da Amostra

\begin{tabular}{|l|r|r|r|r|r|}
\hline & \multicolumn{2}{|c|}{ Vínculo com a Organização } & \multicolumn{2}{c|}{ Gênero } \\
\hline & $\begin{array}{r}\text { Sou Estagiário } \\
\text { (com termo de } \\
\text { compromisso de } \\
\text { estágio vigente) }\end{array}$ & $\begin{array}{c}\text { Sou Empregado } \\
\text { (possuo vínculo } \\
\text { empregatício) }\end{array}$ & Mulher & Homem & Outro \\
\hline Quantidade & 7.376 & 242.407 & 99.001 & 149.703 & 1.079 \\
\hline$\%$ sobre a amostra & $3 \%$ & $97 \%$ & $39,6 \%$ & $59,9 \%$ & $0,4 \%$ \\
\hline
\end{tabular}

Fonte: elaborado pela autora 
Tabela 3 - Descrição da amostra - Faixa Etária

\begin{tabular}{|l|r|r|r|r|r|r|r|}
\hline & \multicolumn{7}{|c|}{ Faixa Etária } \\
\hline & até 20 & até 30 & até 40 & até 50 & até 60 & até 70 & $>70$ \\
\hline $\begin{array}{l}\text { Quantidade } \\
\text { \% sobre a } \\
\text { amostra }\end{array}$ & 6.658 & 82.299 & 93.296 & 47.408 & 17.397 & 2.577 & 148 \\
\hline
\end{tabular}

Fonte: elaborado pela autora

A análise da amostra, observando a distribuição por gênero e faixa etária, quando analisada a variável "Percepção Sobre Prática de DRH Aprendizagem Individual" (PPAI), demonstrou padrão de percepção consistente entre os gêneros masculino e feminino e faixa etárias. Já o comportamento do gênero outro difere em relação ao demais.

Estes padrões foram consistentes em todos os itens que compõem a variável. Aqui ilustraremos a análise através da Tabela 4 que analisa o primeiro item que compõe a variável PPAI, a Apr_Soc_1. Todos os demais itens foram analisados e demais tabelas estão disponíveis no Apêndice B.

Tabela 4 - Percentual de respostas do item Apr_Soc_1 em relação ao total de respostas presentes na amostra por característica do respondente.

\begin{tabular}{|l|r|r|r|r|r|c|}
\cline { 2 - 8 } \multicolumn{1}{c|}{} & \multicolumn{7}{c|}{ Apr_Soc_1 } \\
\cline { 2 - 8 } \multicolumn{1}{c|}{} & NS/NR & \multicolumn{1}{c|}{1} & \multicolumn{1}{c|}{2} & \multicolumn{1}{c|}{3} & \multicolumn{1}{c|}{4} & 5 \\
\hline Mulher & $0,5 \%$ & $2,6 \%$ & $5,5 \%$ & $6,2 \%$ & $34,1 \%$ & $51,1 \%$ \\
\hline Homem & $0,4 \%$ & $2,1 \%$ & $4,1 \%$ & $6,7 \%$ & $32,4 \%$ & $54,2 \%$ \\
\hline Outro & $1,5 \%$ & $8,7 \%$ & $12,6 \%$ & $11,8 \%$ & $34,3 \%$ & $31,1 \%$ \\
\hline até 20 & $0,5 \%$ & $2,1 \%$ & $4,0 \%$ & $7,1 \%$ & $25,6 \%$ & $60,8 \%$ \\
\hline até 30 & $0,4 \%$ & $2,3 \%$ & $4,6 \%$ & $7,0 \%$ & $31,0 \%$ & $54,6 \%$ \\
\hline até 40 & $0,4 \%$ & $2,3 \%$ & $5,1 \%$ & $6,7 \%$ & $34,6 \%$ & $50,8 \%$ \\
\hline até 50 & $0,6 \%$ & $2,4 \%$ & $4,6 \%$ & $5,9 \%$ & $34,8 \%$ & $51,7 \%$ \\
\hline até 60 & $0,6 \%$ & $2,0 \%$ & $3,8 \%$ & $5,2 \%$ & $33,2 \%$ & $55,1 \%$ \\
\hline até 70 & $0,9 \%$ & $2,2 \%$ & $2,9 \%$ & $4,6 \%$ & $30,5 \%$ & $59,0 \%$ \\
\hline$>70$ & $0,7 \%$ & $3,4 \%$ & $6,8 \%$ & $8,8 \%$ & $26,4 \%$ & $54,1 \%$ \\
\hline
\end{tabular}

Fonte: elaborado pela autora

A análise da amostra, observando a distribuição por gênero e faixa etária, quando analisada a variável "Intenção de Permanecer na Organização" (IPO), demonstrou padrão de percepção próximo entre os gêneros masculino e feminino, com um percentual um pouco maior do gênero masculino mais favorável em relação 
a intenção de permanecer na organização, novamente temos um padrão diferente para o grupo outro, consistente com o observado na variável "Percepção Sobre Prática de DRH Aprendizagem Individual" (PPAl). Em relação as faixas etárias, amostra apresentou um padrão de intenção maior de permanecer na organização nas faixas etárias: até 40, até 50 e até 60 . Este padrão demonstra que em empresas cujo perfil é de empresas que tem processos de Gestão de Pessoas desenvolvidos e voluntariamente desejam participar de pesquisa para avaliar as MEPT, existe um percentual maior de pessoas nestas faixas etárias que vislumbram se aposentar nestas empresas nas quais trabalham.

As tabelas a seguir (5) e (6) apresentam percentuais para a intenção de permanecer na organização, pesquisada por gênero e a mesma intenção pesquisada pela faixa etária.

Tabela 5 - Percentual de respostas por item da variável "Intenção de Permanecer na Organização" por característica gênero

\begin{tabular}{|c|r|r|r|r|r|r|r|}
\hline & $\begin{array}{c}\text { Estou } \\
\text { procurando } \\
\text { outra } \\
\text { empresa } \\
\text { neste } \\
\text { momento }\end{array}$ & $\begin{array}{c}\text { Por menos } \\
\text { de 1 ano }\end{array}$ & $\begin{array}{c}\text { Entre 1 e 3 } \\
\text { anos }\end{array}$ & $\begin{array}{c}\text { Entre 3 e 5 } \\
\text { anos }\end{array}$ & $\begin{array}{c}\text { Entre 5 e } \\
10 \text { anos }\end{array}$ & $\begin{array}{c}\text { Mais de 10 } \\
\text { anos }\end{array}$ & $\begin{array}{c}\text { Gostaria } \\
\text { de me } \\
\text { aposentar } \\
\text { nesta } \\
\text { empresa }\end{array}$ \\
\hline Mulher & $3,2 \%$ & $5,2 \%$ & $16,8 \%$ & $13,2 \%$ & $14,7 \%$ & $11,1 \%$ & $35,8 \%$ \\
\hline Homem & $3,2 \%$ & $4,1 \%$ & $12,4 \%$ & $10,8 \%$ & $13,3 \%$ & $12,9 \%$ & $43,4 \%$ \\
\hline Outro & $12,9 \%$ & $8,6 \%$ & $19,1 \%$ & $12,6 \%$ & $10,2 \%$ & $7,9 \%$ & $28,7 \%$ \\
\hline
\end{tabular}

Fonte: elaborado pela autora

Tabela 6 - Percentual de respostas por item da variável "Intenção de Permanecer na Organização" por característica faixa etária

\begin{tabular}{|c|r|r|r|r|r|r|r|}
\hline & $\begin{array}{c}\text { Estou } \\
\text { procurando } \\
\text { outra } \\
\text { empresa } \\
\text { neste } \\
\text { momento }\end{array}$ & $\begin{array}{c}\text { Por menos } \\
\text { de 1 ano }\end{array}$ & $\begin{array}{c}\text { Entre 1 e 3 } \\
\text { anos }\end{array}$ & $\begin{array}{c}\text { Entre 3 e 5 } \\
\text { anos }\end{array}$ & $\begin{array}{c}\text { Entre 5 e } \\
10 \text { anos }\end{array}$ & $\begin{array}{c}\text { Mais de 10 } \\
\text { anos }\end{array}$ & $\begin{array}{c}\text { Gostaria } \\
\text { de me } \\
\text { aposentar } \\
\text { nesta } \\
\text { empresa }\end{array}$ \\
\hline até 20 & $4,3 \%$ & $10,0 \%$ & $26,0 \%$ & $16,1 \%$ & $12,6 \%$ & $8,9 \%$ & $22,1 \%$ \\
\hline até 30 & $4,5 \%$ & $6,4 \%$ & $19,6 \%$ & $14,9 \%$ & $14,2 \%$ & $11,7 \%$ & $28,8 \%$ \\
\hline até 40 & $3,3 \%$ & $3,7 \%$ & $12,2 \%$ & $10,2 \%$ & $12,9 \%$ & $13,4 \%$ & $44,2 \%$ \\
\hline até 50 & $1,9 \%$ & $2,4 \%$ & $7,5 \%$ & $7,8 \%$ & $13,5 \%$ & $11,9 \%$ & $54,9 \%$ \\
\hline até 60 & $0,9 \%$ & $3,4 \%$ & $11,3 \%$ & $13,5 \%$ & $18,2 \%$ & $10,0 \%$ & $42,7 \%$ \\
\hline até 70 & $0,5 \%$ & $5,3 \%$ & $20,2 \%$ & $18,4 \%$ & $15,2 \%$ & $11,8 \%$ & $28,6 \%$ \\
\hline$>70$ & $4,1 \%$ & $5,4 \%$ & $20,3 \%$ & $17,6 \%$ & $16,2 \%$ & $14,9 \%$ & $21,6 \%$ \\
\hline
\end{tabular}

Fonte: elaborado pela autora 
Já na investigação das características da amostra ficou evidente grande favorabilidade da amostra tanto em relação a variável "Percepção Sobre Prática de DRH Aprendizagem Individual" (PPAl), quanto em relação variável "Intenção de Permanecer na Organização" (IPO). A pesquisa não considera isso um problema, mas sim uma característica da amostra, consistente com o fato de a amostra ser composta por empregados de empresas que desejam participar de pesquisa MEPT, acreditando que suas práticas estão ou maduras ou em aperfeiçoamento e voluntariamente submetem a organização a pesquisa.

\subsection{Análise da variável "Percepção Sobre Prática de DRH Aprendizagem Individual" (PPAI)}

O teste foi iniciado mediante a correlação dentro da variável PPAI, testando a associação entre as perguntam que medem esse construto. A seguir a tabela 7 apresenta a matriz da correlação variável.

Tabela 7- Matriz de correlação da variável "Percepção Sobre Prática de DRH Aprendizagem Individual" (PPAl)

\begin{tabular}{|l|r|r|r|r|r|r|r|r|}
\hline & Apr_Exp_1 & Apr_Exp_2 & Apr_For_1 & Apr_For_2 & Apr_Inf_1 & Apr_Inf_2 & Apr_Soc_1 & Apr_Soc_2 \\
\hline Apr_Exp_1 & 1,000 & 0,609 & 0,495 & 0,537 & 0,455 & 0,575 & 0,433 & 0,442 \\
\hline Apr_Exp_2 & 0,609 & 1,000 & 0,499 & 0,544 & 0,436 & 0,538 & 0,427 & 0,442 \\
\hline Apr_For_1 & 0,495 & 0,499 & 1,000 & 0,640 & 0,391 & 0,491 & 0,376 & 0,329 \\
\hline Apr_For_2 & 0,537 & 0,544 & 0,640 & 1,000 & 0,411 & 0,503 & 0,379 & 0,340 \\
\hline Apr_Inf_1 & 0,455 & 0,436 & 0,391 & 0,411 & 1,000 & 0,465 & 0,337 & 0,310 \\
\hline Apr_Inf2 & 0,575 & 0,538 & 0,491 & 0,503 & 0,465 & 1,000 & 0,411 & 0,385 \\
\hline Apr_Soc_1 & 0,433 & 0,427 & 0,376 & 0,379 & 0,337 & 0,411 & 1,000 & 0,633 \\
\hline Apr_Soc_2 & 0,442 & 0,442 & 0,329 & 0,340 & 0,310 & 0,385 & 0,633 & 1,000 \\
\hline
\end{tabular}

Fonte: elaborado pela autora

A matriz de correlação foi analisada segundo a lógica de Cohen (1990), para ciência do comportamento onde correlações que variam entre as faixas podem ser consideradas tendo o impacto conforme o quadro 9.

Quadro 9 - Impacto da faixa de variação da correlação

\begin{tabular}{|l|c|}
\hline Faixa de Variação & Correlação \\
\hline 0,1 --> $\mathbf{R}^{2}=0,1 * 0,1=0,01=1 \%$ & Pequenas \\
\hline 0,3 --> $\mathbf{R}^{2}=0,3 * 0,3=0,09=9 \%$ & Médias \\
\hline 0,5 --> $\mathbf{R}^{2}=0,5 * 0,5=0,25=25 \%$ & Grandes \\
\hline
\end{tabular}

Fonte: elaborado pela autora baseado em Cohen (1990) 
Analisando a matriz é perceptível que todas as correlações podem ser classificadas como altas. Já em relação a confiabilidade da escala, espera-se um resultado de Alfa de Cronbach superior à 0.7 , observa-se resultado superior a 0,8 no alfa padronizado o que significa que a escala é confiável, de acordo com o quadro 10.

Quadro 10 - Análise do alpha padronizado por item da variável PPAI

Alpha reliability $=0,8704$

Standardized alpha $=0,8713$

Reliability deleting each item in turn:

\begin{tabular}{|l|r|r|r|}
\hline & Alpha & Std.Alpha & r(item, total) \\
\hline Apr_Exp_1 & 0,846 & 0,847 & 0,701 \\
\hline Apr_Exp_2 & 0,847 & 0,849 & 0,690 \\
\hline Apr_For_1 & 0,854 & 0,855 & 0,631 \\
\hline Apr_For_2 & 0,851 & 0,852 & 0,661 \\
\hline Apr_Inf1 & 0,864 & 0,865 & 0,538 \\
\hline Apr_Inf2 & 0,851 & 0,852 & 0,662 \\
\hline Apr_Soc_1 & 0,859 & 0,861 & 0,581 \\
\hline Apr_Soc_2 & 0,863 & 0,863 & 0,549 \\
\hline
\end{tabular}

Fonte: extraído do software $\mathrm{R}$ Commander (R version 3.6.1) pela autora

Quando se analisa cada item, ou seja, excluindo um item da escala por vez, observamos que há leve queda no valor do alfa padronizado, o que significa que não há necessidade de excluir nenhum item da escala e assim, a escala está validada. Uma análise preliminar do comportamento das variáveis de "Percepção Sobre Prática de DRH Aprendizagem Individual” (PPAI), demonstrada na tabela 8, demonstrou que a grande maioria das respostas foi muito favorável. Esperava-se este comportamento uma vez que a amostra é de empresas que estão participando da pesquisa MEPT, assim, como já dito anteriormente, elas acreditam que suas práticas estão ou maduras ou em aprefeiçoamento e voluntariamente submetem a organização a pesquisa.

Tabela 8 - Frequência de Respostas por item da Escala da variável PPAI

\begin{tabular}{|c|c|c|c|c|c|c|c|c|}
\hline & V45 & V26 & V65 & V39 & V53 & V72 & V24 & V28 \\
\hline & Apr_Soc_1 & Apr_Soc_2 & Apr_For_1 & Apr_For_2 & Apr_Inf_1 & Apr_Inf_2 & Apr_Exp_1 & Apr_Exp_2 \\
\hline NS/NR & 1.142 & 841 & 2.852 & 2.423 & 6.660 & 2.048 & 1.333 & 3.858 \\
\hline 1 & 5.807 & 10.077 & 10.488 & 10.802 & 10.360 & 6.637 & 8.927 & 10.583 \\
\hline 2 & 11.718 & 17.626 & 14.430 & 15.918 & 11.875 & 8.139 & 12.618 & 16.184 \\
\hline 3 & 16.312 & 17.790 & 14.430 & 19.582 & 25.813 & 14.910 & 16.771 & 24.620 \\
\hline 4 & 82.660 & 84.265 & 56.722 & 71.340 & 66.813 & 62.257 & 71.100 & 86.939 \\
\hline 5 & 132.144 & 119.184 & 150.861 & 129.718 & 128.262 & 155.792 & 139.034 & 107.599 \\
\hline total & 249.783 & 249.783 & 249.783 & 249.783 & 249.783 & 249.783 & 249.783 & 249.783 \\
\hline
\end{tabular}

Fonte: elaborado pela autora 
Tabela 9 - Percentual de Frequência de Respostas no Item sobre o total de Respostas

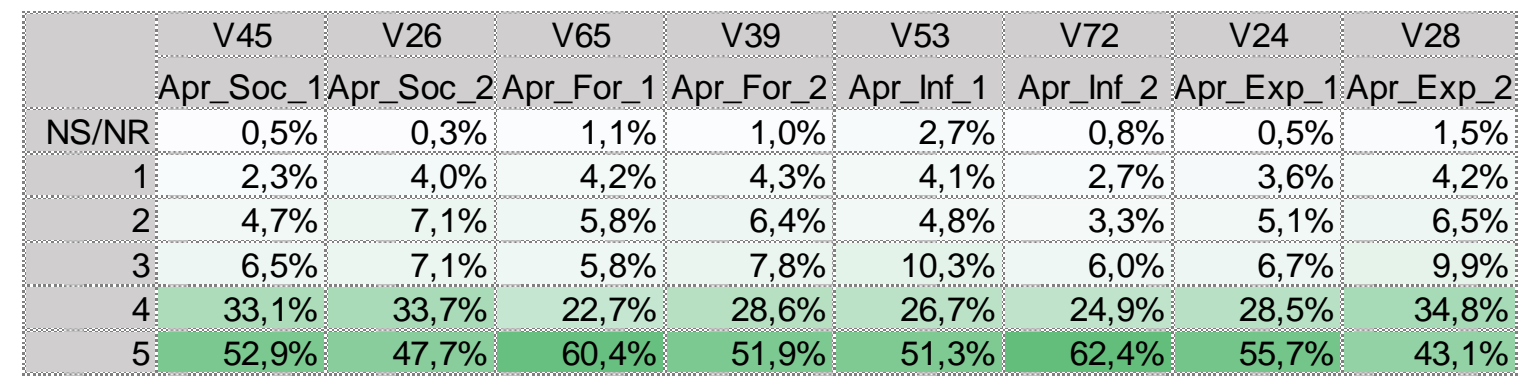

Fonte: elaborado pela autora

Somados os percentuais de respostas favoráveis 4 e 5, apresentados na tabela 9 , todos as perguntas têm percentuais superiores a $80 \%$ de favorabilidade, exceção feita para o item "Apr_Inf_1" (Todos têm oportunidade de participar de atividades de treinamento nesta empresa) com 78,1\% e o item "Apr_Exp_2" (Esta empresa coloca em prática as sugestões de seus funcionários, sempre que possível) com 77,9\%. São variações muito pequenas mas convêm ser apontadas.

\subsection{Análise da variável “Intenção de Permanecer na Organização” (IPO)}

Ao compreender a Intenção de Permanecer na Organização como à força da disposição dos funcionários em permanecer em sua organização no futuro próximo (Uraon, 2018), observou-se a distribuição dos respondentes de acordo com a escala, também ordinal, que contempla 7 categorias, indo de 'Estou procurando emprego atualmente', o que corresponde ao nível mais baixo na intenção de permanência, ao 'Pretendo me aposentar nesta empresa', equivalente ao nível mais alto.

Tabela 10 - Frequência de Respostas e Percentual sobre amostra da variável IPO

\begin{tabular}{|c|c|c|c|c|}
\hline & & & & \\
\hline & & & Total & $\begin{array}{l}\% \text { sobre } \\
\text { Amostra }\end{array}$ \\
\hline \multirow{8}{*}{$\begin{array}{l}\text { Intenção De } \\
\text { Permanecer } \\
\quad \mathrm{Na} \\
\text { Organização }\end{array}$} & \multirow{8}{*}{$\begin{array}{c}\text { Por quanto } \\
\text { tempo mais } \\
\text { você se vê } \\
\text { trabalhando } \\
\text { nesta } \\
\text { empresa? }\end{array}$} & $\begin{array}{l}\text { Estou procurando outra empresa neste } \\
\text { momento }\end{array}$ & 8.086 & $3 \%$ \\
\hline & & Por menos de 1 ano & 11.323 & $5 \%$ \\
\hline & & Entre 1 e 3 anos & 35.331 & $14 \%$ \\
\hline & & Entre 3 e 5 anos & 29.414 & $12 \%$ \\
\hline & & Entre 5 e 10 anos & 34.502 & $14 \%$ \\
\hline & & Mais de 10 anos & 30.461 & $12 \%$ \\
\hline & & Gostaria de me aposentar nesta empresa & 100.666 & $40 \%$ \\
\hline & & Total & 249.783 & $100 \%$ \\
\hline
\end{tabular}

Fonte: elaborado pela autora 
Uma análise preliminar do comportamento da variável "Intenção de Permanecer na Organização" (IPO), apresentada na tabela 10, também demonstrou grande favorabilidade, considerando os itens "Mais de 10 anos" e "Gostaria de me aposentar nesta empresa" como os pontos de maior favorabilidade na escala, temos $52 \%$ dos respondentes posicionados neste pontos. Resultado também consistente com o fato de, como já dito anteriormente, a amostra ser de empresas que estão participando da pesquisa Melhores Empresas para Trabalhar.

\subsection{Investigação da Associação entre as variáveis}

Conforme descrito no capítulo técnicas de análise, a análise natural que deve ser feita quando são considerados cruzamentos de questões categóricas ordinais são as chamadas tabelas de contingência.

As análises iniciam com a construção de tabelas cruzando cada item da escala que mediu cada uma das assertivas da variável "Percepção Sobre Prática de DRH Aprendizagem Individual” (PPAI) e os grupos de respostas da variável "Intenção de Permanecer na Organização" (IPO). Assim, as células da tabela apresentam as contagens de respondentes que pertencem simultaneamente às duas categorias em questão.

Assim, cruzando cada um dos itens das assertivas da variável PPAI (escala Likert em 5 níveis, com 1= "discordo totalmente" a 5="concordo totalmente" e a opção NS/NR (Não Sei / Não Quero Responder) e a variável IPO (com 7 níveis) obtém-se como resultado uma matriz de 6 colunas por 7 linhas. As análises foram feitas por assertiva, aqui apresentaremos tabela que com a análise do item Apr_Soc_1 da variável PPAI, conforme a Tabela 11. As demais tabelas podem ser consultadas no Apêndice C. 
Tabela 11 - Tabela de Contingência Apr_Soc_1 e IPO

\begin{tabular}{|c|c|c|c|c|c|c|c|c|}
\hline \multirow[b]{2}{*}{ Int_Perm } & \multicolumn{8}{|c|}{ Apr_Soc_1 } \\
\hline & NS/NR & 1 & 2 & 3 & 4 & 5 & $\begin{array}{l}\text { Soma c/ } \\
\text { resposta }\end{array}$ & Soma \\
\hline $\begin{array}{l}\text { Estou procurando outra } \\
\text { empresa neste momento }\end{array}$ & 73 & 826 & 1.067 & 1.090 & 2.695 & 2.335 & 8.013 & 8.013 \\
\hline Por menos de 1 ano & 71 & 678 & 1.058 & 1.228 & 3.813 & 4.475 & 11.252 & 11.252 \\
\hline Entre 1 e 3 anos & 177 & 1.088 & 2.409 & 3.073 & 12.727 & 15.857 & 35.154 & 35.154 \\
\hline Entre 3 e 5 anos & 151 & 635 & 1.495 & 2.112 & 10.425 & 14.596 & 29.263 & 29.263 \\
\hline Entre 5 e 10 anos & 127 & 605 & 1.437 & 2.205 & 12.213 & 17.915 & 34.375 & 34.375 \\
\hline Mais de 10 anos & 121 & 462 & 1.032 & 1.668 & 9.906 & 17.272 & 30.340 & 30.340 \\
\hline $\begin{array}{l}\text { Gostaria de me aposentar } \\
\text { nesta empresa }\end{array}$ & 422 & 1.513 & 3.220 & 4.936 & 30.881 & 59.694 & 100.244 & 100.244 \\
\hline Total & 1.142 & 5.807 & 11.718 & 16.312 & 82.660 & 132.144 & 248.641 & 249.783 \\
\hline
\end{tabular}

Fonte: elaborado pela autora

Essa tabela (tabela 11) permitiu que fosse construída uma nova tabela de contingência que analisou o quanto representava em termos percentuais, a quantidade de respostas encontradas na amostra por item da escala Likert da assertiva Aprendizagem Social 1 (Apr Soc 1), componente da variável PPAI e grupo da variável IPO, em relação total de respostas encontradas na assertiva Apr_Soc_1 por cada um dos grupos da variável IPO. Essa análise resultou em matrizes 7 por 6 em cada uma das assertivas da variável PPAI, e se apresenta nomeada como tabela 12, a seguir: 
Tabela 12 - Tabela de Contingência Apr_Soc_1 e IPO com frequência total de respostas sobre o total de respostas do grupo da variável IPO

\begin{tabular}{|l|r|r|r|r|c|c|}
\hline Tabela Resumo & \multicolumn{7}{|c|}{ Apr_Soc_1 } \\
\hline Int_Perm & NS/NR & 1 & 2 & 3 & 4 & 5 \\
\hline Estou procurando outra empresa neste momento & $0,9 \%$ & $10,3 \%$ & $13,3 \%$ & $13,6 \%$ & $33,6 \%$ & $29,1 \%$ \\
\hline Por menos de 1 ano & $0,6 \%$ & $6,0 \%$ & $9,4 \%$ & $10,9 \%$ & $33,9 \%$ & $39,8 \%$ \\
\hline Entre 1 e 3 anos & $0,5 \%$ & $3,1 \%$ & $6,9 \%$ & $8,7 \%$ & $36,2 \%$ & $45,1 \%$ \\
\hline Entre 3 e 5 anos & $0,5 \%$ & $2,2 \%$ & $5,1 \%$ & $7,2 \%$ & $35,6 \%$ & $49,9 \%$ \\
\hline Entre 5 e 10 anos & $0,4 \%$ & $1,8 \%$ & $4,2 \%$ & $6,4 \%$ & $35,5 \%$ & $52,1 \%$ \\
\hline Mais de 10 anos & $0,4 \%$ & $1,5 \%$ & $3,4 \%$ & $5,5 \%$ & $32,6 \%$ & $56,9 \%$ \\
\hline Gostaria de me aposentar nesta empresa & $0,4 \%$ & $1,5 \%$ & $3,2 \%$ & $4,9 \%$ & $30,8 \%$ & $59,5 \%$ \\
\hline \hline $\begin{array}{l}\text { Total de Respostas em cada ponto da escala da } \\
\text { assertiva sobre total da amostra }\end{array}$ & $0,5 \%$ & $\mathbf{2 , 3} \%$ & $\mathbf{4 , 7 \%}$ & $\mathbf{6 , 5 \%}$ & $33,1 \%$ & $52,9 \%$ \\
\hline
\end{tabular}

Fonte: elaborado pela autora

Em uma primeira análise, utilizando o recurso de formatação condicional com escala de cores, é possível notar o já esperado efeito de aumento de respostas no cruzamento da matriz onde temos os itens que representam o maior índice de satisfação em ambas as variáveis. Esse efeito é consistente com a característica da amostra, já discutido anteriormente.

No entanto, quando é observada esta tabela, espera-se também que, se não houver associação entre elas, elas se comportem, percentualmente da mesma forma que o comportamento resultante do cálculo do total de respostas no item da escala Likert utilizada nas assertivas que constituem a variável POAI sobre o total da amostra. Observamos que não foi isso que aconteceu, apontando para associação entre as variáveis. Foi aqui demonstrada a análise do item Apr_Soc_1 da variável PPAI, as análises foram feitas por assertiva e o efeito foi consistente em todos os quadros que estão disponíveis no Apêndice D.

O item da variável PPAI, Aprendizagem Social 1 (Apr_Soc_1), diz respeito a pregunta: Meus colegas estão sempre dispostos a dividir comigo o que sabem. É possível distinguir um adensamento de respostas apontando para uma mais baixa intenção de permanecer na organização em relação ao esperado quando tivemos uma menor satisfação em relação a percepção dos respondentes em relação à assertiva.

Esse efeito, consistente em todas as assertivas direciona a pesquisa para o realizar o teste estatístico $\chi^{2}$, que mede o quanto a diferença (ao quadrado) entre a frequência observada (fo) e a frequência esperada (fe) do cruzamento das variáveis 
em questão, se afasta em relação a frequência esperada, conforme descrito no item "Técnicas de Análise". Caso exista associação entre as variáveis, observa-se um desvio substancial das frequências observadas em relação às esperadas.

A tabela de dados observados foi o primeiro conjunto de tabelas construídas e já demonstrada por meio do exemplo apresentado com a tabela 11.

Nas análises seguintes foram desconsiderados os respondentes que assinalaram na variável PPAI, NS/NR (Não Sei / Não Quero Responder). Os formulários não foram excluídos pois isso significaria a exclusão de 15.015 formulários, mas para a construção das tabelas dados esperados e dados observados, essa coluna foi desconsiderada quando aquela assertiva estava sendo investigada. Assim, um respondente pode ter, por exemplo, sua resposta desconsiderada no item Apr_Soc_1 pois respondeu NS/NR e considerada para os demais itens pois ofereceu resposta dentro da escala likert.

Com os valores dos totais das margens (totais das linhas e totais das colunas) disponíveis nas tabelas de dados observados, pode-se obter uma tabela de frequências esperada. Estão marcados em verde mais escuro os valores esperados mais altos, conformse se observa na tabela 13:

Tabela 13 - Contagens Esperadas no cruzamento das variáveis Apr_Soc_1 e IPO

\begin{tabular}{|c|c|c|c|c|c|}
\hline \multicolumn{6}{|c|}{ Contagens esperadas } \\
\hline Int Perm & 1 & 2 & 3 & 4 & 5 \\
\hline $\begin{array}{l}\text { Estou procurando outra empresa neste } \\
\text { momento }\end{array}$ & 187 & 378 & 526 & 2.664 & 4.259 \\
\hline Por menos de 1 ano & 263 & 530 & 738 & 3.741 & 5.980 \\
\hline Entre 1 e 3 anos & 821 & 1.657 & 2.306 & 11.687 & 18.683 \\
\hline Entre 3 e 5 anos & 683 & 1.379 & 1.920 & 9.728 & 15.552 \\
\hline Entre 5 e 10 anos & 803 & 1.620 & 2.255 & 11.428 & 18.269 \\
\hline Mais de 10 anos & 709 & 1.430 & 1.990 & 10.086 & 16.125 \\
\hline Gostaria de me aposentar nesta emprese & 2.341 & 4.724 & 6.576 & 33.326 & 53.276 \\
\hline
\end{tabular}

Fonte: elaborado pela autora

Caso não exista relação entre as duas variáveis (aprendizado e intenção de permanência), o padrão que se observaria, proporcionalmente ao total dentro de cada categoria da variável de intenção, seria como no gráfico 1, a seguir: 
Gráfico 1 - Resultados Esperados sem o Efeito de Associação para o item Apr_Soc_1 e IPO

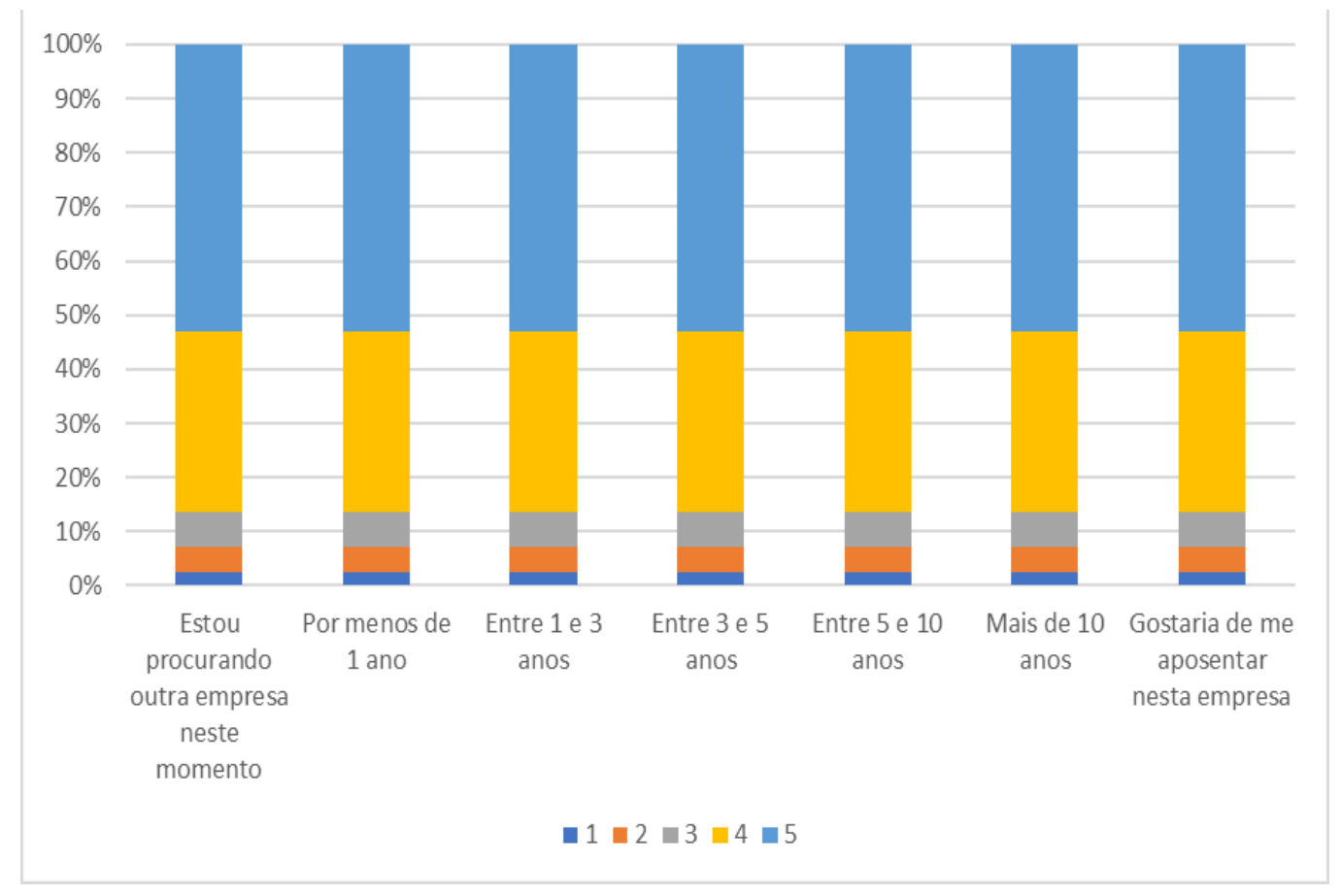

Fonte: elaborado pela autora

A proporção dentro da categoria se mantém para as frequências esperadas, uma vez que elas pressupõem a não associação entre as variáveis.

Foi então realizado o teste estatístico e, caso ele resulte em uma associação estatisticamente significativa, segue-se analisando os padrões resultantes das observação dos gráficos "Resultado Esperado Sem o Efeito" e "Resultados Observados".

A estatística do teste para esse cruzamento foi de $\chi^{2}=10.743,79$, o que, para 24 graus de liberdade, corresponde a um p-valor muito próximo de zero, indicando que as frequências observadas são distintas das esperadas, evidenciando a significativa associação estatística entre a variável "Apr_Soc_1" e a variável “Intenção de Permanecer na Organização", observada no gráfico 2: 
Gráfico 2 - Resultados Observados para o item Apr_Soc_1 e IPO

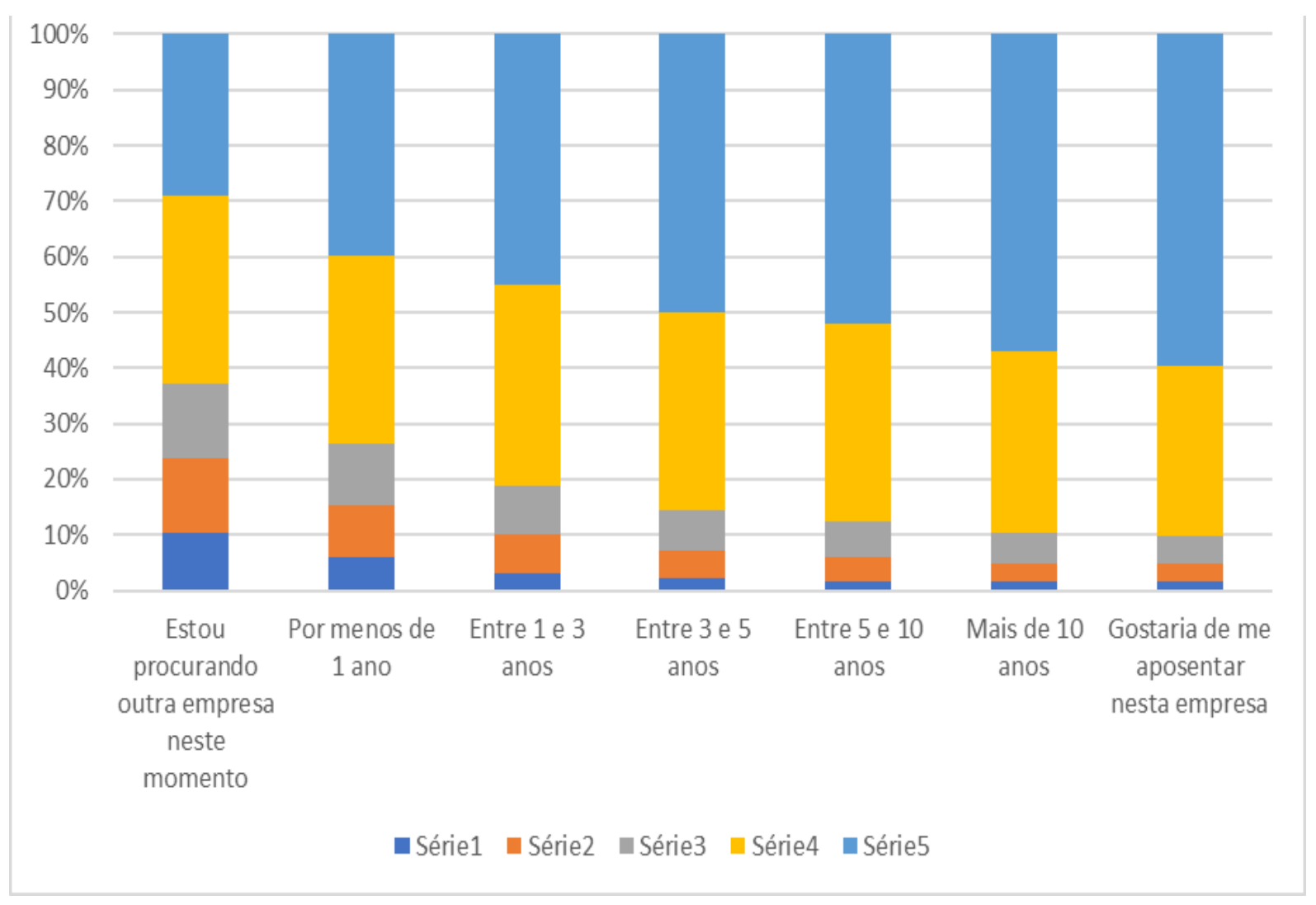

Fonte: elaborado pela autora

Pode-se ver claramente no gráfico 2 o percentual de "concordo totalmente" (azul claro) aumentar com o aumento da intenção de permanência. Já o percentual de discordância, que praticamente nem seria visível, caso não houvesse associação, aparece com percentuais declinantes à medida que a intenção de permanência aumenta (azul escuro, laranja e cinza).

Este padrão foi observado na investigação de todas as assertivas e em todos os casos com p-valor desprezível, muito próximo de zero, evidenciando assim a associação estatística entre todas as assertivas da variável "PPAl" e a variável "Intenção de Permanecer na Organização". Todos os gráficos estão disponíveis no Apêndice $\mathrm{E}$.

Com o objetivo de investigar se a associação é realmente com as variáveis de aprendizado, foi feita a análise da variável "Intenção de Permanecer na Organização" e "Gênero", o efeito de associação é muito baixo e resultou dois gráficos, a saber 3 e 4, a seguir: 
Gráfico 3 - Resultados esperados sem o efeito da associação para o gênero e IPO

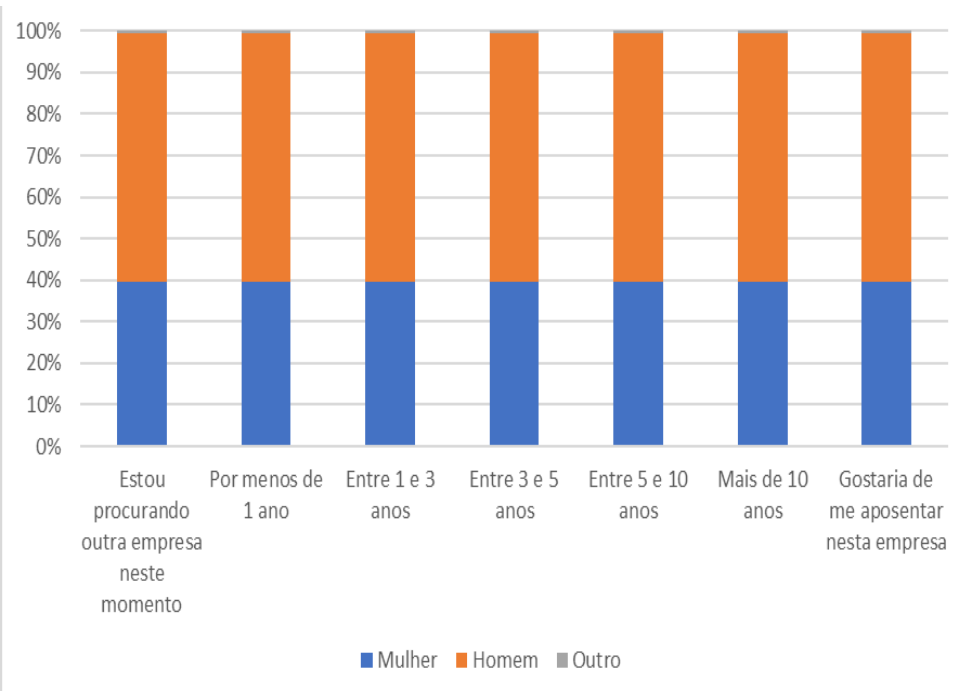

Fonte: elaborado pela autora

Gráfico 4 - Resultados Observados para Gênero e IPO

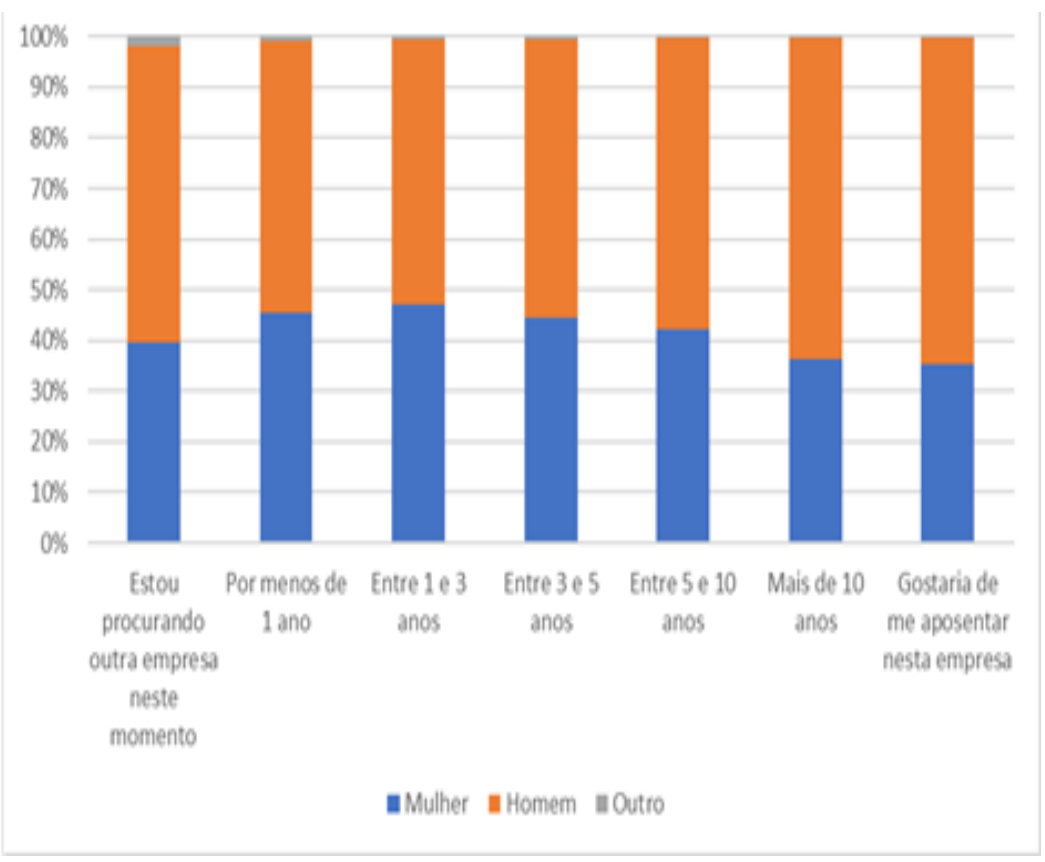

Fonte: elaborado pela autora

A fim de investigar se existe algum padrão que emerge da amostra, foram então aplicadas as mesmas técnicas observando conjuntamente todas as perguntas 
da variável PPAl em relação ao ponto mínimo e máximo da escala IPO ("Estou procurando outra empresa neste momento" e "Gostaria de me aposentar nesta empresa").

Iniciamos descrevendo a análise de todas os itens da variável PPAI, em todas possíveis respostas da escala likert utilizada em relação ao ponto mínimo da variável IPO, "Estou procurando outra empresa neste momento". O gráfico 5 representando os dados esperados e o gráfico 6, representando os dados observados.

Gráfico 5 - Resultados esperados sem o efeito

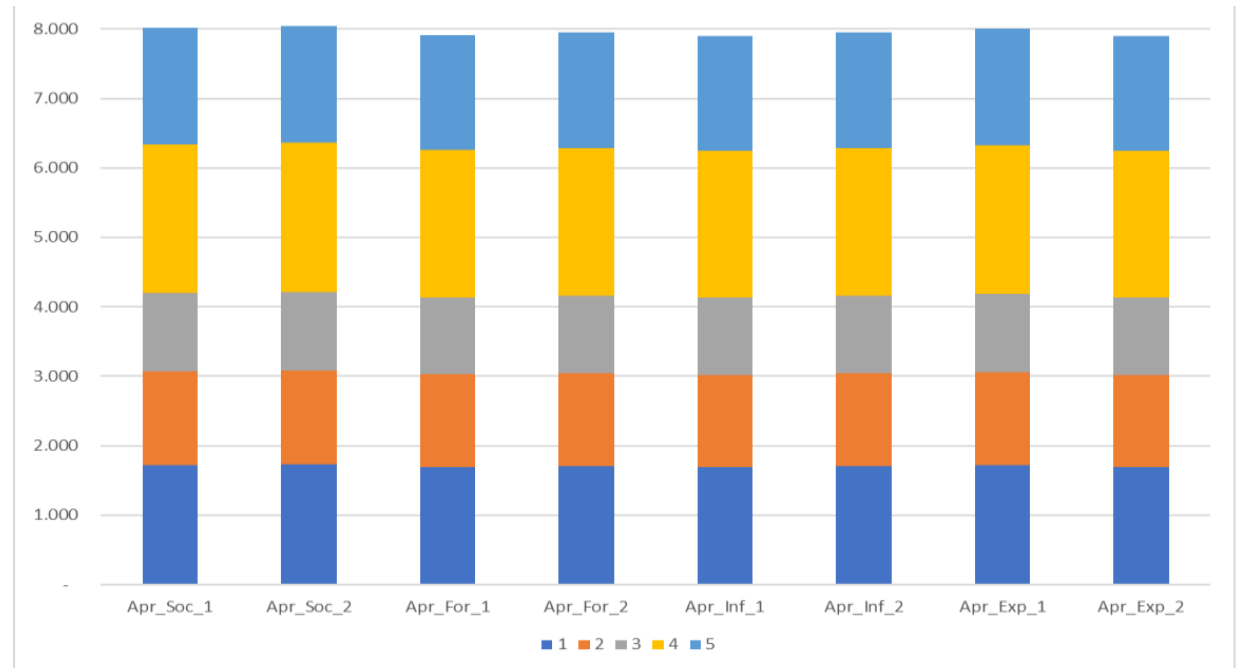

Fonte: elaborado pela autora

Gráfico 6 - Resultados Observados

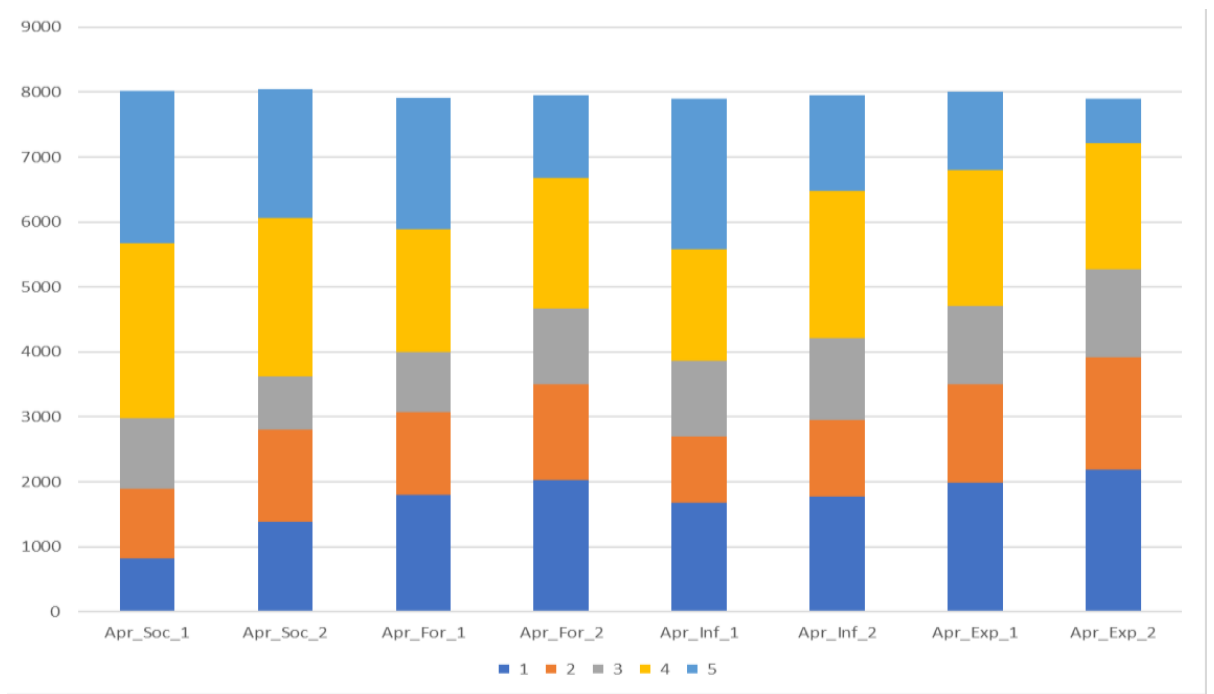

Fonte: elaborado pela autora 
No Gráfico 6 é possível observar o comportamento das perguntas que compõe a variável PPAI em relação ao ponto mínimo de favorabilidade da variável PO.

Observa-se no também que, em relação ao padrão esperado, o item que tem menor frequência de respostas de baixa favorabilidade na aprendizagem é o Apr_Soc_1 ("Meus colegas estão sempre dispostos a dividir comigo o que sabem "), podendo ter menor influência.

As questões que apresentam maior frequência no ponto de menor favorabilidade na variável PPAI são as perguntas relacionadas a aprendizagem experiencial ("Sou estimulado a contribuir para melhorar a forma como é feito o meu trabalho" e "Esta empresa coloca em prática as sugestões de seus funcionários, sempre que possível"). São fundamentos da aprendizagem experiencial o engajamento do aprendiz e a construção ativa por parte dele de sua própria experiência (Didier \& Lucena, 2008).

A terceira pergunta que apresentou maior frequência no ponto de menor favorabilidade na variável PPAI foi a pergunta Apr_For_2 ("Os treinamentos oferecidos pela empresa atendem adequadamente às necessidades do meu trabalho"). A aprendizagem formal, tipicamente patrocinada institucionalmente (Didier \& Lucena, 2008), continua tendo papel importante, em especial quando relacionada com a dimensão prática do trabalho.

Estes aspectos podem iluminar como o processo de aprendizagem, tanto a partir da experiência quanto o formal são percebidos também pela organização, oferecendo oportunidade para futuros aprofundamentos.

Iniciamos descrevendo a análise de todas os itens da variável PPAI, em todas possíveis respostas da escala likert utilizada em relação ao ponto máximo da variável IPO, "Gostaria de me aposentar nesta empresa". O gráfico 7 representando os dados esperados e o gráfico 8, representando os dados observados. 
Gráfico 7 - Resultados esperados sem o efeito - Gostaria de me aposentar nesta empresa

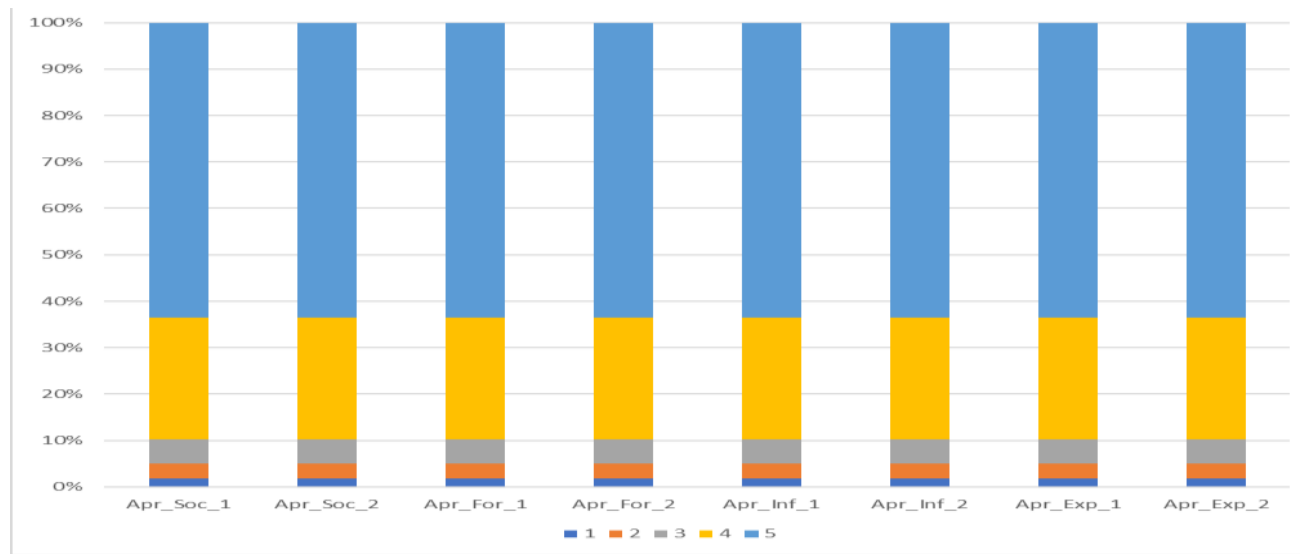

Fonte: elaborado pela autora

Gráfico 8 - Resultados Observados - Gostaria de me aposentar nesta empresa

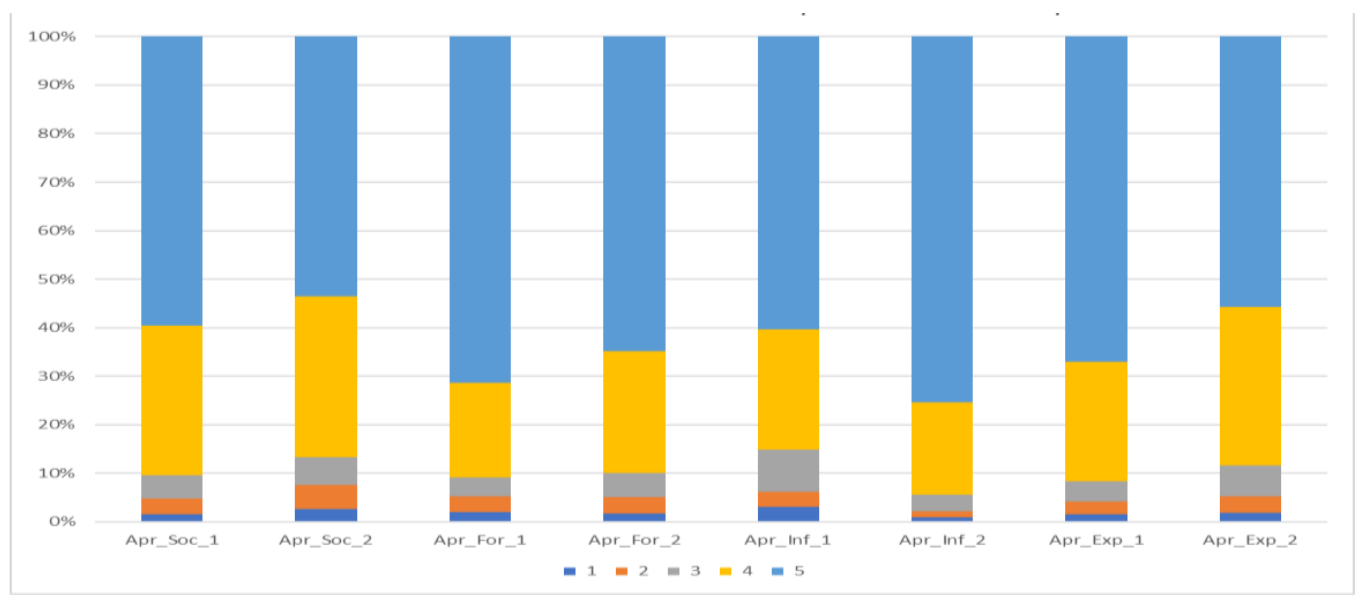

Fonte: elaborado pela autora

De forma análoga a análise anterior, podemos no Gráfico 8 observar o comportamento das perguntas que compõe a variável PPAl em relação ao ponto máximo de favorabilidade da variável PO.

As questões que apresentam maior frequência no ponto de maior favorabilidade na variável PPAI são a pergunta Apr_Inf_2 (O trabalho que realizo nesta empresa apresenta desafios que estimulam o meu desenvolvimento) e a pergunta Apr_For_1 ("Todos têm oportunidade de participar de atividades de treinamento nesta empresa"). A pergunta Apr_Inf_2 está em conexão com a compreensão de que a aprendizagem informal e incidental ocorre fora de atividades formalmente estruturadas e institucionalmente patrocinadas, acontecendo com 
frequência em circunstâncias não rotineiras, ou seja, quando os procedimentos e respostas que as pessoas normalmente usam falham (Marsick et al., 2009). Já a pergunta Apr_For_1 diz respeito a aprendizagem formal, que é a aprendizagem tipicamente patrocinada institucionalmente (Didier \& Lucena, 2008).

Observar pode apontar para papéis igualmente relevantes, na percepção dos empregados, da aprendizagem formal e informal.

\subsection{Associação entre o efeito conjunto da variável (PPAI) e (IPO)}

Uma forma de avaliar o efeito conjunto das variáveis de aprendizado e sua relação com a intenção é gerar uma escala que pondere todas as respostas aos 8 itens que avaliam o aprendizado e observar como ele se distribui por categoria da variável de intenção.

A escala foi gerada por uma análise de componentes principais, como descrito no capítulo de técnicas de análise.

Segue o box-plot com a distribuição de pontuação nessa escala de medida do aprendizado para cada categoria de intenção de permanência na empresa, representado pelo gráfico 9 , a seguir:

Gráfico 9 - Box-plot da variável PPAI e IPO

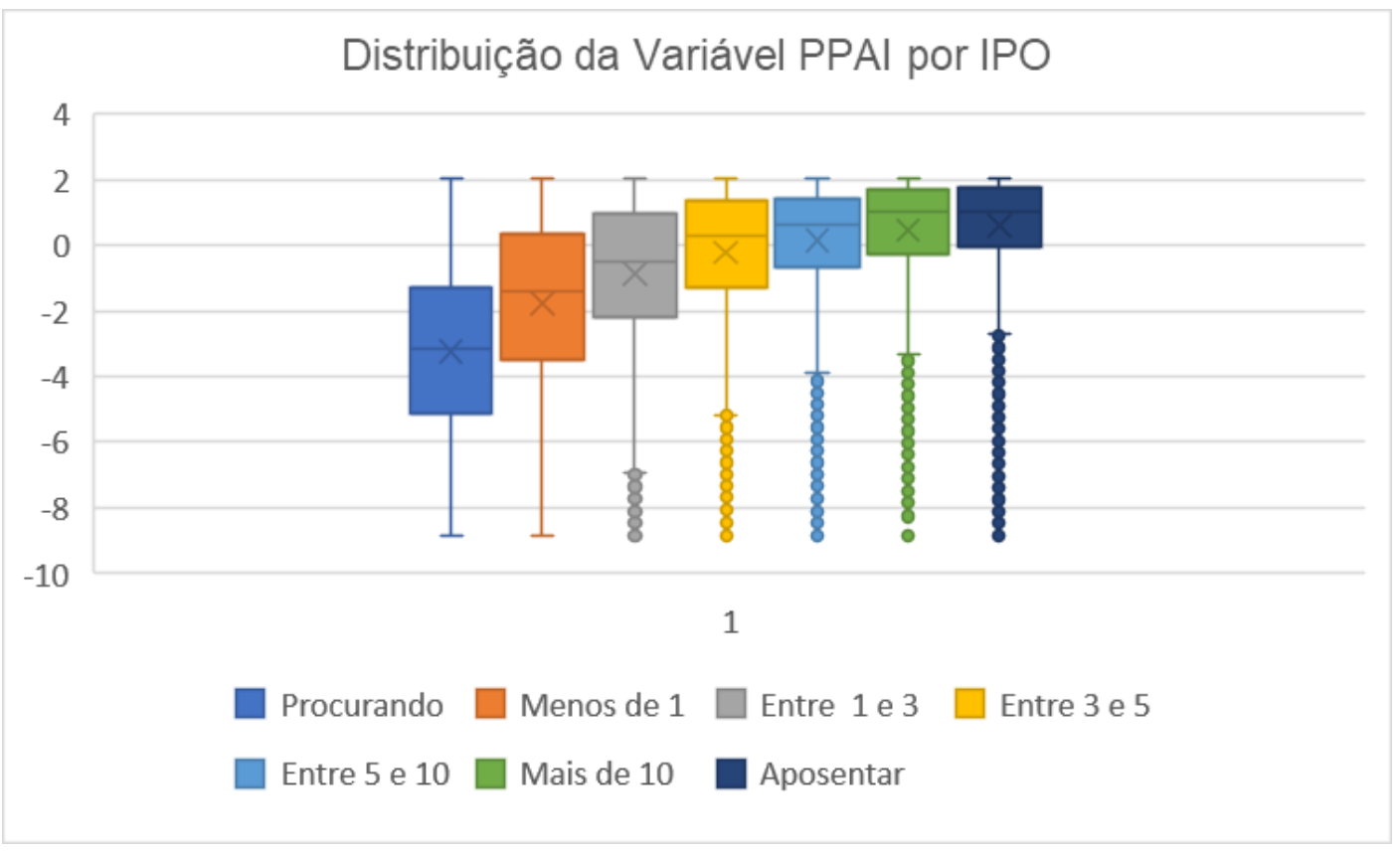

Fonte: elaborado pela autora 
O primeiro aspecto que se nota no gráfico 9 é que a distribuição se concentra em valores mais altos de aprendizado à medida que a intenção de permanecer na empresa é maior. Vê-se que a mediana (barras centrais das caixas) e a média ( $X$ nas caixas) aumentam sistematicamente. Em um box-plot, a caixa representa $50 \%$ dos dados.

Outro ponto que chama atenção é a presença dos outliers. Existem pessoas que responderam que a sua percepção sobre a Prática de DRH Aprendizagem Individual é pouco favorável, mas ainda assim desejam se aposentar na organização, ou seja, vai haver outliers, inevitavelmente. Podemos considerar que a percepção favorável sobre a Aprendizagem Individual não é a única condição necessária para permanecer na organização, um indivíduo pode ter outros motivos, como salário, estar prestes a se aposentar ou outros. Assim, a percepção sobre as Prática de DRH Aprendizagem Individual está associada à Intenção de Permanecer na Organização, mas ela não é condição exclusiva.

Isso aparece em todos os grupos de intenção, mas para quem está procurando emprego ou quer sair em menos de 1 anos isso não se caracteriza como uma resposta atípica. Ela é uma resposta, de certa forma, "esperada" dentro do padrão do grupo. À medida que a intenção aumenta, esse tipo de resposta fica mais "inesperada". Assim, em nenhum momento foi estratégia desta pesquisa eliminar os outliers, até porque o seu número em relação a amostra é muito pequeno.

A sua quantidade parece se acentuar para as categorias que representam maior intenção de permanência. Por esse motivo, foi calculada a quantidade de respondentes classificados como outliers em cada categoria e o quanto eles representam do total. A tabela 14 e o gráfico 10 demonstram isso.

Tabela 14 - Outliers

\begin{tabular}{|l|r|r|r|r|r|r|r|r|}
\hline & Procurando & Menos de Entre 1 e 3 & Entre 3 e 5 & Entre 5 e 10 & Mais de 10 & \multicolumn{2}{c|}{ Aposentar } \\
\hline Contagem & 7438 & 10395 & 32860 & 27540 & 32641 & 28932 & 95139 \\
\hline Outliers & 0 & 0 & 274 & 890 & 2137 & 3146 & 4733 \\
\hline \% Outliers & $0,0 \%$ & $0,0 \%$ & $0,8 \%$ & $3,2 \%$ & $6,5 \%$ & $10,9 \%$ & $5,0 \%$ \\
\hline
\end{tabular}

Fonte: elaborado pela autora 
Gráfico 10 - Quantidade de Respondentes e Outliers da amostra por item da variável IPO

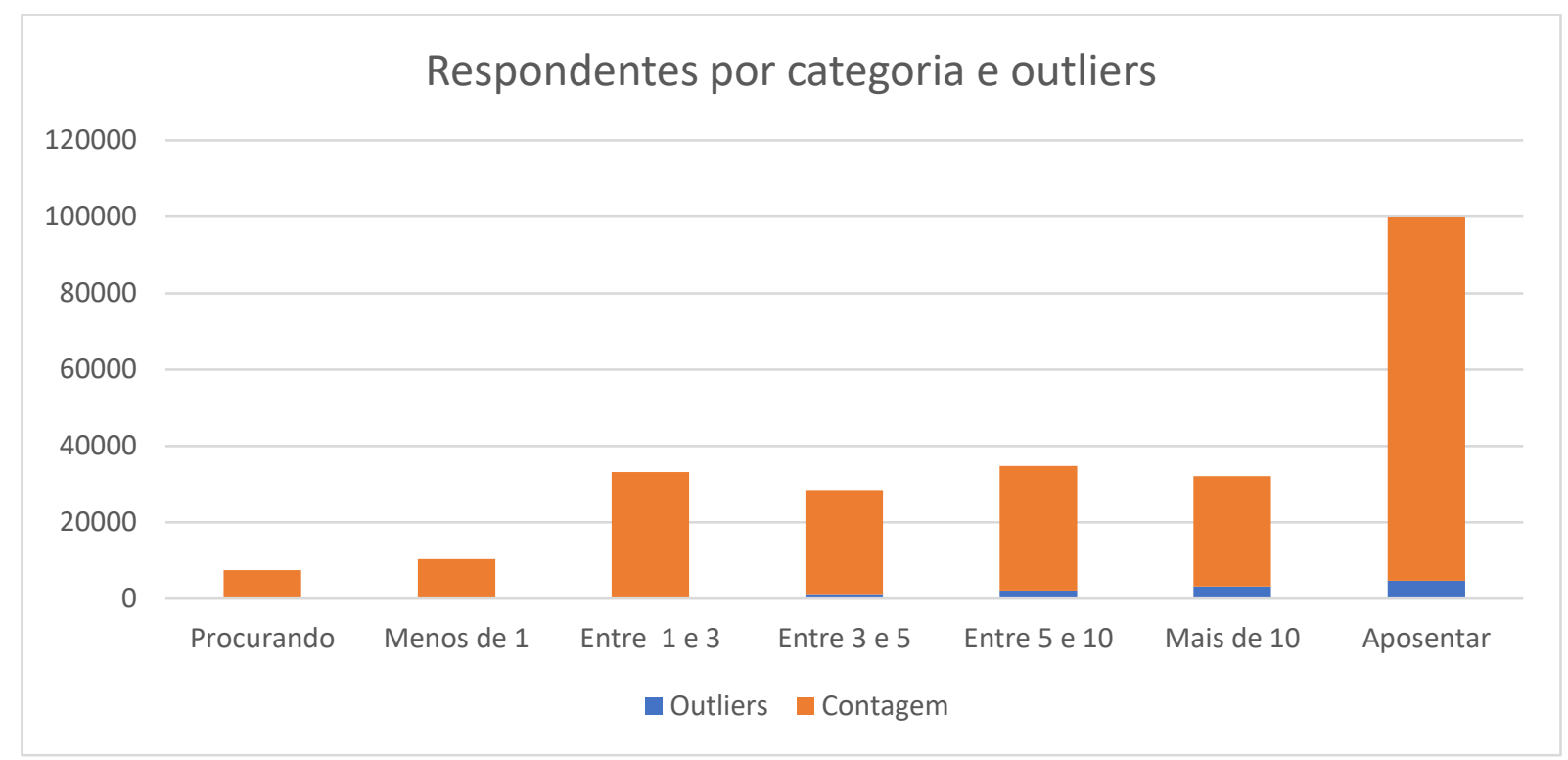

Fonte: elaborado pela autora

Os outliers são pouco representativos na amostra como um todo, mas, mesmo assim, considerando-se a quantidade de respondentes como um todo, compõem um grupo que poderia compor análises de estudos futuros.

O próximo passo é testar se as distribuições diferem entre si de forma estatisticamente significativa. Como explicado no capítulo de técnicas de análise, isso pode ser feito por meio de testes de média, como a ANOVA. Contudo, vê-se que a existência de outliers viola um dos pressupostos da técnica. Além disso, a distribuição da variável em questão (escala de medida da PPAI) precisa ser normal dentro das categorias, o que não acontece, como se pode ver pelos histogramas a seguir, apresentados no quadro 11: 
Quadro 11 - Conjunto de histogramas da variável PPAI por item da variável IPO

IntNew $=$ c1

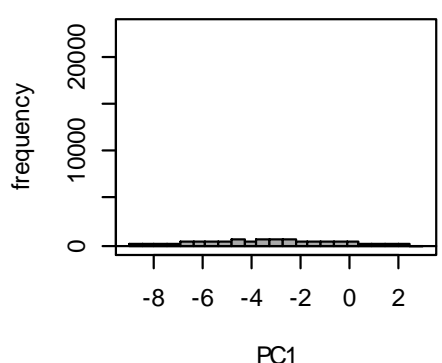

IntNew $=\mathrm{c} 4$

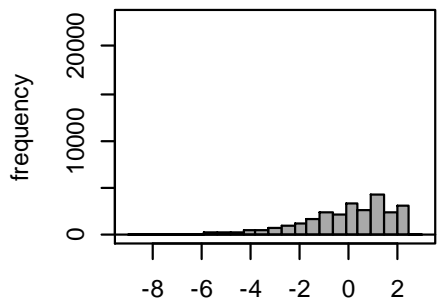

PC1
IntNew $=$ c2

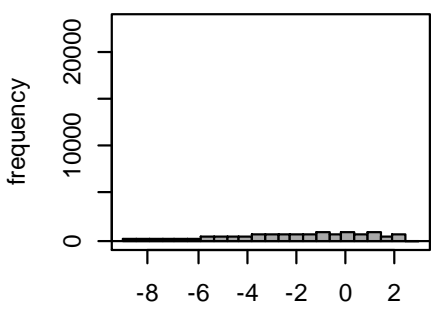

PC1

IntNew $=$ c5

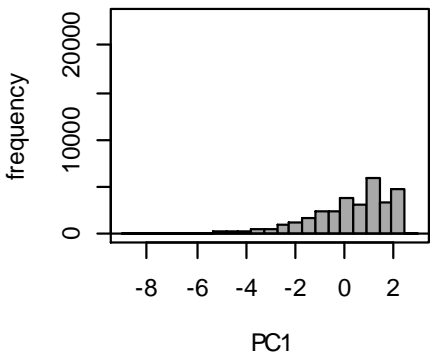

IntNew $=$ c3

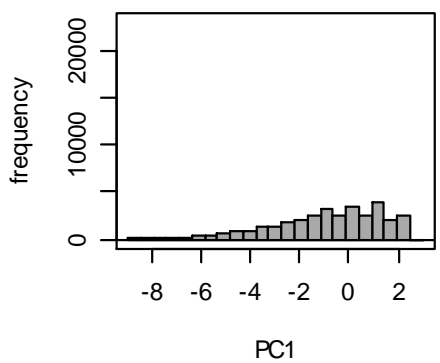

IntNew $=\mathbf{c} 6$

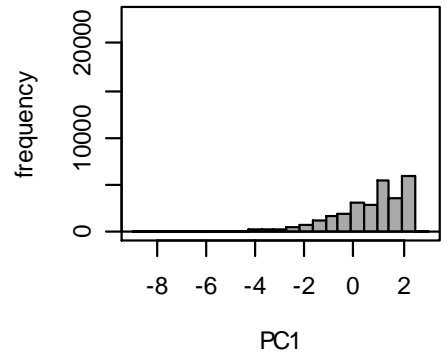

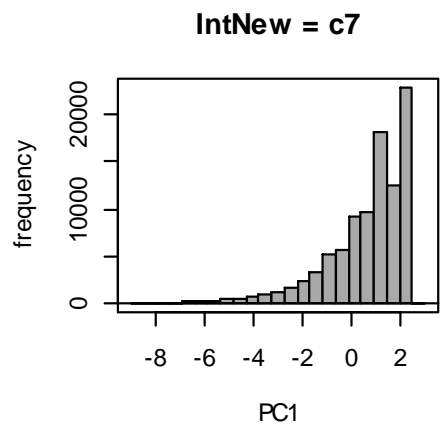

Onde:

\begin{tabular}{|l|l|}
\hline Estou procurando outra empresa neste momento & C1 \\
\hline Por menos de 1 ano & C2 \\
\hline Entre 1 e 3 anos & C3 \\
\hline Entre 3 e 5 anos & C4 \\
\hline Entre 5 e 10 anos & C5 \\
\hline Mais de 10 anos & C6 \\
\hline Gostaria de me aposentar nesta empresa & C7 \\
\hline
\end{tabular}

Fonte: extraído do software R Commander (R version 3.6.1) pela autora 
Seria possível fazer transformações de escalas para tentar superar a não normalidade dos dados, mas é recomendável a utilização de um teste não paramétrico. $O$ equivalente não paramétrico da ANOVA é o teste de Kruskal-Wallis, descrito no capítulo de método.

Aplicando o teste de Kruskal-Wallis para a escala de medida do aprendizado, considerando-se as categorias de intenção, obteve-se uma estatística $\chi^{2}=33.736$, com 6 graus de liberdade, resultando, novamente, em um $p$-valor muito pequeno, próximo de zero. Isso indica que as distribuições são diferentes, como um todo, considerando-se as categorias de intenção.

Para verificar as diferenças dois a dois, comparando duas categorias por vez, utilizou-se o teste pos-hoc de Tukey. A melhor forma de visualizar é pelo diagrama abaixo, em que são mostrados os intervalos de confiança com $95 \%$ de nível de confiança da diferença entre cada par de grupos. Se a diferença intercepta o zero, significa que a diferença não existe do ponto de vista estatístico, observado no gráfico 11.

Gráfico 11 - Representação gráfica do teste Pos-hoc de Tukey $\mathbf{9 5} \%$ family-wise confidence level

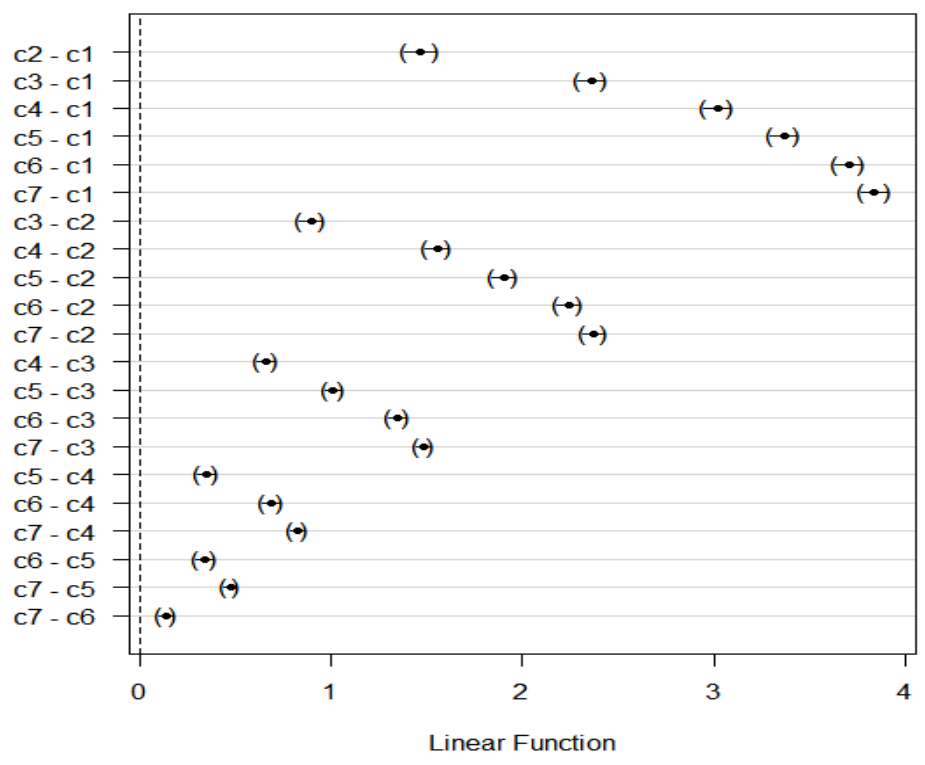

Fonte: extraído do software $\mathrm{R}$ Commander (R version 3.6.1) pela autora

As saídas do teste estão a seguir: 
Quadro 12 - 0 Saída do Testte Tukeyí

\begin{tabular}{|c|c|c|c|c|}
\hline \multicolumn{5}{|c|}{ Linear Hypotheses: } \\
\hline$c 2-c 1==0$ & 1.46555 & 0.02828 & 51.82 & $<2 \mathrm{e}-16^{* * *}$ \\
\hline & 2.35825 & 0.02391 & 98.62 & $<2 \mathrm{e}-16^{* * *}$ \\
\hline$c 4-c 1==0$ & 3.01746 & 0.02433 & 124.00 & $<2 \mathrm{e}-16^{* \star *}$ \\
\hline $\mathrm{c} 5-\mathrm{c} 1==0$ & 3.36776 & 0.02393 & 140.75 & $<2 \mathrm{e}-16^{* \star *}$ \\
\hline $\mathrm{c} 6-\mathrm{c} 1==0$ & 3.70501 & 0.02421 & 153.04 & $<2 \mathrm{e}-16^{\star \star *}$ \\
\hline $\mathrm{c} 7-\mathrm{c} 1==0$ & 3.84001 & 0.02242 & 171.27 & $<2 \mathrm{e}-16^{* \star *}$ \\
\hline$c 3-c 2==0$ & 0.89269 & 0.02096 & 42.60 & $<2 \mathrm{e}-16^{* * *}$ \\
\hline$c 4-c 2==0$ & 1.55190 & 0.02144 & 72.39 & $<2 \mathrm{e}-16^{* * *}$ \\
\hline$c 5-c 2==0$ & 1.90221 & 0.02097 & 90.70 & $<2 \mathrm{e}-16^{* * *}$ \\
\hline$c 2==0$ & 2.23946 & 0.02130 & 105.16 & $<2 \mathrm{e}-16^{* * *}$ \\
\hline$c 7-c 2==0$ & 2.37446 & 0.01924 & 123.43 & $<2 \mathrm{e}-16^{* * *}$ \\
\hline & 0.65921 & 0.01521 & 43.33 & $<2 \mathrm{e}-16 * * *$ \\
\hline$c 5-c 3==0$ & 1.00951 & 0.01455 & 69.37 & $<2 \mathrm{e}-16 * * *$ \\
\hline$c 6-c 3==0$ & 1.34676 & 0.01501 & 89.70 & $<2 \mathrm{e}-16^{* * *}$ \\
\hline$c 7-c 3==0$ & 1.48176 & 0.01192 & 124.35 & $<2 \mathrm{e}-16^{* * *}$ \\
\hline$c 5-c 4==0$ & 0.35030 & 0.01524 & 22.99 & $<2 \mathrm{e}-16^{* * *}$ \\
\hline$c 6-c 4==0$ & 0.68755 & 0.01568 & 43.85 & $<2 \mathrm{e}-16^{* * *}$ \\
\hline$c 7-c 4==0$ & 0.82255 & 0.01274 & 64.55 & $<2 \mathrm{e}-16^{* * *}$ \\
\hline$c 6-c 5==0$ & 0.33725 & 0.01504 & 22.43 & $<2 \mathrm{e}-16^{* * *}$ \\
\hline$c 5==0$ & 0.47225 & 0.01195 & 39.53 & $<2 \mathrm{e}-16{ }^{* * *}$ \\
\hline & & 0.01250 & 10.80 & $<2 \mathrm{c}-1$ \\
\hline
\end{tabular}

Fonte: extraído do software $R$ Commander (R version 3.6.1) pela autora

A diferença de aprendizado entre as categorias de intenção é maior para grupos mais "distantes" e menor para os mais próximos. E, mais do que isso, essa diferença ela diminui à medida que se "sobe" na escala de intenção. Ou seja, a diferença de avaliação na escala de aprendizado entre o "quero me aposentar" e ficaria mais de 10 anos é pequena (em média) e a do grupo "estou procurando emprego" é maior em relação ao "quero me aposentar". Essa análise corrobora com os achados dos testes de $\chi^{2}$ quando analisamos cada uma das perguntas que compõe a variável PPAI de forma independente. Assim, seja analisando cada uma das perguntas que compõe a variável PPAI ou avaliando a variável PPAI como efeito conjunto de itens aprendizado e suas relações com a variável IPO, os resultados encontrados demonstram associação entre as variáveis.

\subsection{Principais aspectos levantados na pesquisa}

Os dados observados na pesquisa apontaram, tanto quando analisadas cada uma das perguntas que compõe a variável PPAI de forma independente quanto 
avaliando a variável PPAI como efeito conjunto de itens aprendizado e suas relações com a variável IPO, resultados que corroboram a hipótese da pesquisa de que há associação entre as variáveis, podendo-se pensar que quanto menos favorável a Percepção dos empregados das empresas alvo sobre a Prática de DRH Aprendizagem Individual, menor a Intenção dos Empregados em Permanecer na Organização, em todos os testes, a associação foi significativa estatisticamente.

Observou-se também que os gêneros "Mulher" e "Homem" têm padrões de resposta muito próximos em relação a percepção sobre a prática de $\mathrm{DRH}$ Aprendizagem Individual. Esse padrão foi observado em todos os itens que compõem a variável. Já o gênero "Outros" apresentou um padrão distinto com frequências de respostas menos favoráveis maiores do que nos outros gêneros e isso aconteceu em todas as assertivas que compões a variável PPAl.

Outro aspecto que a pesquisa observou é que a distribuição de frequência de respostas para cada um dos itens que compões a variável PPAl também demonstrou o mesmo padrão com leve variações podendo apontar por independência da idade quando perguntada a percepção sobre a prática de $\mathrm{DRH}$ aprendizagem Individual. As maiores variações foram identificadas no grupo classificado como maiores de 70 anos.

Já quando investiga a variável Intenção de Permanecer na Organização, pode-se observar um padrão levemente mais alto de favorabilidade na frequência de respostas do gênero "Homem". No entanto, ainda que o gênero "Mulher" apresente um padrão um pouco diferente, estas diferenças não são tão acentuadas como no padrão apresentado pelo gênero "Outro". Assim como nos padrões de frequência de resposta dos itens da variável PPAI, o gênero "Outro" apresentou uma maior quantidade de frequência de respostas nos itens de menor favorabilidade da variável IPO.

Também foi observado que em relação à distribuição das frequências de resposta da variável IPO com relação às faixas etárias, pode-se observar o mesmo padrão de favorabilidade alta, com adensamento nos grupos de até 40, até 50 e até 60 , padrões esperados considerando que a amostra é de empresas que desejam participar de pesquisa MEPT, acreditando que suas práticas estão ou maduras ou em aperfeiçoamento e voluntariamente submetem a organização a pesquisa 
Foi possível também observar que o aprendizado formal e informal tem um significado importante para os respondentes, constituindo fator de favorabilidade mais destacada quando analisamos os itens que compões o ponto máximo de resposta da escala IPO, ou seja, dentre o grupo que expressou desejo de se aposentar na organização, os itens de maior favorabilidade da variável Percepção da Prática de DRH Aprendizagem Individual foram ligados a aprendizagem Formal e Informal.

Por outro lado, quando analisado o ponto mínimo da escala IPO, ou seja, o grupo que expressou estar procurando outra empresa neste momento, encontramos como fatores de menor favorabilidade os itens da variável PPAl que constituem questões ligadas com a aprendizagem experiencial.

Outro aspecto observado pela pesquisa foi a distribuição dos outliers conforme a favorabilidade da variável IPO aumentava. Notou-se que, ainda que poucos em termos de presença perante a amostra investigada, seu comportamento mostrou um comportamento atípico que ia se acentuando ao longo da escala da variável IPO.

É sabido que são inúmeros os motivos pelos quais os empregados tem intenção de permanecer na organização que atuam, mas podemos dizer que as associações encontradas aqui corroboram com os achados de Mello (Mello, 2014), onde alto percentual de empregados indicaram as oportunidades de aprendizado e crescimento na carreira como um fator de retenção na organização, assim como os achados de Uruan (2018) que apontam a associação entre práticas de DRH e a intenção de permanecer na organização. 


\section{CONSIDERAÇÕES FINAIS}

O objetivo geral desta pesquisa foi Investigar a Percepção dos Empregados sobre as Práticas de DRH no componente Aprendizagem Individual e sua associação a Intenção de Permanecer na Empresa em Empresas Alvo no Brasil.

A pesquisa investigou essa associação item a item da variável de Percepção da Prática de DRH Aprendizagem Individual e, também como efeito conjunto dos itens que a compõe. Todas as análises corroboram para que se conclua que existe associação entre as variáveis e elas se comportam de acordo com o padrão, quanto menor a favorabilidade dos respondentes em relação a percepção que eles têm sobre a variável de Aprendizado, menor a intenção de permanecer na organização.

Variáveis estão associadas quando existe covariação, o que significa dizer que uma variável muda em relação a outra, no entanto, ainda que exista covariação, ela precisa ser estatisticamente significativa (J. F. Hair Jr. et al., 2005), o que se mostrou válido para todos os testes realizados.

Os objetivos "Investigar a Percepção dos empregados das empresas alvo sobre a Prática de DRH Aprendizagem Individual" e "Investigar Intenção dos Empregados em Permanecer na Organização nas empresas Alvo" foram percorridos no preparo dos dados e entendimento da amostra e possibilitaram que a amostra fosse entendida como uma amostra que tende a ter altos graus de favorabilidade em relação aos itens medidos, a pesquisa não considerou isso um problema, mas sim uma característica da amostra, consistente com o fato da amostra ser composta por empregados de empresas que desejam participar de pesquisa MEPT, acreditando que suas práticas estão ou maduras ou em aprefeiçoamento e voluntariamente submetem a organização a pesquisa e não foi um aspecto que impediu que os testes fossem feitos e os padrões observados.

A investigação dos objetivos específicos permitiu também os achados citados anteriormente relacionados a gênero e faixa etária.

Outra consideração é em relação à escala da variável Intenção de Permancer na Empresa, que ainda sendo uma escala categórica ordinal, ela é de característica não paramétrica o que estimulou também a identificação de testes consistentes com a natureza dos dados, este é sempre um desafio com o uso de 
bases de dados secundários com as quais os pesquisador lida com o fato de que a coleta dos dados já foi feita. No entanto, isso não foi uma limitação para a pesquisa e não impediu que as análises fossem realizadas.

Considera-se, portanto, que tanto o objetivo geral quanto os objetivos específicos da pesquisa foram alcançados, quanto as hipóteses descritas validadas pelos resultados encontrados.

\subsection{Contribuições Do Estudo}

Esta pesquisa não esgota de forma alguma o campo do conhecimento das práticas de $\mathrm{DRH}$, deseja que seu esforço contribua para a ampliação e aprofundamento do tema, mas ainda que se reconheça isso, compreende que no campo teórico, esta pesquisa contribui por evidenciar inconsistências teóricas sobre quais são e como podem ser definidos os componentes que constituem as Práticas de $\mathrm{DRH}$, também contribui demonstrando a lacuna existente no estudo sobre as Práticas de DRH em contexto nacional.

Utilizando a intenção de permanecer como recurso, esta pesquisa contribui para ampliar a compreensão sobre a percepção dos empregados sobre a aprendizagem individual, possibilitando explorar a relação entre os componentes da aprendizagem propostos e sua coesão.

Ainda no campo teórico, o estudo aponta para oportunidade de aprofundamento da investigação da Percepção da Prática de DRH Aprendizagem Individual em relação a percepção do gênero outros, reforçando que as questões de gênero são um desafio dentro das organizações, inclusive estas que fazem parte de um recorte de empresas com processos e políticas mais maduras.

Esta pesquisa contribui em caráter exploratório com o entendimento de componentes da aprendizagem individual, indicando pontos de atenção em relação a aprendizagem experiencial.

Sob o ponto de vista prático, a pesquisa contribui com sua aderência a realidade brasileira e investigação de campo, oferecendo também oportunidade de reflexão para as organizações de foco de atenção e investimento em práticas de DRH que podem gerar mais impacto na percepção dos empregados. 
Ainda no campo prático, o estudo contribui evidenciado a associação entre as variáveis Percepção sobre a Prática Aprendizagem Individual e a variável Intenção de Permanecer na Organização, orientando a tomada de decisão sobre estes elementos dentro da estratégia e investimento organizacional.

O estudo contribui para o campo da prática oferecendo a perspectiva de que a Aprendizagem Formal e Informal tem relevância na percepção dos empregados e o campo da Aprendizagem Experiencial pode ser mais explorado.

O estudo descontrói a visão de que as pessoas se relacionam de forma diferente com o aprendizado por conta de suas faixas etárias, o estudo demonstra que os padrões de percepção sobre o aprendizado são constantes, independente de faixa etária.

\subsection{Limitações}

Muito embora as características da amostra não tenham sido um impeditivo para o desenvolvimento da pesquisa, não se pode expandir os resultados desta pesquisa para toda a realidade de empresas brasileiras. As empresas que constituem a amostra são empresas que desejam participar de pesquisa MEPT, acreditando que suas práticas estão ou maduras ou em aprefeiçoamento e voluntariamente submetem a organização a pesquisa, sendo assim, não representam a totalidade de empresas brasileiras.

\subsection{Recomendações Para Estudos Futuros}

Os achados desta pesquisa apontam para oportunidade de aprofundamento das questões investigadas a partir das lentes de gênero, em especial na perspectiva do gênero "Outro".

Outra oportunidade para que esta pesquisa aponta é a ampliação desta pesquisa para outras empresas brasileiras buscando fazer paralelo entre o comportamento das diferentes amostras.

Além disso é possível uma investigação profunda dos outliers que podem oferecer insights interessantes para outras perspectivas que levam as pessoas a escolher permanecer mais tempo na organização. 


\section{REFERÊNCIAS}

Ahadi, S., \& Jacobs, R. L. (2017). A Review of the Literature on Structured On-theJob Training and Directions for Future Research. HUMAN RESOURCE DEVELOPMENT REVIEW, 16(4), 323-349.

https://doi.org/10.1177/1534484317725945

Akhavan, P., Shahabipour, A., \& Hosnavi, R. (2018). A Model to Optimize Knowledge Flow in Team Working. JOURNAL OF ORGANISATIONAL STUDIES AND INNOVATION, 5(1), 1-20.

Benevene, P., Dal Corso, L., De Carlo, A., Falco, A., Carluccio, F., \& Vecina, M. L. (2018). Ethical leadership as antecedent of job satisfaction, affective organizational commitment and intention to stay among volunteers of non-profit organizations. Frontiers in Psychology. https://doi.org/10.3389/fpsyg.2018.02069

Bido, D. de S., Godoy, A. S., Araujo, B. F. V. B. de, \& Louback, J. C. (2010). Articulação entre as aprendizagens individual, grupal e organizacional: um estudo no ambiente industrial. RAM. Revista de Administração Mackenzie. https://doi.org/10.1590/s1678-69712010000200004

Bido, D. de S., Godoy, A. S., Ferreira, J. F., Kenski, J. M., \& Scartezini, V. N. (2011). Examinando a relação entre aprendizagem individual, grupal e organizacional em uma instituição financeira. REAd. Revista Eletrônica de Administração (Porto Alegre). https://doi.org/10.1590/s1413-23112011000100003

Bierema, L., \& Callahan, J. L. (2014). Transforming HRD: A Framework for Critical HRD Practice. Advances in Developing Human Resources. https://doi.org/10.1177/1523422314543818

Brook, C. (2012). A PROTEAN PRACTICE? ISSUES IN THE USES AND PRACTICE OF ACTION LEARNING AMONGST PRACTITIONERS AND ACADEMICS. In Chova, LG and Martinez, AL and Torres, IC (Ed.), 5TH INTERNATIONAL CONFERENCE OF EDUCATION, RESEARCH AND INNOVATION (ICERI 2012) (pp. 4733-4738).

Brook, Cheryl, \& Milner, C. (2014). Reflections on 'creative' action learning in business education: some issues in its theory and practice. TEACHING IN HIGHER EDUCATION, 19(2), 126-137. 
https://doi.org/10.1080/13562517.2013.827651

Camillis, P. K. de, \& Antonello, C. S. (2010). Um estudo sobre os processos de aprendizagem dos trabalhadores que não exercem função gerencial. $R A M$. Revista de Administração Mackenzie. https://doi.org/10.1590/s167869712010000200002

Chai, D. S., Kim, S., \& Kim, M. (2018). A Work and Learning Dual System Model for Talent Development in South Korea: A Multiple Stakeholder View. ADVANCES IN DEVELOPING HUMAN RESOURCES, 20(4, SI), 410-427. https://doi.org/10.1177/1523422318803085

Cho, S., Johanson, M. M., \& Guchait, P. (2009). Employees intent to leave: A comparison of determinants of intent to leave versus intent to stay. International Journal of Hospitality Management. https://doi.org/10.1016/j.jihm.2008.10.007

Cohen, J. (1990). Things I have learned (so far). American Psychologist. https://doi.org/10.1037/0003-066X.45.12.1304

Cook-Greuter, S. R. (2004). Making the case for a developmental perspective. Industrial and Commercial Training. https://doi.org/10.1108/00197850410563902

Cumberland, D. M., Alagaraja, M., Shuck, B., \& Kerrick, S. A. (2018). Organizational Social Capital: Ties Between HRD, Employee Voice, and CEOs. HUMAN RESOURCE DEVELOPMENT REVIEW, 17(2), 199-221. https://doi.org/10.1177/1534484318772488

Dias, C. A. de F. (2017). Desenvolvimento estratégico de recursos humanos e suas relações com o desempenho organizacional: uma análise dos fatores contingenciais - Tese de Doutorado. São Paulo: Faculdade de Economia, Administração e Contabilidade. https://doi.org/10.11606/T.12.2018

Didier, J. M. de O. L., \& Lucena, E. de A. (2008). Aprendizagem de praticantes da estratégia: contribuições da aprendizagem situada e da aprendizagem pela experiência. Organizações \& Sociedade. https://doi.org/10.1590/s198492302008000100007

Dutra, J. S. (2017). Competências - Conceitos, Instrumentos e Experiências. São Paulo: Atlas.

Emiroğlu, B. D., Akova, O., \& Tanrıverdi, H. (2015). The relationship between turnover intention and demographic factors in hotel businesses: A study at five star hotels in Istanbul. In 11th International Strategic Management Conference. 
Elsevier Ltd. https://doi.org/10.1016/j.sbspro.2015.10.108

Fischer, A. L. (1998). A constituição do modelo competitivo de gestão de pessoas no Brasil: um estudo sobre as empresas consideradas exemplares Tese de Doutorado. São Paulo: Faculdade de Economia, Administração e Contabilidade, Universidade de São Paulo. https://doi.org/10.11606/T.12.1998.tde-03042009125228

Froehlich, D. E., Beausaert, S., \& Segers, M. (2017). Development and validation of a scale measuring approaches to work-related informal learning.

INTERNATIONAL JOURNAL OF TRAINING AND DEVELOPMENT, 21(2), 130144. https://doi.org/10.1111/ijtd.12099

Garavan, T. N. (1997). Training, development, education and learning: different or the same? Journal of European Industrial Training.

https://doi.org/10.1108/03090599710161711

Garavan, T. N. (2007). A Strategic Perspective on Human Resource Development. Advances in Developing Human Resources. https://doi.org/10.1177/1523422306294492

Garavan, T. N., McGuire, D., \& Lee, M. (2015). Reclaiming the "D" in HRD: A Typology of Development Conceptualizations, Antecedents, and Outcomes. Human Resource Development Review. https://doi.org/10.1177/1534484315607053

Garavan, T. N., Mcguire, D., \& O'donnell, D. (2004). Exploring Human Resource Development: A Levels of Analysis Approach. Human Resource Development Review. https://doi.org/10.1177/1534484304271669

Gil, A. C. (org). (2008). Métodos e Técncias de Pesquisa Social. Editora Atlas. Gouveia Jr, A. (1999). O conceito de modelo e sua utilização nas ciências do comportamento: breves notas introdutórias. Estudos de Psicologia (Campinas). https://doi.org/10.1590/s0103-166x1999000100002

Hair Jr., J. F., Babin, B., Money, A. H., \& Samuel, P. (2005). Fundamentos de métodos de pesquisa em adiministração. Porto Alegre, RS, Brasil: Bookman Companhia Editora.

Hair Jr., J. F., Black, W. C., Babin, B. J., Anderson, R. E., \& Tatham, R. L. (2009). Análise multivariada de dados. Porto Alegre, RS, Brasil: Bookman Companhia Editora. 
Hair Jr, J., Hult, G. T., Ringle, C., \& Sarstedt, M. (2014). A Primer on Partial Least Squares Structural Equation Modeling (PLS-SEM) - Joseph F. Hair, Jr., G. Tomas M. Hult, Christian Ringle, Marko Sarstedt - Google Books.

Hubner, S. V., \& Baum, M. (2018). Entrepreneurs' human resources development. HUMAN RESOURCE DEVELOPMENT QUARTERLY, 29(4), 356-380. https://doi.org/10.1002/hrdq.21328

Jones, O., Gold, J., \& Claxton, J. (2017). A Little Less Conversation, a Little More Action: Illustrations of the Mediated Discourse Analysis Method. HUMAN RESOURCE DEVELOPMENT QUARTERLY, 28(4), 481-513.

https://doi.org/10.1002/hrdq.21289

Korte, R., \& Mercurio, Z. A. (2017). Pragmatism and Human Resource Development: Practical Foundations for Research, Theory, and Practice. HUMAN RESOURCE DEVELOPMENT REVIEW, 16(1), 60-84. https://doi.org/10.1177/1534484317691707

Kuchinke, K. P. (2017). The ethics of HRD practice. HUMAN RESOURCE DEVELOPMENT INTERNATIONAL, 20(5, SI), 361-370.

https://doi.org/10.1080/13678868.2017.1329369

Lammintakanen, J., Kivinen, T., \& Kinnunen, J. (2010). Managers' perspectives on recruitment and human resource development practices in primary health care. INTERNATIONAL JOURNAL OF CIRCUMPOLAR HEALTH, 69(5, SI), 462-469. https://doi.org/10.3402/ijch.v69i5.17689

Lee, M. (2007). Human Resource Development from a Holistic Perspective. Advances in Developing Human Resources. https://doi.org/10.1177/1523422306294498

Mankin, D. P. (2001). A model for human resource development. Human Resource Development International. https://doi.org/10.1080/13678860121714

Marsick, V. J., Watkins, K. E., Callahan, M. W., \& Volpe, M. (2009). Informal and Incidental Learning in the Workplace. In M. C. Smith \& N. DeFrates-Densch (Eds.), Handbook of Research on Adult Learning and Development (1st ed., pp. 570-600). Routledge.

Mello, D. A. de. (2014). Análise dos fatores de retenção de empregados em organizações que atuam no Brasil. Dissertação de Mestrado. São Paulo: Faculdade de Economia, Administração e Contabilidade, Universidade de São 
Paulo. https://doi.org/10.11606/D.12.2014

Otoo, F. N. K. (2019). Human resource development (HRD) practices and banking industry effectiveness: The mediating role of employee competencies. EUROPEAN JOURNAL OF TRAINING AND DEVELOPMENT, 43(3-4), 250271. https://doi.org/10.1108/EJTD-07-2018-0068

Otoo, F. N. K., \& Mishra, M. (2018a). Influence of human resource development (HRD) practices on hotel industry's performance: The role of employee competencies. EUROPEAN JOURNAL OF TRAINING AND DEVELOPMENT, 42(7/8), 435-454. https://doi.org/10.1108/EJTD-12-2017-0113

Otoo, F. N. K., \& Mishra, M. (2018b). Measuring the impact of human resource development (HRD) practices on employee performance in small and medium scale enterprises. EUROPEAN JOURNAL OF TRAINING AND DEVELOPMENT, 42(7/8), 517-534. https://doi.org/10.1108/EJTD-07-2017-0061

Otoo, F. N. K., Otoo, E. A., Abledu, G. K., \& Bhardwaj, A. (2019). Impact of human resource development (HRD) practices on pharmaceutical industry's performance The mediating role of employee performance. EUROPEAN JOURNAL OF TRAINING AND DEVELOPMENT, 43(1-2), 188-210. https://doi.org/10.1108/EJTD-09-2018-0096

Peretz, M., \& McGraw, P. (2011). Trends in Australian human resource development practice, 1996-2009. ASIA PACIFIC JOURNAL OF HUMAN RESOURCES, 49(1), 36-54. https://doi.org/10.1177/1038411110391707

Richadson, R. J. (2017). Pesquisa Social: métodos e técnicas. (D. K. Pfeiffer, Ed.) (4th ed.). São Paulo: Atlas.

Sablok, G., Stanton, P., Bartram, T., Burgess, J., \& Boyle, B. (2017). Human resource development practices, managers and multinational enterprises in Australia Thinking globally, acting locally. EDUCATION AND TRAINING, 59(5), 483-501. https://doi.org/10.1108/ET-02-2016-0023

Shuck, B., Twyford, D., Reio Jr., T. G., \& Shuck, A. (2014). Human Resource Development Practices and Employee Engagement: Examining the Connection With Employee Turnover Intentions. HUMAN RESOURCE DEVELOPMENT QUARTERLY, 25(2), 239-270. https://doi.org/10.1002/hrdq.21190

Swanson, R. A., \& Holton, E. F. (2009). Foundations of Human Resource Development (2nd ed.). San Francisco: Berrett-Koehler Publishers. 
Takahashi, A. R. W. (2015). Competências, aprendizagem organizacional e gestão do conhecimento (1st ed.). Curitiba: InterSaberes.

Uraon, R. S. (2018). Examining the Impact of HRD Practices on Organizational Commitment and Intention to Stay Within Selected Software Companies in India. ADVANCES IN DEVELOPING HUMAN RESOURCES, 20(1), 11-43. https://doi.org/10.1177/1523422317741691

Veth, K. N., Emans, B. J. M., der Heijden, B. I. J. M., Korzilius, H. P. L. M., \& De Lange, A. H. (2015). Development (f) or Maintenance? An Empirical Study on the Use of and Need for HR Practices to Retain Older Workers in Health Care Organizations. HUMAN RESOURCE DEVELOPMENT QUARTERLY, 26(1), 5380. https://doi.org/10.1002/hrdq.21200

Wang, G. G., Werner, J. M., Sun, J. Y., Gilley, A., \& Gilley, J. W. (2017). Means vs ends: theorizing a definition of human resource development. PERSONNEL REVIEW, 46(6), 1165-1181. https://doi.org/10.1108/PR-11-2015-0306

Webster, J., \& Watson, R. T. (2002). Analyzing the Past to Prepare for the Future: Writing a Literature Review. MIS Quarterly. https://doi.org/10.1.1.104.6570 Wickramasinghe, V. (2015). Effects of human resource development practices on service quality of services offshore outsourcing firms. INTERNATIONAL JOURNAL OF QUALITY \& RELIABILITY MANAGEMENT, 32(7), 703+. https://doi.org/10.1108/IJQRM-03-2013-0047

Yeganeh, B., \& Kolb, D. (2009). Mindfulness and experiential learning. $O D$ Practitioner. https://doi.org/Article

Zavyalova, E. K., Kucherov, D. G., \& Tsybova, V. S. (2018). Approaches to HRD in Russian IT-companies in the period of economic crisis. HUMAN RESOURCE DEVELOPMENT INTERNATIONAL, 21(4), 319-339. https://doi.org/10.1080/13678868.2017.1419736 


\section{APÊNDICE}

Apêndice A - Análise dos artigos da revisão teórica de Práticas de Desenvolvimento de Recursos Humanos.

\begin{tabular}{|c|c|c|c|c|c|c|c|}
\hline Título & Autor & Data & Local & $\begin{array}{c}\text { Unidade de } \\
\text { Análise }\end{array}$ & Tema & Prática DRH & Observação \\
\hline $\begin{array}{l}\text { Development and } \\
\text { validation of a scale } \\
\text { measuring approaches } \\
\text { to work-related informal } \\
\text { learning }\end{array}$ & $\begin{array}{l}\text { Dominik E. } \\
\text { Froehlich, } \\
\text { Simon } \\
\text { Beausaert e } \\
\text { Mien Segers }\end{array}$ & 2017 & $\begin{array}{l}\text { Áustria e } \\
\text { Países } \\
\text { Baixos }\end{array}$ & indivíduo & Aprendizagem & $\begin{array}{l}\text { Fatores da Aprendizagem } \\
\text { Informal identificados na } \\
\text { pesquisa: } \\
\text { busca proativa de feedback } \\
\text { (superior e pares), } \\
\text { busca de ajuda e } \\
\text { busca de informações, }\end{array}$ & \\
\hline $\begin{array}{l}\text { Managers' perspectives } \\
\text { on recruitment and } \\
\text { human resource } \\
\text { development practices } \\
\text { in primary health care }\end{array}$ & $\begin{array}{l}\text { Johanna } \\
\text { Lammintakanen, } \\
\text { Tuula Kivinen e } \\
\text { Juhu Kinnunen }\end{array}$ & 2010 & Finlândia & indivíduo & Aprendizagem & $\begin{array}{l}\text { descritas como uma visão } \\
\text { geral de DRH investigam } \\
\text { percepção sobre } \\
\text { desenvolvimento, } \\
\text { aprendizagem formal e } \\
\text { informal. }\end{array}$ & $\begin{array}{l}\text { Medidas de Práticas de DRH } \\
\text { As necessidades organizacionais formam uma base para o } \\
\text { desenvolvimento de recursos humanos em nossa } \\
\text { organização. } \\
\text { Desenvolvimento profissional é a preocupação individual de } \\
\text { todos } \\
\text { As competências necessárias no trabalho não foram } \\
\text { definidas com base na estratégia da organização. } \\
\text { É importante promover habilidades e conhecimentos } \\
\text { relacionados a processos e procedimentos, além do } \\
\text { desenvolvimento profissional. } \\
\text { É aceitável que nem todos estejam dispostos a se } \\
\text { desenvolver profissionalmente. } \\
\text { As habilidades e o conhecimento dos funcionários são } \\
\text { avaliados regularmente } \\
\text { Funcionários mais experientes orientam os inexperientes no } \\
\text { início. } \\
\text { As habilidades e o conhecimento dos indivíduos são levados } \\
\text { em consideração ao compartilhar tarefas em nossa unidade. } \\
\text { As necessidades de desenvolvimento dos funcionários são } \\
\text { levadas a sério e são criadas oportunidades para melhorar }\end{array}$ \\
\hline
\end{tabular}




\begin{tabular}{|c|c|c|c|c|c|c|c|}
\hline $\begin{array}{l}\text { Training, motivation and } \\
\text { teamwork improvement: } \\
\text { The case of } \\
\text { construction firms }\end{array}$ & $\begin{array}{l}\text { Amin Akhavan } \\
\text { Tabassi, } \\
\text { Mahyuddin } \\
\text { Ramli e Abu } \\
\text { Hassan Abu } \\
\text { Bakar }\end{array}$ & 2011 & Irã & indivíduo & Aprendizagem & \begin{tabular}{|l|} 
Treinamento é o esforço \\
sistemático e planejado para \\
modificar ou desenvolver \\
conhecimentos, atitudes, \\
habilidades através de \\
experiências de \\
aprendizagem, para atingir \\
desempenho em uma \\
atividade ou em uma série de \\
atividades.
\end{tabular} & itens analisados não foram descritos \\
\hline $\begin{array}{l}\text { A Protean Practice? } \\
\text { Issues In The Uses And } \\
\text { Practice Of Action } \\
\text { Learning Amongst } \\
\text { Practitioners And } \\
\text { Academics }\end{array}$ & $\begin{array}{l}\text { Cheryl Brook, } \\
\text { Mike Pedler e } \\
\text { John Burgoyne }\end{array}$ & 2013 & UK & indivíduo & Aprendizagem & action learning & \\
\hline $\begin{array}{l}\text { A study of trends in } \\
\text { mentoring relationships } \\
\text { existing in the Indian IT } \\
\text { industry }\end{array}$ & $\begin{array}{l}\text { Suruchi Pandey } \\
\text { e Tanya Chhaila }\end{array}$ & 2013 & Índia & indivíduo & Aprendizagem & mentoring & \\
\hline $\begin{array}{l}\text { Response to Nieminen } \\
\text { et al.'s Feature Article } \\
\text { on Executive Coaching } \\
\text { and Facilitated } \\
\text { Multisource Feedback: } \\
\text { Toward Better } \\
\text { Understanding of a } \\
\text { Growing HRD Practice }\end{array}$ & Toby Egan & 2013 & EUA & indivíduo & Aprendizagem & coaching & $\begin{array}{l}\text { implicações em DRH através de análise crítica de artigo com } \\
\text { estudo de amostras que receberam e não receberam } \\
\text { coaching como parte de programa de desenvolvimento. }\end{array}$ \\
\hline $\begin{array}{l}\text { Reflections on 'creative' } \\
\text { action learning in } \\
\text { business education: } \\
\text { some issues in its } \\
\text { theory and practice }\end{array}$ & $\begin{array}{l}\text { Cheryl Brook e } \\
\text { Christopher } \\
\text { Milner }\end{array}$ & 2014 & ND & indivíduo & Aprendizagem & Action learning & $\begin{array}{l}\text { implicações em DRH através da reflexão e análise das } \\
\text { experiências de grupo de alunos em Action Learning }\end{array}$ \\
\hline
\end{tabular}


Training

comprehensiveness:

construct development

and relation with

role behavior
Anugamini Priya

Srivastava and

Rajib Lochan

Dhar
2015

India

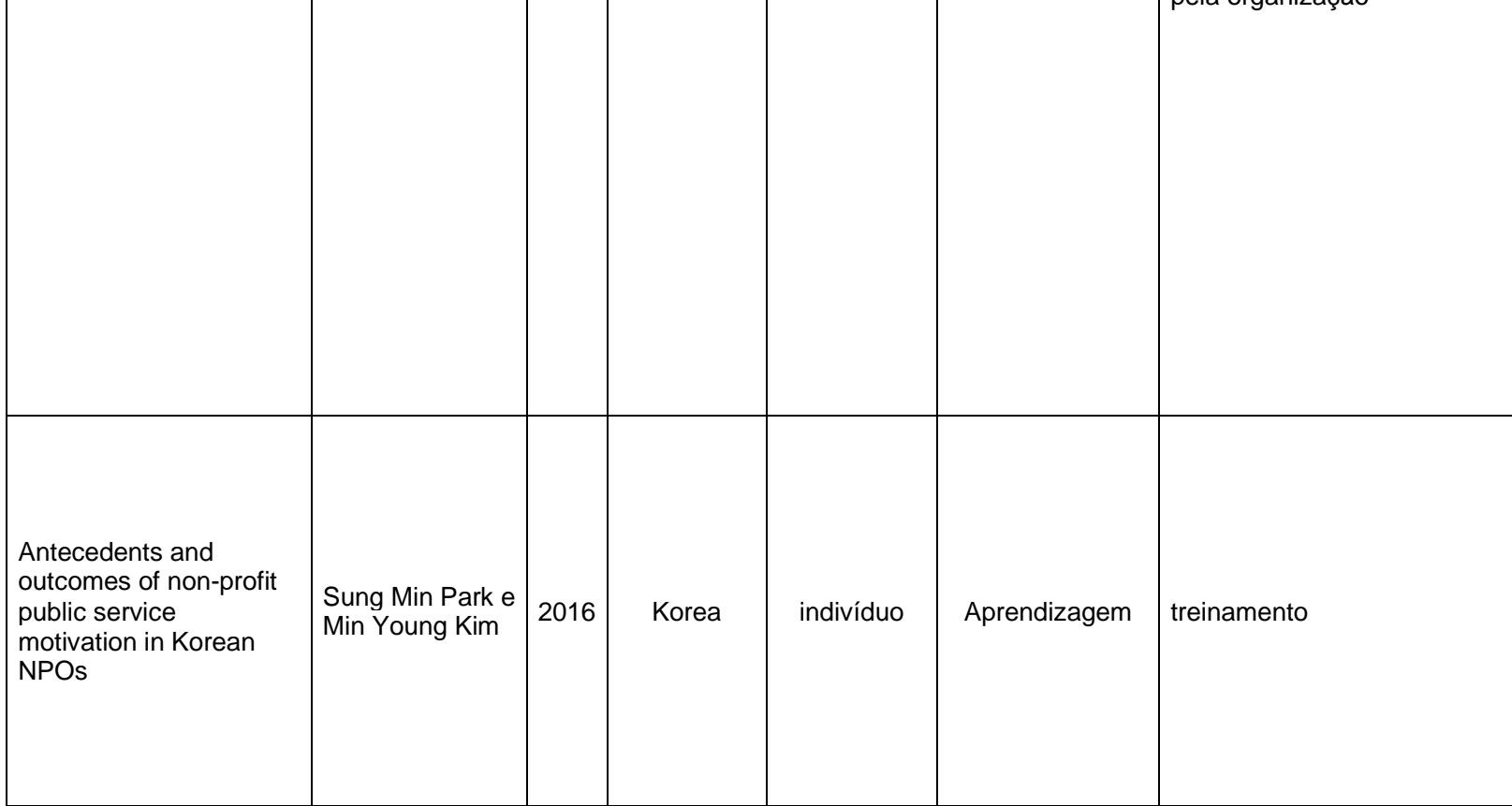

Abrangência do Treinamento é refere-se a impressão dos funcionários sobre a

extensão das oportunidades extensao das oportunidades

\section{Abrangência do treinamento}

Recebo treinamentos regularmente / em intervalos diferentes Os supervisores explicam claramente a agenda / objetivo do treinamento

O conteúdo do treinamento é relevante, útil e de fácil compreensão

Minhas funções e responsabilidades são claramente discutidas como membro da equipe e individualmente

Supervisores aproveitam sessões de treinamento

motivacionais e interativas

Os supervisores fornecem sessões de treinamento

específicas e direcionadas para o desenvolvimento individual

Os instrutores são conhecedores e demonstram habilidades

de treinamento eficazes

Eu recebo uma supervisão adequada para implementar as habilidades aprendidas em treinamento

Recebo treinamento com base em nossos problemas e

questões práticas

Recebo conhecimento prático por meio de treinamento para realizar meu trabalho

Recebo recursos e equipamentos suficientes para um treinamento eficaz

Eu aprendo novas habilidades cada vez

Recebo diferentes estilos de treinamento (por exemplo,

jogos, palestras e seminários)

Recebo horas suficientes de treinamento

Pocebo horas sulicientes de treinamento vida real
Mosso aplicar habilidades de treinamento em situações Minha real

Minhas necessidades de treinamento são atendidas

Tenho a oportunidade de aprender, adaptar e melhorar

Meu desempenho melhora com o treinamento fornecido

$\mathrm{O}$ treinamento fornecido me inspira a trabalhar para o

sucesso organizacional

Mediç
itens)
(1) Eu

1) Eu sei que os programas de treinamento têm um impacto

positivo no desempenho no trabalho;

(2) o programa de treinamento é útil para melhorar

(3) uso os Conhecimentos, Habilidades e Atitudes ( $\mathrm{CHA})$ aprendidos no programa de treinamento no meu local de tabalho;

(4) os CHA aprendidos com o programa de treinamento são necessários para o meu desempenho no trabalho; e

(5) a situação do programa de treinamento é semelhante às circunstâncias reais do trabalho. 


\begin{tabular}{|c|c|c|c|c|c|c|c|}
\hline $\begin{array}{l}\text { A Review of the } \\
\text { Literature on Structured } \\
\text { On-the-Job Training and } \\
\text { Directions for Future } \\
\text { Research }\end{array}$ & $\begin{array}{l}\text { Sahar Ahadi e } \\
\text { Ronald L. } \\
\text { Jacobs }\end{array}$ & 2017 & USA & indivíduo & Aprendizagem & on the job training & \\
\hline $\begin{array}{l}\text { A Work and Learning } \\
\text { Dual System Model for } \\
\text { Talent Development in } \\
\text { South Korea: A Multiple } \\
\text { Stakeholder View } \\
\end{array}$ & $\begin{array}{l}\text { Dae Seok Chai, } \\
\text { Sehoon Kim e } \\
\text { Minjung Kim }\end{array}$ & 2018 & $\begin{array}{l}\text { Coreia do } \\
\text { Sul }\end{array}$ & nação & Aprendizagem & on the job training & \\
\hline $\begin{array}{l}\text { Examining training and } \\
\text { skills development of } \\
\text { youth and young adults } \\
\text { in the Ghanaian context: } \\
\text { an HRD perspective }\end{array}$ & $\begin{array}{l}\text { Nana Arthur- } \\
\text { Mensah e } \\
\text { Meera Alagaraja }\end{array}$ & 2018 & Ghana & nação & Aprendizagem & $\begin{array}{l}\text { Discussão sobres as Práticas } \\
\text { de DRH listadas como } \\
\text { políticas nacionais. } \\
\text { - Treinamento de habilidades } \\
\text { empreendedoras } \\
\text { - Educação e treinamento } \\
\text { profissional técnico } \\
\text { - Educação profissional e } \\
\text { desenvolvimento de } \\
\text { habilidades nas escolas } \\
\text { secundárias } \\
\text { - Iniciativas de treinamento e } \\
\text { desenvolvimento de } \\
\text { habilidades }\end{array}$ & \\
\hline $\begin{array}{l}\text { A Conceptual Model for } \\
\text { Developing Mindsets for } \\
\text { Strategic Insight } \\
\text { Under Conditions of } \\
\text { Complexity and High } \\
\text { Uncertainty }\end{array}$ & $\begin{array}{l}\text { Lyle Yorks e } \\
\text { Aliki Nicolaides }\end{array}$ & 2012 & EUA & organização & Aprendizagem & $\begin{array}{l}\text { estratégias de aprendizado } \\
\text { para reflexão crítica }\end{array}$ & \\
\hline $\begin{array}{l}\text { New employee } \\
\text { orientation: cases of } \\
\text { Korean corporations }\end{array}$ & $\begin{array}{l}\text { Minjung Kim, } \\
\text { Dae Seok Chai, } \\
\text { Sehoon Kim \& } \\
\text { Soyoun Park }\end{array}$ & 2015 & $\begin{array}{l}\text { Coreia do } \\
\text { Sul }\end{array}$ & organização & Aprendizagem & $\begin{array}{l}\text { Integração } \\
\text { a prática foi analisada a partir } \\
\text { de documentação enviada } \\
\text { pelas organizações } \\
\text { participantes do estudo. }\end{array}$ & \\
\hline $\begin{array}{l}\text { A Model to Optimize } \\
\text { Knowledge Flow in } \\
\text { Team Working }\end{array}$ & $\begin{array}{l}\text { Peyman } \\
\text { Akhavan, Ali } \\
\text { Shahabipour e } \\
\text { Reza Hosnavi }\end{array}$ & 2018 & Irã & organização & Aprendizagem & $\begin{array}{l}\text { fluxos de aprendizagem em } \\
\text { time }\end{array}$ & \\
\hline $\begin{array}{l}\text { Approaches to HRD in } \\
\text { Russian IT-companies } \\
\text { in the period of } \\
\text { economic crisis }\end{array}$ & $\begin{array}{l}\text { Elena K. } \\
\text { Zavyalova, } \\
\text { Dmitry G. } \\
\text { Kucherov e } \\
\text { Victoria S. } \\
\text { Tsybova }\end{array}$ & 2018 & Rússia & organização & Aprendizagem & treinamento formal e informal & $\begin{array}{l}\text { As práticas de DRH mais utilizadas em tempos de crise são } \\
\text { as de treinamento: } \\
\text { - treinamento interno } \\
\text { - treinamentos financiados } \\
\text { - estágios entre departamentos } \\
\text { - mentoria }\end{array}$ \\
\hline
\end{tabular}




\begin{tabular}{|c|c|c|c|c|c|c|c|}
\hline $\begin{array}{l}\text { HRD practices in local } \\
\text { private sector } \\
\text { companies and MNC } \\
\text { subsidiaries in Australia, } \\
1996-2009\end{array}$ & $\begin{array}{l}\text { Peter McGraw e } \\
\text { Melissa Peretz }\end{array}$ & 2011 & Austrália & organização & $\mathrm{DRH}$ & $\begin{array}{l}\text { descritas na pesquisa } \\
\text { CRANET }\end{array}$ & $\begin{array}{l}\text { Eficácia do treinamento } 2 \text { itens } \\
\text { Avaliação do treinamento } 3 \text { itens } \\
\text { Desenvolvimento de carreira } 5 \text { itens } \\
\text { Avaliação formal de desempenho } 4 \text { itens } \\
\text { Entradas no processo de avaliação de desempenho } 6 \text { itens } \\
\text { Dados de avaliação de desempenho para tomada de decisão } \\
4 \text { itens }\end{array}$ \\
\hline $\begin{array}{l}\text { Human resource } \\
\text { development practices, } \\
\text { managers and } \\
\text { multinational enterprises } \\
\text { in Australia Thinking } \\
\text { globally, acting locally }\end{array}$ & $\begin{array}{l}\text { Gitika Sablok, } \\
\text { Pauline Stanton, } \\
\text { Timothy } \\
\text { Bartram, John } \\
\text { Burgess e } \\
\text { Brendan Boyle }\end{array}$ & 2017 & Austrália & organização & $\begin{array}{l}\text { Aprendizagem e } \\
\text { Carreira }\end{array}$ & $\begin{array}{l}\text { As variáveis usadas para } \\
\text { representar a DRH são: } \\
\text { Gastos com treinamento e } \\
\text { desenvolvimento } \\
\text { Sistema formal de } \\
\text { planejamento de sucessão } \\
\text { para gerentes } \\
\text { Programa de } \\
\text { desenvolvimento gerencial } \\
\text { Sistema formal de Gestão de } \\
\text { Talentos }\end{array}$ & \\
\hline $\begin{array}{l}\text { Effects of human } \\
\text { resource development } \\
\text { practices on service } \\
\text { quality of services } \\
\text { offshore outsourcing } \\
\text { firms }\end{array}$ & $\begin{array}{l}\text { Vathsala } \\
\text { Wickramasinghe }\end{array}$ & 2015 & Sri Lanka & organização & $\begin{array}{l}\text { Aprendizagem e } \\
\text { Carreira }\end{array}$ & $\begin{array}{l}\text { engajamento de talentos se } \\
\text { conecta a temas de } \\
\text { desenvolvimento de carreira } \\
\text { e gestão de desempenho, já } \\
\text { o treinamento diz respeito a } \\
\text { aprendizagem formal. }\end{array}$ & $\begin{array}{l}\text { Engajamento de talentos, percepção sobre: } \\
\text { - sistema de gestão de performance e talento } \\
\text { - preenchimento de vagas interno } \\
\text { - plano de desenvolvimento formal } \\
\text { - identificação de performance diferenciada } \\
\text { - reconhecimento de realizações e conquistas } \\
\text { Treinamento, percepção sobre: } \\
\text { - treinamento de processos } \\
\text { - treinamento relacionado ao trabalho como prioridade } \\
\text { - avaliação da efetividade dos treinamentos } \\
\text { - programas relevantes para execução de tarefas } \\
\text { - sistema para tomada de decisão em relação a treinamento } \\
\text { - programa de treinamento para novos empregados }\end{array}$ \\
\hline $\begin{array}{l}360 \text { degree feedback: } \\
\text { how many raters are } \\
\text { needed for reliable } \\
\text { ratings on the capacity } \\
\text { to develop } \\
\text { competences, with } \\
\text { personal qualities as } \\
\text { developmental goals? }\end{array}$ & $\begin{array}{l}\text { Rainer Hensel, } \\
\text { Frans Meijers, } \\
\text { Rien van der } \\
\text { Leeden e } \\
\text { Joseph Kessels }\end{array}$ & 2010 & $\begin{array}{l}\text { Países } \\
\text { Baixos }\end{array}$ & organização & $\begin{array}{l}\text { Desenvolvimento } \\
\text { Organizacional }\end{array}$ & 360 feedback & \\
\hline $\begin{array}{l}\text { Supporting staff through } \\
\text { stressful organizational } \\
\text { change }\end{array}$ & Roy K Smollan & 2017 & $\begin{array}{c}\text { Nova } \\
\text { Zelândia }\end{array}$ & indivíduo & $\begin{array}{l}\text { Desenvolvimento } \\
\text { Organizacional }\end{array}$ & não descritas & $\begin{array}{l}\text { implicações em DRH através de análise do papel do suporte } \\
\text { em situação organizacionais e profunda mudança. }\end{array}$ \\
\hline
\end{tabular}




\begin{tabular}{|c|c|c|c|c|c|c|c|}
\hline $\begin{array}{l}\text { Contractors' human } \\
\text { resource development } \\
\text { practices and their } \\
\text { effects on employee soft } \\
\text { skills }\end{array}$ & $\begin{array}{l}\text { Benson T.H. } \\
\text { Lim e Florence } \\
\text { Y.Y. Ling }\end{array}$ & 2011 & Singapura & indivíduo & $\mathrm{DRH}$ & $\begin{array}{l}\text { Práticas de DRH } \\
-9 \text { itens de aprendizagem } \\
-3 \text { carreira } \\
-5 \text { reconhecimento } \\
-3 \text { mudança }\end{array}$ & $\begin{array}{l}\text { Adesão às práticas de } \mathrm{DRH} \text { e relação com competências e } \\
\text { resistência à mudança }\end{array}$ \\
\hline $\begin{array}{l}\text { Development (f) or } \\
\text { Maintenance? An } \\
\text { Empirical Study on the } \\
\text { Use of and Need for HR } \\
\text { Practices to Retain } \\
\text { Older Workers in Health } \\
\text { Care Organizations }\end{array}$ & $\begin{array}{l}\text { Klaske N. Veth, } \\
\text { Ben J. M. } \\
\text { Emans, Beatrice } \\
\text { I. J. M. Van der, } \\
\text { Heijden, Hubert } \\
\text { P. L. M. } \\
\text { Korzilius, Annet } \\
\text { H. De Lange }\end{array}$ & 2015 & $\begin{array}{l}\text { Países } \\
\text { Baixos }\end{array}$ & indivíduo & DRH & $\begin{array}{l}\text { Práticas de } \mathrm{RH} \text { com foco em } \\
\text { desenvolvimento levantadas } \\
\text { pela pesquisa } \\
\text { Coaching de carreira e } \\
\text { aposentadoria } \\
\text { Designação de tarefas de } \\
\text { mentor } \\
\text { Treinamentos de TI } \\
\text { Monitoramento de habilidade } \\
\text { de trabalhar }\end{array}$ & $\begin{array}{l}\text { Práticas de DRH e RH para retenção de empregados mais } \\
\text { velhos. Apesar da discussão inicial ser de práticas de DRH e } \\
\mathrm{RH} \text {, a pesquisa é focada em Práticas de } \mathrm{RH} \text { em geral }\end{array}$ \\
\hline $\begin{array}{l}\text { Examining the Impact of } \\
\text { HRD Practices on } \\
\text { Organizational } \\
\text { Commitment and } \\
\text { Intention to Stay Within } \\
\text { Selected Software } \\
\text { Companies in India }\end{array}$ & $\begin{array}{l}\text { Ram Shankar } \\
\text { Uraon }\end{array}$ & 2018 & Índia & indivíduo & DRH & $\begin{array}{l}\text { As práticas de DRH incluem: } \\
\text { Planejamento e } \\
\text { Recrutamento de RH } \\
\text { Treinamento e Aprendizagem } \\
\text { Reconhecimento e } \\
\text { Recompensa } \\
\text { Avaliação e promoção de } \\
\text { potenciais } \\
\text { Avaliação e desenvolvimento } \\
\text { de performance } \\
\text { Planejamento e } \\
\text { desenvolvimento de carreira }\end{array}$ & Práticas de DRH e Intenção de Permanecer na Organização \\
\hline
\end{tabular}


Influence of human resource development (HRD) practices on hotel industry's

of employee

competencies performance: The role
Frank Nana

Kweku Otoo,

Mridula Mishra

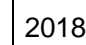

Ghana

$\mathrm{DRH}$

Avaliação de Desempenho

Desenvolvimento de Carreira

Treinamento e

Desenvolvimento
Avaliação de Performance

Sistema de avaliação de performance forma

Avaliação de performance baseadas em resultados

qualitativos e quantitativos

Avaliação de performance com processos de feedback

counseling

Qualidade e cuidado na avaliação de performance

Desenvolvimento de Carreira

Coaching de carreira

Estratégias de desenvolvimento individual

Disponibilidade de orientação de carreira sem preconceito

Gestão indica tarefas para melhorar minhas habilidades

Treinamento e Desenvolvimento

Conhecimentos desenvolvidos no programa de treinamento

estão disponíveis para usar no trabalho

As atividades do programa de treinamento fornecidas

As ativades do programa de treinamento tor

Os funcionários que vão aos programas de treinamento com

base em reais necessidades

Conhecimentos e habilidades adequados e relevantes são

adquiridos através de programa de treinamento

Programas de treinamento compreendem todas as facetas da qualidade

\section{Human resource}

development (HRD)

practices and banking

industry effectiveness:

The mediating role of

employee competencies

Impact of human

resource development

(HRD) practices on

pharmaceutical

industry's performance

The mediating role of

employee performance

Measuring the impact of

human resource

development (HRD)

practices on employee

performance in small

and medium scale

enterprises

\begin{tabular}{|c|c|c|c|c|c|}
\hline $\begin{array}{l}\text { Frank Nana } \\
\text { Kweku Otoo }\end{array}$ & 2019 & Ghana & indivíduo & DRH & $\begin{array}{l}\text { Treinamento e } \\
\text { Desenvolvimento } \\
\text { Desenvolvimento de Carreira } \\
\text { Engajamento de Empregados }\end{array}$ \\
\hline $\begin{array}{l}\text { Frank Nana } \\
\text { Kweku Otoo, } \\
\text { Evelyn Akosua } \\
\text { Otoo, Godfred } \\
\text { Kwame Abledu, } \\
\text { and } \\
\text { Akash Bhardwa }\end{array}$ & 2019 & Ghana & indivíduo & DRH & $\begin{array}{l}\text { Avaliação de Desempenho } \\
\text { Desenvolvimento de Carreira } \\
\text { Treinamento e } \\
\text { Desenvolvimento }\end{array}$ \\
\hline $\begin{array}{l}\text { Frank Nana } \\
\text { Kweku Otoo e } \\
\text { Mridula Mishra }\end{array}$ & 2018 & Ghana & indivíduo & DRH & $\begin{array}{l}\text { Avaliação de Desempenho } \\
\text { Desenvolvimento de Carreira } \\
\text { Treinamento e } \\
\text { Desenvolvimento }\end{array}$ \\
\hline
\end{tabular}

mesmos itens do artigo de 2018

mesmos itens do artigo de 2018 


\begin{tabular}{|c|c|c|c|c|c|c|c|}
\hline $\begin{array}{l}\text { Linking Human } \\
\text { Resource Development } \\
\text { Practices to } \\
\text { Counterproductive Work } \\
\text { Behaviour: Does } \\
\text { Employee Engagement } \\
\text { Matter }\end{array}$ & $\begin{array}{l}\text { Kabiru Maitama } \\
\text { Kura, } \\
\text { Faridahwati } \\
\text { Mohd. } \\
\text { Shamsudin, } \\
\text { Waheed Ali } \\
\text { Umrani e } \\
\text { Noor Maya } \\
\text { Salleh } \\
\end{array}$ & 2019 & Nigéria & indivíduo & DRH & $\begin{array}{l}\text { Utiliza a escala Perceived } \\
\text { Investment in Employee } \\
\text { Development (PIED) de Lee } \\
\text { e Bruvold (Lee e Bruvold, } \\
\text { 2003) para medir as práticas } \\
\text { de DRH }\end{array}$ & \\
\hline $\begin{array}{l}\text { Trends in Australian } \\
\text { human resource } \\
\text { development practice, } \\
\text { 1996-2009 }\end{array}$ & $\begin{array}{l}\text { Melissa Peretz e } \\
\text { Peter McGraw }\end{array}$ & 2011 & Austrália & organização & $\mathrm{DRH}$ & $\begin{array}{l}\text { descritas na pesquisa } \\
\text { CRANET }\end{array}$ & $\begin{array}{l}\text { Eficácia do treinamento } 2 \text { itens } \\
\text { Avaliação do treinamento } 3 \text { itens } \\
\text { Desenvolvimento de carreira } 5 \text { itens } \\
\text { Avaliação formal de desempenho } 4 \text { itens } \\
\text { Entradas no processo de avaliação de desempenho } 6 \text { itens } \\
\text { Dados de avaliação de desempenho para tomada de decisão } \\
4 \text { itens }\end{array}$ \\
\hline $\begin{array}{l}\text { General self-efficacy's } \\
\text { effect on career choice } \\
\text { goals via vocational } \\
\text { interests and person-job } \\
\text { fit: A mediation model }\end{array}$ & $\begin{array}{l}\text { Zibin Song e } \\
\text { Kaye Chon }\end{array}$ & 2011 & China & indivíduo & $\begin{array}{c}\text { implicações em } \\
\text { DRH }\end{array}$ & não descritas & $\begin{array}{l}\text { implicações em DRH através de investigação sobre como } \\
\text { metas individuais de carreira são influenciadas pela interação } \\
\text { de autoeficácia geral, interesses vocacionais, e percepções } \\
\text { de ajuste pessoa-trabalho. }\end{array}$ \\
\hline $\begin{array}{l}\text { Intern newcomers' } \\
\text { global self-esteem, } \\
\text { overall job satisfaction, } \\
\text { and choice intention } \\
\text { Person-organization fit } \\
\text { as a mediator }\end{array}$ & $\begin{array}{l}\text { Zibin Song e } \\
\text { Prakash K. } \\
\text { Chathoth }\end{array}$ & 2011 & China & indivíduo & $\begin{array}{c}\text { implicações em } \\
\text { DRH }\end{array}$ & não descritas & $\begin{array}{l}\text { implicações em DRH através de discussão sobre percepção } \\
\text { de estagiários recém chegados nas organizações em relação } \\
\text { ao ajuste pessoa-organização, efeitos da autoestima global e } \\
\text { satisfação geral do trabalho. }\end{array}$ \\
\hline $\begin{array}{l}\text { Core self-evaluations } \\
\text { and job performance: } \\
\text { The mediating role of } \\
\text { employees' } \\
\text { assimilation-specific } \\
\text { adjustment factors }\end{array}$ & $\begin{array}{l}\text { Zibin Songa e } \\
\text { Prakash K. } \\
\text { Chathothb }\end{array}$ & 2013 & China & indivíduo & $\begin{array}{c}\text { implicações em } \\
\text { DRH }\end{array}$ & não descritas & $\begin{array}{l}\text { implicações em DRH através de análise da relação entre } \\
\text { autoavaliações e desempenho, mediadas por ajustes de } \\
\text { assimilação }\end{array}$ \\
\hline $\begin{array}{l}\text { Equity Theory } \\
\text { Constructs in a } \\
\text { Romanian Cultural } \\
\text { Context }\end{array}$ & Carmen Buzea & 2014 & Romênia & indivíduo & $\begin{array}{c}\text { implicações em } \\
\text { DRH }\end{array}$ & não descritas & $\begin{array}{l}\text { implicações em DRH através de investigação da percepção } \\
\text { de indivíduos sobre equidade em questões relacionadas ao } \\
\text { trabalho, performance e recompensa. }\end{array}$ \\
\hline $\begin{array}{l}\text { Human Resource } \\
\text { Development Practices } \\
\text { and Employee } \\
\text { Engagement: } \\
\text { Examining the } \\
\text { Connection With } \\
\text { Employee Turnover } \\
\text { Intentions }\end{array}$ & $\begin{array}{l}\text { Brad Shuck, } \\
\text { Devon Twyford, } \\
\text { Thomas G. Reio } \\
\text { Jr. e Angie } \\
\text { Shuck }\end{array}$ & 2014 & ND & indivíduo & $\begin{array}{c}\text { implicações em } \\
\text { DRH }\end{array}$ & não descritas & $\begin{array}{l}\text { implicações em DRH através de discussão sobre o suporte } \\
\text { que empregados recebem para participar das práticas de } \\
\text { DRH influenciando engajamento e intenção de turnover. }\end{array}$ \\
\hline
\end{tabular}




\begin{tabular}{|c|c|c|c|c|c|c|c|}
\hline $\begin{array}{l}\text { Factors Affecting } \\
\text { Perceptions of } \\
\text { Procedural Fairness of } \\
\text { Downsizing: A Policy } \\
\text { Capturing Approach }\end{array}$ & \begin{tabular}{|l} 
Jennifer \\
Bragger, Diana \\
Evans, Gene \\
Kutcher, Ken \\
Sumner e Emily \\
Fritzky \\
\end{tabular} & 2015 & USA & indivíduo & $\begin{array}{l}\text { implicações em } \\
\text { DRH }\end{array}$ & não descritas & $\begin{array}{l}\text { implicações em DRH através de investigação da percepção } \\
\text { de indivíduos sobre justiça na tomada de decisão e suporte } \\
\text { aos demitidos em processos de downsizing }\end{array}$ \\
\hline $\begin{array}{l}\text { HRD challenges faced } \\
\text { in the post-global } \\
\text { financial crisis period - } \\
\text { insights from the UK }\end{array}$ & $\begin{array}{l}\text { Diane Rose } \\
\text { Keeble-Ramsay } \\
\text { e Andrew } \\
\text { Armitage }\end{array}$ & 2015 & UK & indivíduo & $\begin{array}{l}\text { implicações em } \\
\text { DRH }\end{array}$ & não descritas & \begin{tabular}{|l|} 
implicações em DRH através de discussão percepção dos \\
participantes de após a crise uma diminuição controle \\
pessoal sobre as mudanças no local de trabalho e uma \\
mudança cultural em direção a um clima de trabalho mais \\
severo e um papel de DRH ausente e associado apenas ao \\
e-learning de baixo custo, em vez de atuar em funções \\
estratégicas de apoio objetivos de negócios sustentáveis. \\
\end{tabular} \\
\hline $\begin{array}{l}\text { Impact of organizational } \\
\text { socialization tactics on } \\
\text { newcomer job } \\
\text { satisfaction and } \\
\text { engagement: Core self- } \\
\text { evaluations as } \\
\text { moderators }\end{array}$ & $\begin{array}{l}\text { Zibin Songa, } \\
\text { Kaye Chonb, } \\
\text { Geng Dinga e } \\
\text { Cao Guca }\end{array}$ & 2015 & China & indivíduo & $\begin{array}{l}\text { implicações em } \\
\text { DRH }\end{array}$ & não descritas & $\begin{array}{l}\text { implicações em DRH através de discussão sobre o impacto } \\
\text { de estratégias de socialização na adaptação, auto avaliação } \\
\text { e engajamento no novos contratados. }\end{array}$ \\
\hline $\begin{array}{l}\text { Hearing the voices of } \\
\text { Generation Y } \\
\text { employees: a } \\
\text { hermeneutic } \\
\text { phenomenological study }\end{array}$ & $\begin{array}{l}\text { Tabitha K. L. } \\
\text { Coates }\end{array}$ & 2017 & USA & indivíduo & $\begin{array}{l}\text { implicações em } \\
\text { DRH }\end{array}$ & não descritas & $\begin{array}{l}\text { implicações em DRH através de discussão sobre como os } \\
\text { cinco empregados da geração Y percebem e descrevem o } \\
\text { significado do trabalho. }\end{array}$ \\
\hline $\begin{array}{l}\text { Confucian philosophy } \\
\text { and influence on } \\
\text { perceived values and } \\
\text { behavioural orientations } \\
\text { by Taiwan's millennials }\end{array}$ & $\begin{array}{l}\text { Szufang } \\
\text { Chuang e Greg } \\
\text { G Wang }\end{array}$ & 2018 & Taiwan & indivíduo & $\begin{array}{l}\text { implicações em } \\
\text { DRH }\end{array}$ & não descritas & $\begin{array}{l}\text { implicações em DRH através de análise de qual a aderência } \\
\text { da geração milênio aos valores da filosofia de Confúcio } \\
\text { organizados em } 6 \text { dimensões. }\end{array}$ \\
\hline $\begin{array}{l}\text { An Interactional } \\
\text { Approach To } \\
\text { Organizations' Success } \\
\text { In Socializing Their } \\
\text { Intern Newcomers: The } \\
\text { Role Of General Self- } \\
\text { Efficacy And } \\
\text { Organizational } \\
\text { Socialization Inventory }\end{array}$ & $\begin{array}{l}\text { Zibin Song e } \\
\text { Prakash K. } \\
\text { Chathoth }\end{array}$ & 2010 & China & indivíduo & $\begin{array}{l}\text { implicações em } \\
\text { DRH }\end{array}$ & não descritas & $\begin{array}{l}\text { oferece implicações em DRH a partir de análise de Auto } \\
\text { Eficácia Geral e Inventário Organizacional de Socialização } \\
\text { em relação com a Satisfação Geral com o Trabalho do } \\
\text { Empregado Iniciante e sua Intenção de Retornar. }\end{array}$ \\
\hline $\begin{array}{l}\text { Self-Awareness of } \\
\text { Mastery and } \\
\text { Improvability of } \\
\text { Entrepreneurial } \\
\text { Competence in Small } \\
\text { Businesses in the } \\
\text { Agrifood Sector }\end{array}$ & $\begin{array}{l}\text { Thomas Lans, } \\
\text { Harm Biemans, } \\
\text { Martin Mulder, } \\
\text { Jos Verstegen }\end{array}$ & 2010 & $\begin{array}{l}\text { Países } \\
\text { Baixos }\end{array}$ & indivíduo & $\begin{array}{l}\text { implicações em } \\
\text { DRH }\end{array}$ & $\begin{array}{l}\text { auto avaliação de } \\
\text { competências }\end{array}$ & $\begin{array}{l}\text { implicações em DRH através de análise de auto avaliação e } \\
\text { avaliação de outros em relação à competências e maestria. }\end{array}$ \\
\hline
\end{tabular}


Work meaning among mid-level professional employees: A study of
the importance of work centrality and extrinsic and intrinsic work goals in eight countries

\begin{tabular}{|l} 
\\
\hline Bias in strategic \\
initiative continuance
\end{tabular}

initiative continuance decisions: framing interactions and HRD practices

The Role of Perceived

External Prestige in

Predicting Customer-

Oriented Citizenship

Behaviors

Women and training: an empirical investigation

in the Arab Middle East

Learning at the

workplace and

sustainable

employability: a multi-

source model

moderated by age

On the Discourse of

Affirmative Action and

Reservation in the

Unites States and India:

Clarifying HRD's Role in

Fostering Global

Diversity

\begin{tabular}{|c|c|c|c|c|c|c|}
\hline $\begin{array}{l}\text { K Peter } \\
\text { Kuchinke, } \\
\text { Alexandre } \\
\text { Ardichvili, } \\
\text { Margaret } \\
\text { Borchert, } \\
\text { Edgard B. } \\
\text { Cornachione Jr, } \\
\text { Maria Cseh, } \\
\text { Hye-Seung } \\
\text { (Theresa) Kang, } \\
\text { Seok Young Oh, } \\
\text { Andrzej } \\
\text { Rozanski, Urmat } \\
\text { Tynaliev e Elena } \\
\text { Zav'jalova }\end{array}$ & 2011 & Vários & indivíduo & $\begin{array}{c}\text { implicações em } \\
\text { DRH }\end{array}$ & não descritas & $\begin{array}{l}\text { Implicações no DRH após investigação do significado do } \\
\text { trabalho em } 8 \text { países utilizando a pesquisa MOW (Meaning of } \\
\text { Work) dentro do estudo GLOBE. }\end{array}$ \\
\hline $\begin{array}{l}\text { Michael } \\
\text { Workman }\end{array}$ & 2012 & USA & indivíduo & $\begin{array}{c}\text { implicações em } \\
\text { DRH }\end{array}$ & não descritas & $\begin{array}{l}\text { implicações em DRH através de análise de como vieses } \\
\text { cognitivos e os efeitos de enquadramento influenciam a } \\
\text { tomada de decisões gerenciais sobre iniciativas estratégicas. }\end{array}$ \\
\hline $\begin{array}{l}\text { Dae-seok Kang, } \\
\text { Kenneth R. } \\
\text { Bartlett }\end{array}$ & 2013 & $\begin{array}{l}\text { Coreia do } \\
\text { Sul }\end{array}$ & indivíduo & $\begin{array}{c}\text { implicações em } \\
\text { DRH }\end{array}$ & não descritas & $\begin{array}{l}\text { Implicações no DRH a partir da compreensão que prestígio } \\
\text { externo percebido foi um indicador significativo para o } \\
\text { desempenho da cidadania dos funcionários organizações do } \\
\text { setor de serviço e o impacto percebido na reputação está } \\
\text { relacionando ao empoderamento psicológico dos indivíduos. }\end{array}$ \\
\hline $\begin{array}{l}\text { Hayfaa A. Tlaiss } \\
\text { e Khalil M. } \\
\text { Dirani }\end{array}$ & 2015 & $\begin{array}{l}\text { Oriente } \\
\text { Médio }\end{array}$ & indivíduo & $\begin{array}{c}\text { implicações em } \\
\text { DRH }\end{array}$ & não descritas & $\begin{array}{l}\text { Implicações no DRH após compreensão de escassez de } \\
\text { oportunidades de treinamento profissionais e aprendizado } \\
\text { para as mulheres, ilustram como a discriminação } \\
\text { organizacional, culturas e tensão influenciadas por gênero } \\
\text { influenciam o aprendizado das mulheres. }\end{array}$ \\
\hline $\begin{array}{l}\text { Beatrice I.J.M. } \\
\text { Van der } \\
\text { Heijden, Marjan } \\
\text { J. Gorgievski e } \\
\text { Annet H. De } \\
\text { Lange } \\
\end{array}$ & 2016 & $\begin{array}{l}\text { Países } \\
\text { Baixos }\end{array}$ & indivíduo & $\begin{array}{c}\text { implicações em } \\
\text { DRH }\end{array}$ & não descritas & $\begin{array}{l}\text { implicações em DRH através de análise a autopercepção e } \\
\text { percepção do supervisor sobre empregabilidade, estilos de } \\
\text { aprendizagem e idade }\end{array}$ \\
\hline $\begin{array}{l}\text { Ray Haynes e } \\
\text { Meera Alagaraja }\end{array}$ & 2016 & $\begin{array}{l}\text { EUA e } \\
\text { Índia }\end{array}$ & Indivíduo & $\begin{array}{c}\text { implicações em } \\
\text { DRH }\end{array}$ & não descritas & $\begin{array}{l}\text { implicações em DRH através de reflexões sobre o sistema de } \\
\text { Ação Afirmativa (AA) desenvolvido no EUA e o sistema de } \\
\text { Reserva desenvolvido na Índia para acabar com práticas } \\
\text { discriminatórias e aumentar a diversidade }\end{array}$ \\
\hline
\end{tabular}




\begin{tabular}{|c|c|c|c|c|c|c|c|}
\hline $\begin{array}{l}\text { An empirical study on } \\
\text { the relationship between } \\
\text { perceived } \\
\text { employability and } \\
\text { employee performance }\end{array}$ & $\begin{array}{l}\text { Huh-Jung Hahn } \\
\text { e Sungjun Kim }\end{array}$ & 2017 & $\begin{array}{l}\text { Coreia do } \\
\text { Sul }\end{array}$ & indivíduo & $\begin{array}{l}\text { implicações em } \\
\text { DRH }\end{array}$ & não descritas & $\begin{array}{l}\text { oferece implicações em DRH a partir de análise de } \\
\text { Empregabilidade Percebida e Performance }\end{array}$ \\
\hline $\begin{array}{l}\text { Using a portfolio-based } \\
\text { process to develop } \\
\text { agility among } \\
\text { employees }\end{array}$ & $\begin{array}{l}\text { Sandra B. } \\
\text { Doeze Jager- } \\
\text { van Vliet, Marise } \\
\text { Ph. Born e Henk } \\
\text { T. van der } \\
\text { Molen }\end{array}$ & 2019 & $\begin{array}{l}\text { Países } \\
\text { Baixos }\end{array}$ & indivíduo & $\begin{array}{l}\text { implicações em } \\
\text { DRH }\end{array}$ & não descritas & $\begin{array}{l}\text { Implicações no DRH a partir do estudo objetivos traçados a } \\
\text { partir de portfólio aumentaram no tempo a agilidade dos } \\
\text { empregados. }\end{array}$ \\
\hline $\begin{array}{l}\text { Human resource } \\
\text { development in } \\
\text { Mauritius: context, } \\
\text { challenges and } \\
\text { opportunities }\end{array}$ & $\begin{array}{l}\text { Thomas N. } \\
\text { Garavan, Harris } \\
\text { Neeliah, Raj } \\
\text { Auckloo e Raj } \\
\text { Ragaven }\end{array}$ & 2014 & $\begin{array}{l}\text { llhas } \\
\text { Maurício }\end{array}$ & nação & $\begin{array}{l}\text { implicações em } \\
\text { DRH }\end{array}$ & não descritas & $\begin{array}{l}\text { implicações em DRH através de discussão sobre o } \\
\text { desenvolvimento nacional do capital humano através de } \\
\text { melhoria da empregabilidade que compreendem } \\
\text { aprimoramento de skills, modernização e inovação no uso de } \\
\text { práticas de DRH, como treinamento on the job e } \\
\text { aprendizagem no local de trabalho e também o } \\
\text { desenvolvimento intervenções de treinamento especializadas } \\
\text { por setor da indústria. }\end{array}$ \\
\hline $\begin{array}{l}\text { HRD Education in the } \\
\text { Netherlands }\end{array}$ & Rob F. Poell & 2015 & $\begin{array}{l}\text { Países } \\
\text { Baixos }\end{array}$ & nação & $\begin{array}{c}\text { implicações em } \\
\text { DRH }\end{array}$ & não descritas & $\begin{array}{l}\text { implicações em DRH através de discussão sobre evolução e } \\
\text { estado atual da formação em DRH no país }\end{array}$ \\
\hline $\begin{array}{l}\text { International HRD and } \\
\text { Offshore Outsourcing: A } \\
\text { Conceptual Review and } \\
\text { Research Agenda }\end{array}$ & $\begin{array}{l}\text { Valerie } \\
\text { Anderson }\end{array}$ & 2015 & ND & nação & $\begin{array}{l}\text { implicações em } \\
\text { DRH }\end{array}$ & não descritas & $\begin{array}{l}\text { implicações em DRH através de discussão sobre o DRH } \\
\text { internacional e a contratação de mão de obra "offshore" com } \\
\text { proposição de modelo conceitual integrado. }\end{array}$ \\
\hline $\begin{array}{l}\text { The factors and } \\
\text { conditions for national } \\
\text { human resource } \\
\text { development in Brazil }\end{array}$ & $\begin{array}{l}\text { Torrence E. } \\
\text { Sparkman }\end{array}$ & 2015 & Brasil & nação & $\begin{array}{l}\text { implicações em } \\
\text { DRH }\end{array}$ & não descritas & $\begin{array}{l}\text { Implicações no DRH a partir de entendimento de fatores e } \\
\text { condições que influenciam Desenvolvimento Nacional de } \\
\text { Recursos Humanos (DNRH) no Brasil. Análise da natureza } \\
\text { de transição de condições políticas, econômicas, sociais e } \\
\text { educacionais; os desafios e tendências atuais que podem } \\
\text { gerar um DNRH de impacto. }\end{array}$ \\
\hline $\begin{array}{l}\text { Is Mauritius ready to } \\
\text { become the HRD leader } \\
\text { in Africa? An } \\
\text { assessment of strategic } \\
\text { human resource } \\
\text { development in } \\
\text { Mauritius }\end{array}$ & $\begin{array}{l}\text { Indravidoushi C. } \\
\text { Dusoye e Kavi } \\
\text { Oogarah }\end{array}$ & 2016 & $\begin{array}{l}\text { llhas } \\
\text { Maurício }\end{array}$ & nação & $\begin{array}{l}\text { implicações em } \\
\text { DRH }\end{array}$ & não descritas & $\begin{array}{l}\text { implicações em DRH através de análise do status de } \\
\text { implementação de Desenvolvimento de Recursos Humanos } \\
\text { Estratégico }\end{array}$ \\
\hline $\begin{array}{l}\text { The capability approach } \\
\text { and national } \\
\text { development in Nigeria: } \\
\text { towards a youth } \\
\text { transition model }\end{array}$ & $\begin{array}{l}\text { D.O. Arubayi \& } \\
\text { L.A. Akobo }\end{array}$ & 2018 & Nigéria & nação & $\begin{array}{l}\text { implicações em } \\
\text { DRH }\end{array}$ & não descritas & $\begin{array}{l}\text { implicações em DRH utilizando uma estrutura analítica de } \\
\text { capacidade para jovens } \\
\text { para entender como essas capacidades podem ser mais } \\
\text { desenvolvidas e alinhadas estrategicamente no tratamento } \\
\text { de desafios do desenvolvimento nacional à medida que os } \\
\text { jovens navegam pela educação no caminho de transição } \\
\text { para o trabalho }\end{array}$ \\
\hline
\end{tabular}




\begin{tabular}{|c|c|c|c|c|c|c|c|}
\hline $\begin{array}{l}\text { Exploring the Social } \\
\text { Foundations of Human } \\
\text { Resource Development: } \\
\text { A Theoretical } \\
\text { Framework for } \\
\text { Research and Practice }\end{array}$ & Russell Korte & 2012 & ND & ND & $\begin{array}{l}\text { implicações em } \\
\text { DRH }\end{array}$ & não descritas & $\begin{array}{l}\text { Reflexão teórica sobre espaço social como uma estrutura } \\
\text { fundamental de HRD }\end{array}$ \\
\hline $\begin{array}{l}\text { Inspecting the Hierarchy } \\
\text { of Life Roles: A } \\
\text { Systematic Review of } \\
\text { Role Salience Literature } \\
\end{array}$ & $\begin{array}{l}\text { Tomika W. } \\
\text { Greer e Toby M. } \\
\text { Egan }\end{array}$ & 2012 & ND & ND & $\begin{array}{l}\text { implicações em } \\
\text { DRH }\end{array}$ & não descritas & $\begin{array}{l}\text { implicações em DRH através de discussão sobre a } \\
\text { importância dos papéis, em especial nos processos de } \\
\text { aconselhamento de carreira, dimensão da Prática } \\
\text { Desenvolvimento de Carreira }\end{array}$ \\
\hline $\begin{array}{l}\text { Illustrating Relevance, } \\
\text { Questioning Norms, and } \\
\text { Creating Space: Three } \\
\text { Steps for Teaching } \\
\text { Critical Perspectives in } \\
\text { the HRD Classroom }\end{array}$ & $\begin{array}{l}\text { Joshua C. } \\
\text { Collins }\end{array}$ & 2013 & USA & ND & $\begin{array}{l}\text { implicações em } \\
\text { DRH }\end{array}$ & não descritas & $\begin{array}{l}\text { artigo discutindo estratégia de ensino baseada em identidade } \\
\text { para formação de pessoas de DRH }\end{array}$ \\
\hline $\begin{array}{l}\text { Invited Reaction: The } \\
\text { Strategic Value of HRD } \\
\text { in Lean } \\
\text { Strategy Implementation }\end{array}$ & $\begin{array}{l}\text { Lyle Yorks, Jody } \\
\text { Barto }\end{array}$ & 2013 & ND & ND & $\begin{array}{c}\text { implicações em } \\
\text { DRH }\end{array}$ & não descritas & $\begin{array}{l}\text { implicações em DRH através de discussão sobre DRH } \\
\text { estratégico e o sistema Lean Manufacturing }\end{array}$ \\
\hline $\begin{array}{l}\text { Greening HRD: } \\
\text { Conceptualizing the } \\
\text { Triple Bottom Line for } \\
\text { HRD Practice, } \\
\text { Teaching, and } \\
\text { Research }\end{array}$ & Claire Valentin & 2015 & ND & ND & $\begin{array}{l}\text { implicações em } \\
\text { DRH }\end{array}$ & não descritas & $\begin{array}{l}\text { implicações em DRH através de discussão teórica sobre o } \\
\text { papel do HRD e sustentabilidade, discutindo as diferentes } \\
\text { orientações do DRH sob os pontos de vista: Compliance, } \\
\text { Cooperação e Coexistência com ênfase na aprendizagem }\end{array}$ \\
\hline $\begin{array}{l}\text { The Problem of } \\
\text { Transgender } \\
\text { Marginalization and } \\
\text { Exclusion: Critical } \\
\text { Actions for Human } \\
\text { Resource Development }\end{array}$ & $\begin{array}{l}\text { Joshua C. } \\
\text { Collins, Ciarán } \\
\text { McFadden, } \\
\text { Tonette S. } \\
\text { Rocco e Mary } \\
\text { Katherine } \\
\text { Mathis }\end{array}$ & 2015 & ND & ND & $\begin{array}{l}\text { implicações em } \\
\text { DRH }\end{array}$ & não descritas & $\begin{array}{l}\text { Implicações no DRH situando as experiências transgêneros } \\
\text { como relevantes e levantando questões importantes para a } \\
\text { DRH, fornecendo ações críticas para acadêmicos e } \\
\text { profissionais de RH poderem moldar uma realidade mais } \\
\text { inclusiva para as pessoas trans no local de trabalho }\end{array}$ \\
\hline
\end{tabular}




\begin{tabular}{|c|c|c|c|c|c|c|c|}
\hline $\begin{array}{l}\text { HRD Scholars Who Laid } \\
\text { the Foundations of HRD }\end{array}$ & Darren C. Short & 2016 & ND & ND & $\begin{array}{l}\text { implicações em } \\
\text { DRH }\end{array}$ & $\begin{array}{l}\text { Frederick L. Otte - } \\
\text { desenvolvimento de carreira } \\
\text { Ronald L. Jacobs - } \\
\text { treinamento on the job } \\
\text { Victoria J. Marsick Karen E. } \\
\text { Watkins - aprendizagem } \\
\text { informal e incidental no local } \\
\text { de trabalho } \\
\text { Gary N. McLean - } \\
\text { desenvolvimento } \\
\text { organizacional } \\
\text { Darlene F. Russ-Eft - } \\
\text { métodos de treinamento e } \\
\text { efetividade de programas de } \\
\text { treinamento } \\
\text { Richard A. Swanson - } \\
\text { publicações e organização } \\
\text { teórica }\end{array}$ & $\begin{array}{l}\text { implicações em DRH através de discussão sobre os AHRD } \\
\text { Outstanding Scholar Award até } 2000 \text {. }\end{array}$ \\
\hline $\begin{array}{l}\text { Propensity score } \\
\text { analysis: an alternative } \\
\text { statistical approach for } \\
\text { HRD researchers }\end{array}$ & $\begin{array}{l}\text { Greggory L. } \\
\text { Keiffer e } \\
\text { Forrest C. Lane }\end{array}$ & 2016 & ND & ND & $\begin{array}{l}\text { implicações em } \\
\text { DRH }\end{array}$ & não descritas & $\begin{array}{l}\text { implicações em DRH através de sugestão de uso de } \\
\text { metodologia de análise de escores de propensão. }\end{array}$ \\
\hline $\begin{array}{l}\text { Means vs ends: } \\
\text { theorizing a definition of } \\
\text { human resource } \\
\text { development }\end{array}$ & $\begin{array}{l}\text { Greg G. Wang, } \\
\text { Jon M. Werner, } \\
\text { Judy Y. Sun, } \\
\text { Ann Gilley e } \\
\text { Jerry W. Gilley }\end{array}$ & 2017 & ND & ND & $\begin{array}{l}\text { implicações em } \\
\text { DRH }\end{array}$ & não descritas & discussão crítica sobre definições de DRH \\
\hline $\begin{array}{l}\text { The ethics of HRD } \\
\text { practice }\end{array}$ & $\begin{array}{l}\text { K. Peter } \\
\text { Kuchinke }\end{array}$ & 2017 & ND & ND & $\begin{array}{l}\text { implicações em } \\
\text { DRH }\end{array}$ & não descritas & $\begin{array}{l}\text { Implicações em DRH descrevendo os principais princípios da } \\
\text { ética davirtude no contexto de organização e do trabalho e } \\
\text { argumentando que o foco em sabedoria prática deve ser vista } \\
\text { como uma preocupação central da prática DRH e educaçãa } \\
\text { em direitos humanos. }\end{array}$ \\
\hline $\begin{array}{l}\text { Why is organizing } \\
\text { human resource } \\
\text { development so } \\
\text { problematic? } \\
\text { Perspectives from the } \\
\text { learning-network theory } \\
\text { (Part II). }\end{array}$ & $\begin{array}{l}\text { Rob F. Poell e } \\
\text { Ferd van der } \\
\text { Krogt }\end{array}$ & 2017 & $\begin{array}{l}\text { Países } \\
\text { Baixos }\end{array}$ & ND & $\begin{array}{l}\text { implicações em } \\
\text { DRH }\end{array}$ & não descritas & $\begin{array}{l}\text { Implicações no DRH após reflexão dos eixos de organização } \\
\text { do DRH. }\end{array}$ \\
\hline $\begin{array}{l}\text { Pragmatism and Human } \\
\text { Resource Development: } \\
\text { Practical Foundations } \\
\text { for Research, Theory, } \\
\text { and Practice }\end{array}$ & $\begin{array}{l}\text { Russell Korte e } \\
\text { Zachary A. } \\
\text { Mercurio }\end{array}$ & 2017 & ND & ND & $\begin{array}{l}\text { implicações em } \\
\text { DRH }\end{array}$ & não descritas & $\begin{array}{l}\text { implicações em DRH através de reflexão teórica de uma } \\
\text { perspectiva do DRH baseado em Filosofia Pragmatista e } \\
\text { teorias emergentes da prática }\end{array}$ \\
\hline
\end{tabular}




\begin{tabular}{|c|c|c|c|c|c|c|c|}
\hline $\begin{array}{l}\text { Exploring human } \\
\text { resource development } \\
\text { research themes: A } \\
\text { keyword network } \\
\text { analysis }\end{array}$ & $\begin{array}{l}\text { Sangok Yoo, } \\
\text { SoebinJang } \\
\text {,Sang Won } \\
\text { Byun e } \\
\text { Sunyoung Park }\end{array}$ & 2018 & ND & ND & $\begin{array}{l}\text { implicações em } \\
\text { DRH }\end{array}$ & não descritas & $\begin{array}{l}\text { implicações em DRH através de revisão de temas de artigos } \\
\text { de DRH. }\end{array}$ \\
\hline $\begin{array}{l}\text { Engaging Employees at } \\
\text { Work: Insights From } \\
\text { India }\end{array}$ & Manish Gupta & 2018 & Índia & ND & $\begin{array}{l}\text { implicações em } \\
\text { DRH }\end{array}$ & não descritas & $\begin{array}{l}\text { implicações em DRH através de discussão de artigos sobre } \\
\text { engajamento }\end{array}$ \\
\hline $\begin{array}{l}\text { Is HRD in need of an } \\
\text { ethics of care? }\end{array}$ & $\begin{array}{l}\text { Andrew } \\
\text { Armitage }\end{array}$ & 2018 & ND & ND & $\begin{array}{l}\text { implicações em } \\
\text { DRH }\end{array}$ & não descritas & $\begin{array}{l}\text { implicações em DRH através de reflexão teórica sobre os } \\
\text { valores éticos que influenciam a construção das práticas de } \\
\text { DRH }\end{array}$ \\
\hline $\begin{array}{l}\text { Organizational Social } \\
\text { Capital: Ties Between } \\
\text { HRD, Employee Voice, } \\
\text { and CEOs }\end{array}$ & $\begin{array}{l}\text { Denise M. } \\
\text { Cumberland, } \\
\text { Meera } \\
\text { Alagaraja, Brad } \\
\text { Shuck e Sharon } \\
\text { A. Kerrick } \\
\end{array}$ & 2018 & ND & ND & $\begin{array}{l}\text { implicações em } \\
\text { DRH }\end{array}$ & não descritas & $\begin{array}{l}\text { implicações em DRH através da proposta de modelo } \\
\text { conceitual que identifica conexões entre as práticas de DRH, } \\
\text { o capital social da organização, e o papel do CEO como } \\
\text { facilitador de ambiente e mecanismos para propiciar espaço } \\
\text { para a voz dos empregados }\end{array}$ \\
\hline $\begin{array}{l}\text { Making an HRD } \\
\text { domain: identity work in } \\
\text { an online professional } \\
\text { community }\end{array}$ & Peter Evans & 2019 & ND & ND & $\begin{array}{l}\text { implicações em } \\
\text { DRH }\end{array}$ & não descritas & $\begin{array}{l}\text { implicações em DRH através de análise do chat do Twitter } \\
\text { de eventos de DRH como exemplos de comunidades de } \\
\text { aprendizagem profissional engajadas no processo de } \\
\text { construção coletiva de senso de identidade }\end{array}$ \\
\hline $\begin{array}{l}\text { The roles of the } \\
\text { psychology, systems } \\
\text { and economic theories } \\
\text { in human resource } \\
\text { development }\end{array}$ & Boreum Ju & 2019 & ND & ND & $\begin{array}{l}\text { implicações em } \\
\text { DRH }\end{array}$ & não descritas & $\begin{array}{l}\text { Implicações no DRH a partir de investigação das teorias que } \\
\text { fundamentam o DRH }\end{array}$ \\
\hline $\begin{array}{l}\text { Perspectives in HRD- } \\
\text { Hart's Hardware and } \\
\text { Supply: An Independent } \\
\text { Consulting Dilemma }\end{array}$ & $\begin{array}{l}\text { Sandra L. } \\
\text { Willians }\end{array}$ & 2017 & EUA & Organização & $\begin{array}{l}\text { implicações em } \\
\text { DRH }\end{array}$ & não descritas & $\begin{array}{l}\text { implicações em DRH através de estudo de caso com } \\
\text { reflexões sobre o papel do consultor em organização. }\end{array}$ \\
\hline
\end{tabular}

Fonte: elaborado pela autora 


\section{Apêndice B: Tabelas Desenvolvidas na Análise de Dados}

Seguem as tabelas que descrevem a amostra, analisando o percentual de respostas de cada item da variável "Percepção Sobre Prática de DRH Aprendizagem Individual" (PPAl), em relação ao total de respostas presentes na amostra por característica do respondente.

As tabelas demonstram padrões consistentes, a exceção feita ao grupo "Outro" da característica gênero.

Tabela 15 - Percentual de respostas sobre a amostra de Apr_Soc_1, Apr_Soc_2 por Gênero e Faixa Etária

\begin{tabular}{|c|c|c|c|c|c|c|c|c|c|c|c|c|}
\hline & \multicolumn{6}{|c|}{ Apr_Soc_1 } & \multicolumn{6}{|c|}{ Apr_Soc_2 } \\
\hline & NS/NR & 1 & 2 & 3 & 4 & 5 & NS/NR & 1 & 2 & 3 & 4 & 5 \\
\hline Mulher & $0,5 \%$ & $2,6 \%$ & $5,5 \%$ & $6,2 \%$ & $34,1 \%$ & $51,1 \%$ & $0,4 \%$ & $4,7 \%$ & $8,3 \%$ & $6,7 \%$ & $34,8 \%$ & $45,3 \%$ \\
\hline Homem & $0,4 \%$ & $2,1 \%$ & $4,1 \%$ & $6,7 \%$ & $32,4 \%$ & $54,2 \%$ & $0,3 \%$ & $3,6 \%$ & $6,2 \%$ & $7,4 \%$ & $33,1 \%$ & $49,5 \%$ \\
\hline Outro & $1,5 \%$ & $8,7 \%$ & $12,6 \%$ & $11,8 \%$ & $34,3 \%$ & $31,1 \%$ & $1,0 \%$ & $13,2 \%$ & $14,5 \%$ & $10,8 \%$ & $30,4 \%$ & $30,2 \%$ \\
\hline até 20 & $0,5 \%$ & $2,1 \%$ & $4,0 \%$ & $7,1 \%$ & $25,6 \%$ & $60,8 \%$ & $0,5 \%$ & $5,0 \%$ & $7,2 \%$ & $9,7 \%$ & $28,0 \%$ & $49,6 \%$ \\
\hline até 30 & $0,4 \%$ & $2,3 \%$ & $4,6 \%$ & $7,0 \%$ & $31,0 \%$ & $54,6 \%$ & $0,3 \%$ & $4,6 \%$ & $7,8 \%$ & $8,6 \%$ & $32,1 \%$ & $46,6 \%$ \\
\hline até 40 & $0,4 \%$ & $2,3 \%$ & $5,1 \%$ & $6,7 \%$ & $34,6 \%$ & $50,8 \%$ & $0,3 \%$ & $4,1 \%$ & $7,3 \%$ & $6,9 \%$ & $35,1 \%$ & $46,3 \%$ \\
\hline até 50 & $0,6 \%$ & $2,4 \%$ & $4,6 \%$ & $5,9 \%$ & $34,8 \%$ & $51,7 \%$ & $0,4 \%$ & $3,5 \%$ & $6,2 \%$ & $5,6 \%$ & $35,1 \%$ & $49,3 \%$ \\
\hline até 60 & $0,6 \%$ & $2,0 \%$ & $3,8 \%$ & $5,2 \%$ & $33,2 \%$ & $55,1 \%$ & $0,5 \%$ & $2,8 \%$ & $5,0 \%$ & $4,9 \%$ & $33,3 \%$ & $53,6 \%$ \\
\hline até 70 & $0,9 \%$ & $2,2 \%$ & $2,9 \%$ & $4,6 \%$ & $30,5 \%$ & $59,0 \%$ & $0,2 \%$ & $2,6 \%$ & $4,1 \%$ & $3,9 \%$ & $28,4 \%$ & $60,8 \%$ \\
\hline$>70$ & $0,7 \%$ & $3,4 \%$ & $6,8 \%$ & $8,8 \%$ & $26,4 \%$ & $54,1 \%$ & $0,0 \%$ & $6,1 \%$ & $4,1 \%$ & $10,1 \%$ & $24,3 \%$ & $55,4 \%$ \\
\hline
\end{tabular}

Fonte: elaborado pela autora

Tabela 16 - Percentual de respostas sobre a amostra de Apr_For_1, Apr_For_2 por Gênero e Faixa Etária

\begin{tabular}{|l|r|r|r|r|r|r|r|r|r|r|r|c|}
\cline { 2 - 14 } \multicolumn{1}{c|}{} & \multicolumn{9}{|c|}{ Apr_For_1 } & \multicolumn{6}{c|}{ Apr_For_2 } \\
\cline { 2 - 15 } & NS/NR & 1 & 2 & 3 & 4 & 5 & NS/NR & 1 & 2 & 3 & 4 & 5 \\
\hline Mulher & $1,3 \%$ & $4,2 \%$ & $6,1 \%$ & $5,0 \%$ & $22,9 \%$ & $60,5 \%$ & $1,1 \%$ & $4,2 \%$ & $6,9 \%$ & $7,6 \%$ & $29,9 \%$ & $50,3 \%$ \\
\hline Homem & $1,0 \%$ & $4,1 \%$ & $5,5 \%$ & $6,2 \%$ & $22,6 \%$ & $60,5 \%$ & $0,9 \%$ & $4,3 \%$ & $6,0 \%$ & $8,0 \%$ & $27,7 \%$ & $53,2 \%$ \\
\hline Outro & $2,8 \%$ & $13,5 \%$ & $14,6 \%$ & $12,3 \%$ & $22,5 \%$ & $34,2 \%$ & $2,0 \%$ & $15,8 \%$ & $14,7 \%$ & $14,6 \%$ & $25,4 \%$ & $27,5 \%$ \\
\hline até 20 & $2,5 \%$ & $3,6 \%$ & $4,4 \%$ & $6,9 \%$ & $19,5 \%$ & $63,0 \%$ & $2,0 \%$ & $3,2 \%$ & $4,6 \%$ & $9,5 \%$ & $25,1 \%$ & $55,6 \%$ \\
\hline até 30 & $1,4 \%$ & $4,7 \%$ & $6,1 \%$ & $6,7 \%$ & $22,4 \%$ & $58,6 \%$ & $1,2 \%$ & $4,6 \%$ & $6,8 \%$ & $9,1 \%$ & $28,2 \%$ & $50,0 \%$ \\
\hline até 40 & $0,9 \%$ & $4,5 \%$ & $6,3 \%$ & $5,9 \%$ & $23,6 \%$ & $58,7 \%$ & $0,8 \%$ & $4,8 \%$ & $7,0 \%$ & $8,0 \%$ & $29,2 \%$ & $50,4 \%$ \\
\hline até 50 & $0,8 \%$ & $3,4 \%$ & $5,0 \%$ & $4,6 \%$ & $22,5 \%$ & $63,7 \%$ & $0,7 \%$ & $3,7 \%$ & $5,6 \%$ & $6,2 \%$ & $28,7 \%$ & $55,1 \%$ \\
\hline até 60 & $1,2 \%$ & $2,7 \%$ & $4,2 \%$ & $3,9 \%$ & $21,5 \%$ & $66,6 \%$ & $0,8 \%$ & $2,9 \%$ & $4,3 \%$ & $5,3 \%$ & $28,6 \%$ & $58,0 \%$ \\
\hline até 70 & $1,2 \%$ & $2,4 \%$ & $3,2 \%$ & $3,6 \%$ & $20,2 \%$ & $69,4 \%$ & $1,2 \%$ & $3,1 \%$ & $3,7 \%$ & $5,2 \%$ & $25,4 \%$ & $61,4 \%$ \\
\hline$>70$ & $2,7 \%$ & $6,8 \%$ & $2,7 \%$ & $8,1 \%$ & $18,9 \%$ & $60,8 \%$ & $2,0 \%$ & $5,4 \%$ & $7,4 \%$ & $8,8 \%$ & $24,3 \%$ & $52,0 \%$ \\
\hline
\end{tabular}

Fonte: elaborado pela autora 
Tabela 17- Percentual de respostas sobre a amostra de Apr_Inf_1, Apr_Inf_2 por Gênero e Faixa Etária

\begin{tabular}{|c|c|c|c|c|c|c|c|c|c|c|c|c|}
\hline & \multicolumn{6}{|c|}{ Apr_Inf_1 } & \multicolumn{6}{|c|}{ Apr_Inf_2 } \\
\hline & NS/NR & 1 & 2 & 3 & 4 & 5 & NS/NR & 1 & 2 & 3 & 4 & 5 \\
\hline Mulher & $2,9 \%$ & $4,1 \%$ & $4,9 \%$ & $9,9 \%$ & $26,6 \%$ & $51,7 \%$ & $0,9 \%$ & $2,7 \%$ & $3,6 \%$ & $5,9 \%$ & $25,9 \%$ & $60,9 \%$ \\
\hline Homem & $2,5 \%$ & $4,1 \%$ & $4,6 \%$ & $10,6 \%$ & $26,8 \%$ & $51,3 \%$ & $0,7 \%$ & $2,5 \%$ & $3,0 \%$ & $5,9 \%$ & $24,2 \%$ & $63,6 \%$ \\
\hline Outro & $4,4 \%$ & $12,7 \%$ & $9,6 \%$ & $13,8 \%$ & $26,1 \%$ & $33,4 \%$ & $3,7 \%$ & $10,1 \%$ & $8,6 \%$ & $13,1 \%$ & $30,4 \%$ & $34,1 \%$ \\
\hline até 20 & $3,4 \%$ & $2,9 \%$ & $3,4 \%$ & $10,7 \%$ & $23,3 \%$ & $56,3 \%$ & $1,1 \%$ & $2,8 \%$ & $3,0 \%$ & $7,2 \%$ & $24,1 \%$ & $61,8 \%$ \\
\hline até 30 & $2,4 \%$ & $4,0 \%$ & $4,5 \%$ & $10,4 \%$ & $25,6 \%$ & $53,0 \%$ & $0,8 \%$ & $3,1 \%$ & $3,7 \%$ & $6,9 \%$ & $25,3 \%$ & $60,2 \%$ \\
\hline até 40 & $2,4 \%$ & $4,3 \%$ & $5,1 \%$ & $10,6 \%$ & $27,2 \%$ & $50,4 \%$ & $0,7 \%$ & $2,7 \%$ & $3,5 \%$ & $5,9 \%$ & $25,5 \%$ & $61,8 \%$ \\
\hline até 50 & $3,1 \%$ & $4,1 \%$ & $4,7 \%$ & $9,6 \%$ & $28,1 \%$ & $50,3 \%$ & $0,8 \%$ & $2,1 \%$ & $2,6 \%$ & $4,7 \%$ & $24,1 \%$ & $65,6 \%$ \\
\hline até 60 & $3,6 \%$ & $4,5 \%$ & $4,6 \%$ & $10,1 \%$ & $27,7 \%$ & $49,5 \%$ & $1,0 \%$ & $2,0 \%$ & $2,1 \%$ & $5,0 \%$ & $23,5 \%$ & $66,3 \%$ \\
\hline até 70 & $3,5 \%$ & $4,3 \%$ & $4,5 \%$ & $9,2 \%$ & $25,6 \%$ & $52,9 \%$ & $1,5 \%$ & $2,3 \%$ & $1,7 \%$ & $4,3 \%$ & $21,3 \%$ & $68,8 \%$ \\
\hline$>70$ & $2,7 \%$ & $7,4 \%$ & $4,7 \%$ & $12,8 \%$ & $20,9 \%$ & $51,4 \%$ & $1,4 \%$ & $6,1 \%$ & $6,8 \%$ & $7,4 \%$ & $20,3 \%$ & $58,1 \%$ \\
\hline
\end{tabular}

Fonte: elaborado pela autora

Tabela 18 - Percentual de respostas sobre a amostra de Apr_Exp_1, Apr_Exp_2 por Gênero e Faixa Etária

\begin{tabular}{|c|c|c|c|c|c|c|c|c|c|c|c|c|}
\hline & \multicolumn{6}{|c|}{ Apr_Exp_1 } & \multicolumn{6}{|c|}{ Apr_Exp_2 } \\
\hline & NS/NR & 1 & 2 & 3 & 4 & 5 & NS/NR & 1 & 2 & 3 & 4 & 5 \\
\hline Mulher & $0,6 \%$ & $3,5 \%$ & $5,4 \%$ & $6,3 \%$ & $28,6 \%$ & $55,6 \%$ & $1,9 \%$ & $4,2 \%$ & $6,9 \%$ & $9,5 \%$ & $35,2 \%$ & $42,3 \%$ \\
\hline Homem & $0,5 \%$ & $3,6 \%$ & $4,8 \%$ & $6,9 \%$ & $28,4 \%$ & $55,9 \%$ & $1,3 \%$ & $4,2 \%$ & $6,2 \%$ & $10,0 \%$ & $34,6 \%$ & $43,8 \%$ \\
\hline Outro & $1,9 \%$ & $13,4 \%$ & $14,4 \%$ & $16,7 \%$ & $26,9 \%$ & $26,8 \%$ & $2,7 \%$ & $14,6 \%$ & $15,7 \%$ & $17,3 \%$ & $31,6 \%$ & $18,2 \%$ \\
\hline até 20 & $1,0 \%$ & $2,3 \%$ & $3,2 \%$ & $6,7 \%$ & $25,1 \%$ & $61,7 \%$ & $2,8 \%$ & $4,1 \%$ & $5,8 \%$ & $13,5 \%$ & $31,0 \%$ & $42,7 \%$ \\
\hline até 30 & $0,6 \%$ & $3,5 \%$ & $4,9 \%$ & $7,5 \%$ & $28,2 \%$ & $55,3 \%$ & $1,9 \%$ & $4,6 \%$ & $6,9 \%$ & $11,8 \%$ & $34,3 \%$ & $40,5 \%$ \\
\hline até 40 & $0,5 \%$ & $4,0 \%$ & $5,7 \%$ & $7,0 \%$ & $29,3 \%$ & $53,6 \%$ & $1,3 \%$ & $4,3 \%$ & $6,8 \%$ & $9,7 \%$ & $35,4 \%$ & $42,5 \%$ \\
\hline até 50 & $0,5 \%$ & $3,3 \%$ & $4,8 \%$ & $5,5 \%$ & $28,2 \%$ & $57,8 \%$ & $1,2 \%$ & $3,6 \%$ & $5,8 \%$ & $7,6 \%$ & $35,2 \%$ & $46,6 \%$ \\
\hline até 60 & $0,5 \%$ & $3,0 \%$ & $4,1 \%$ & $5,3 \%$ & $28,1 \%$ & $59,0 \%$ & $1,5 \%$ & $3,7 \%$ & $5,2 \%$ & $6,9 \%$ & $34,7 \%$ & $48,1 \%$ \\
\hline até 70 & $0,8 \%$ & $2,6 \%$ & $3,6 \%$ & $4,5 \%$ & $24,9 \%$ & $63,6 \%$ & $1,2 \%$ & $3,5 \%$ & $4,0 \%$ & $6,6 \%$ & $34,5 \%$ & $50,3 \%$ \\
\hline$>70$ & $0,7 \%$ & $7,4 \%$ & $6,1 \%$ & $11,5 \%$ & $18,9 \%$ & $55,4 \%$ & $2,7 \%$ & $6,8 \%$ & $6,1 \%$ & $9,5 \%$ & $28,4 \%$ & $46,6 \%$ \\
\hline
\end{tabular}

Fonte: elaborado pela autora 


\section{Apêndice C: Tabelas de Contingência}

Seguem as tabelas de contingência que contaram a frequência de respostas no encontro de cada item da escala que mediu cada uma das assertivas da variável "Percepção Sobre Prática de DRH Aprendizagem Individual" (PPAI) com cada possível resposta para a variável "Intenção de Permanecer na Organização" (IPO). As análises foram feitas por assertiva e apresentaremos todas elas, sendo que a tabela de contingência que analisou o item Apr_Soc_1 e IPO foi apresentada no corpo do texto sob a denominação Tabela 11.

Tabela 11 - Tabela de Contingência Apr_Soc_1 e IPO

\begin{tabular}{|l|r|r|r|r|r|r|r|r|}
\hline \multirow{2}{*}{ Int_Perm } & \multicolumn{9}{|c|}{ Apr_Soc_1 } \\
\cline { 2 - 10 } & NS/NR & 1 & 2 & 3 & 4 & 5 & $\begin{array}{c}\text { Soma Cl } \\
\text { resposta }\end{array}$ & $\begin{array}{c}\text { Contagem } \\
\text { geral }\end{array}$ \\
\hline Estou procurando outra empresa neste momento & 73 & 826 & 1.067 & 1.090 & 2.695 & 2.335 & 8.013 & 8.086 \\
\hline Por menos de 1 ano & 71 & 678 & 1.058 & 1.228 & 3.813 & 4.475 & 11.252 & 11.323 \\
\hline Entre 1 $\mathrm{e} 3$ anos & 177 & 1.088 & 2.409 & 3.073 & 12.727 & 15.857 & 35.154 & 35.331 \\
\hline Entre 3 e 5 anos & 151 & 635 & 1.495 & 2.112 & 10.425 & 14.596 & 29.263 & 29.414 \\
\hline Entre 5 e 10 anos & 127 & 605 & 1.437 & 2.205 & 12.213 & 17.915 & 34.375 & 34.502 \\
\hline Mais de 10 anos & 121 & 462 & 1.032 & 1.668 & 9.906 & 17.272 & 30.340 & 30.461 \\
\hline Gostaria de me aposentar nesta empresa & 422 & 1.513 & 3.220 & 4.936 & 30.881 & 59.694 & 100.244 & 100.666 \\
\hline & & & & & & & & \\
\hline Total & 1.142 & 5.807 & 11.718 & 16.312 & 82.660 & 132.144 & & 249.783 \\
\hline
\end{tabular}

Fonte: elaborado pela autora

Tabela 19 - Tabela de Contingência Apr_Soc_2 e IPO

\begin{tabular}{|c|c|c|c|c|c|c|c|c|}
\hline \multirow{2}{*}{ Int_Perm } & \multicolumn{8}{|c|}{ Apr_Soc_2 } \\
\hline & NS/NR & 1 & 2 & 3 & 4 & 5 & $\begin{array}{l}\text { Soma cl } \\
\text { resposta }\end{array}$ & $\begin{array}{c}\text { Contagem } \\
\text { geral }\end{array}$ \\
\hline Estou procurando outra empresa neste momento & 40 & 1.380 & 1.427 & 810 & 2.443 & 1.986 & 8.046 & 8.086 \\
\hline Por menos de 1 ano & 54 & 1.140 & 1.519 & 1.169 & 3.542 & 3.899 & 11.269 & 11.323 \\
\hline Entre 1 e 3 anos & 145 & 1.961 & 3.667 & 3.179 & 12.251 & 14.128 & 35.186 & 35.331 \\
\hline Entre 3 e 5 anos & 109 & 1.169 & 2.258 & 2.362 & 10.330 & 13.186 & 29.305 & 29.414 \\
\hline Entre 5 e 10 anos & 90 & 1.021 & 2.249 & 2.551 & 12.202 & 16.389 & 34.412 & 34.502 \\
\hline Mais de 10 anos & 105 & 800 & 1.520 & 1.920 & 10.319 & 15.797 & 30.356 & 30.461 \\
\hline Gostaria de me aposentar nesta empresa & 298 & 2.606 & 4.986 & 5.799 & 33.178 & 53.799 & 100.368 & 100.666 \\
\hline Total & 841 & 10.077 & 17.626 & 17.790 & 84.265 & 119.184 & & 249.783 \\
\hline
\end{tabular}

Fonte: elaborado pela autora 
Tabela 20 - Tabela de Contingência Apr_For_1 e IPO

\begin{tabular}{|c|c|c|c|c|c|c|c|c|}
\hline \multirow[b]{2}{*}{ Int_Perm } & \multicolumn{8}{|c|}{ Apr_For_1 } \\
\hline & NS/NR & 1 & 2 & 3 & 4 & 5 & $\begin{array}{l}\text { Soma c/ } \\
\text { resposta }\end{array}$ & $\begin{array}{c}\text { Contagem } \\
\text { geral }\end{array}$ \\
\hline Estou procurando outra empresa neste momento & 179 & 1.804 & 1.276 & 919 & 1.892 & 2.016 & 7.907 & 8.086 \\
\hline Por menos de 1 ano & 219 & 1.329 & 1.357 & 1.114 & 2.896 & 4.408 & 11.104 & 11.323 \\
\hline Entre 1 e 3 anos & 597 & 2.460 & 3.378 & 3.086 & 9.466 & 16.344 & 34.734 & 35.331 \\
\hline Entre 3 e 5 anos & 383 & 1.220 & 2.112 & 2.103 & 7.672 & 15.924 & 29.031 & 29.414 \\
\hline Entre 5 e 10 anos & 389 & 1.026 & 1.834 & 1.983 & 8.712 & 20.558 & 34.113 & 34.502 \\
\hline Mais de 10 anos & 277 & 663 & 1.175 & 1.404 & 6.648 & 20.294 & 30.184 & 30.461 \\
\hline Gostaria de me aposentar nesta empresa & 808 & 1.986 & 3.298 & 3.821 & 19.436 & 71.317 & 99.858 & 100.666 \\
\hline Total & 2.852 & 10.488 & 14.430 & 14.430 & 56.722 & 150.861 & & 249.783 \\
\hline
\end{tabular}

Fonte: elaborado pela autora

Tabela 21 - Tabela de Contingência Apr_For_2 e IPO

\begin{tabular}{|l|r|r|r|r|r|r|r|r|}
\hline & \multicolumn{9}{|c|}{ Apr_For_2 } \\
\cline { 2 - 9 } & NSt_NR & 1 & 2 & 3 & 4 & 5 & $\begin{array}{c}\text { Soma C/ } \\
\text { resposta }\end{array}$ & $\begin{array}{c}\text { Contagem } \\
\text { geral }\end{array}$ \\
\hline Estou procurando outra empresa neste momento & 138 & 2.031 & 1.477 & 1.166 & 2.008 & 1.266 & 7.948 & 8.086 \\
\hline Por menos de 1 ano & 215 & 1.444 & 1.585 & 1.565 & 3.283 & 3.231 & 11.108 & 11.323 \\
\hline Entre 1 3 3 anos & 495 & 2.719 & 3.898 & 4.405 & 11.620 & 12.194 & 34.836 & 35.331 \\
\hline Entre 3 e 5 anos & 351 & 1.252 & 2.273 & 2.987 & 9.800 & 12.751 & 29.063 & 29.414 \\
\hline Entre 5e 10 anos & 320 & 972 & 2.106 & 2.752 & 10.969 & 17.383 & 34.182 & 34.502 \\
\hline Mais de 10 anos & 215 & 635 & 1.189 & 1.818 & 8.605 & 17.999 & 30.246 & 30.461 \\
\hline Gostaria de me aposentar nesta empresa & 689 & 1.749 & 3.390 & 4.889 & 25.055 & 64.894 & 99.977 & 100.666 \\
\hline Total & 2.423 & 10.802 & 15.918 & 19.582 & 71.340 & 129.718 & & 249.783 \\
\hline
\end{tabular}

Fonte: elaborado pela autora

Tabela 22 - Tabela de Contingência Apr_Inf_1 e IPO

\begin{tabular}{|l|r|r|r|r|r|r|r|r|}
\hline & \multicolumn{9}{|c|}{ Apr_Inf_1 } \\
\cline { 2 - 10 } & NS/NR & 1 & 2 & 3 & 4 & 5 & $\begin{array}{c}\text { Soma C/ } \\
\text { resposta }\end{array}$ & $\begin{array}{c}\text { Contagem } \\
\text { geral }\end{array}$ \\
\hline Estou procurando outra empresa neste momento & 187 & 1.683 & 1.010 & 1.166 & 1.716 & 2.324 & 7.899 & 8.086 \\
\hline Por menos de 1 ano & 312 & 1.219 & 1.105 & 1.669 & 3.011 & 4.007 & 11.011 & 11.323 \\
\hline Entre 1 e 3 anos & 756 & 1.961 & 2.715 & 5.018 & 10.840 & 14.041 & 34.575 & 35.331 \\
\hline Entre 3 e 5 anos & 722 & 925 & 1.504 & 3.466 & 9.009 & 13.788 & 28.692 & 29.414 \\
\hline Entre 5e 10 anos & 814 & 891 & 1.428 & 3.512 & 10.185 & 17.672 & 33.688 & 34.502 \\
\hline Mais de 10 anos & 755 & 734 & 975 & 2.623 & 7.817 & 17.557 & 29.706 & 30.461 \\
\hline Gostaria de me aposentar nesta empresa & 3.114 & 2.947 & 3.138 & 8.359 & 24.235 & 58.873 & 97.552 & 100.666 \\
\hline Total & 6.660 & 10.360 & 11.875 & 25.813 & 66.813 & 128.262 & & 249.783 \\
\hline
\end{tabular}

Fonte: elaborado pela autora 
Tabela 23 - Tabela de Contingência Apr_Inf_2 e IPO

\begin{tabular}{|c|c|c|c|c|c|c|c|c|}
\hline \multirow[b]{2}{*}{ Int_Perm } & \multicolumn{8}{|c|}{ Apr_Inf_2 } \\
\hline & NS/NR & 1 & 2 & 3 & 4 & 5 & $\begin{array}{l}\text { Soma cl } \\
\text { resposta }\end{array}$ & $\begin{array}{c}\text { Contagem } \\
\text { geral }\end{array}$ \\
\hline Estou procurando outra empresa neste momento & 135 & 1.778 & 1.179 & 1.254 & 2.265 & 1.475 & 7.951 & 8.086 \\
\hline Por menos de 1 ano & 173 & 1.180 & 1.247 & 1.607 & 3.516 & 3.600 & 11.150 & 11.323 \\
\hline Entre 1 e 3 anos & 376 & 1.480 & 2.200 & 3.703 & 12.447 & 15.125 & 34.955 & 35.331 \\
\hline Entre 3 e 5 anos & 264 & 582 & 1.074 & 2.093 & 9.108 & 16.293 & 29.150 & 29.414 \\
\hline Entre 5 e 10 anos & 259 & 448 & 720 & 1.782 & 9.325 & 21.968 & 34.243 & 34.502 \\
\hline Mais de 10 anos & 192 & 278 & 429 & 1.122 & 6.570 & 21.870 & 30.269 & 30.461 \\
\hline Gostaria de me aposentar nesta empresa & 649 & 891 & 1.290 & 3.349 & 19.026 & 75.461 & 100.017 & 100.666 \\
\hline Total & 2.048 & 6.637 & 8.139 & 14.910 & 62.257 & 155.792 & & 249.783 \\
\hline
\end{tabular}

Fonte: elaborado pela autora

Tabela 24 - Tabela de Contingência Apr_Exp_1 e IPO

\begin{tabular}{|l|r|r|r|r|r|r|r|r|}
\hline & \multicolumn{9}{|c|}{ Apr_Exp_1 } \\
\cline { 2 - 10 } & NS/NR & 1 & 2 & 3 & 4 & 5 & $\begin{array}{c}\text { Soma c/ } \\
\text { resposta }\end{array}$ & $\begin{array}{c}\text { Contagem } \\
\text { geral }\end{array}$ \\
\hline Estou procurando outra empresa neste momento & 84 & 1.991 & 1.509 & 1.214 & 2.079 & 1.209 & 8.002 & 8.086 \\
\hline Por menos de 1 ano & 104 & 1.330 & 1.458 & 1.568 & 3.472 & 3.391 & 11.219 & 11.323 \\
\hline Entre $1 \mathrm{e} 3$ anos & 232 & 1.979 & 3.201 & 3.701 & 12.320 & 13.898 & 35.099 & 35.331 \\
\hline Entre 3 e 5 anos & 164 & 829 & 1.637 & 2.322 & 9.786 & 14.676 & 29.250 & 29.414 \\
\hline Entre 5 e 10 anos & 137 & 749 & 1.365 & 2.234 & 10.582 & 19.435 & 34.365 & 34.502 \\
\hline Mais de 10 anos & 145 & 464 & 890 & 1.454 & 8.174 & 19.334 & 30.316 & 30.461 \\
\hline Gostaria de me aposentar nesta empresa & 467 & 1.585 & 2.558 & 4.278 & 24.687 & 67.091 & 100.199 & 100.666 \\
\hline Total & 1.333 & 8.927 & 12.618 & 16.771 & 71.100 & 139.034 & & 249.783 \\
\hline
\end{tabular}

Fonte: elaborado pela autora

Tabela 25 - Tabela de Contingência Apr_Exp_2 e IPO

\begin{tabular}{|c|c|c|c|c|c|c|c|c|}
\hline \multirow[b]{2}{*}{ Int_Perm } & \multicolumn{8}{|c|}{ Apr_Exp_2 } \\
\hline & NS/NR & 1 & 2 & 3 & 4 & 5 & $\begin{array}{l}\text { Soma c/ } \\
\text { resposta }\end{array}$ & $\begin{array}{c}\text { Contagem } \\
\text { geral }\end{array}$ \\
\hline Estou procurando outra empresa neste momento & 185 & 2.183 & 1.735 & 1.356 & 1.938 & 689 & 7.901 & 8.086 \\
\hline Por menos de 1 ano & 283 & 1.543 & 1.811 & 1.879 & 3.566 & 2.241 & 11.040 & 11.323 \\
\hline Entre 1 e 3 anos & 750 & 2.460 & 4.031 & 5.488 & 13.409 & 9.193 & 34.581 & 35.331 \\
\hline Entre 3 e 5 anos & 576 & 1.151 & 2.173 & 3.563 & 11.652 & 10.299 & 28.838 & 29.414 \\
\hline Entre 5 e 10 anos & 511 & 845 & 1.896 & 3.527 & 13.288 & 14.435 & 33.991 & 34.502 \\
\hline Mais de 10 anos & 393 & 578 & 1.206 & 2.394 & 10.584 & 15.306 & 30.068 & 30.461 \\
\hline Gostaria de me aposentar nesta empresa & 1.160 & 1.823 & 3.332 & 6.413 & 32.502 & 55.436 & 99.506 & 100.666 \\
\hline Total & 3.858 & 10.583 & 16.184 & 24.620 & 86.939 & 107.599 & & 249.783 \\
\hline
\end{tabular}

Fonte: elaborado pela autor 


\section{Apêndice D: Tabelas de contingência com percentual de respondentes}

Seguem as Tabelas de contingência com percentual de respondentes em cada possível resposta da assertiva investigada da variável "Percepção Sobre Prática de DRH Aprendizagem Individual” (PPAI), em relação ao total de respostas para cada um dos grupos da variável "Intenção de Permanecer na Organização" (IPO).

Sendo que a tabela de contingência que apresentou Apr_Soc_1 e IPO com frequência total de respostas sobre o total de respostas do grupo da variável IPO foi apresentada no corpo do texto sob a denominação Tabela 12.

Tabela 12 - Tabela de Contingência Apr_Soc_1 e IPO com frequência total de respostas sobre o total de respostas do grupo da variável IPO.

\begin{tabular}{|l|r|r|r|r|c|c|}
\hline Tabela Resumo & \multicolumn{7}{|c|}{ Apr_Soc_1 } \\
\hline Int_Perm & NS/NR & 1 & 2 & 3 & 4 & 5 \\
\hline Estou procurando outra empresa neste momento & $0,9 \%$ & $10,3 \%$ & $13,3 \%$ & $13,6 \%$ & $33,6 \%$ & $29,1 \%$ \\
\hline Por menos de 1 ano & $0,6 \%$ & $6,0 \%$ & $9,4 \%$ & $10,9 \%$ & $33,9 \%$ & $39,8 \%$ \\
\hline Entre 1 e 3 anos & $0,5 \%$ & $3,1 \%$ & $6,9 \%$ & $8,7 \%$ & $36,2 \%$ & $45,1 \%$ \\
\hline Entre 3 e 5 anos & $0,5 \%$ & $2,2 \%$ & $5,1 \%$ & $7,2 \%$ & $35,6 \%$ & $49,9 \%$ \\
\hline Entre 5 e 10 anos & $0,4 \%$ & $1,8 \%$ & $4,2 \%$ & $6,4 \%$ & $35,5 \%$ & $52,1 \%$ \\
\hline Mais de 10 anos & $0,4 \%$ & $1,5 \%$ & $3,4 \%$ & $5,5 \%$ & $32,6 \%$ & $56,9 \%$ \\
\hline Gostaria de me aposentar nesta empresa & $0,4 \%$ & $1,5 \%$ & $3,2 \%$ & $4,9 \%$ & $30,8 \%$ & $59,5 \%$ \\
\hline \hline Total de Respostas em cada ponto da escala da & $0,5 \%$ & $2,3 \%$ & $4,7 \%$ & $6,5 \%$ & $33,1 \%$ & $52,9 \%$ \\
\hline assertiva sobre total da amostra & & & & & & \\
\hline Fonte:
\end{tabular}

Fonte: elaborado pela autora

As demais tabelas estão dispostas apenas aqui, no Apêndice.

Tabela 26 - Tabela de Contingência Apr_Soc_2 e IPO com frequência total de respostas sobre o total de respostas do grupo da variável IPO.

\begin{tabular}{|l|r|r|r|r|r|r|}
\hline Tabela Resumo & \multicolumn{7}{|c|}{ Apr_Soc_2 } \\
\hline Int_Perm & NS/NR & 1 & 2 & 3 & 4 & 5 \\
\hline Estou procurando outra empresa neste momento & $0,5 \%$ & $17,2 \%$ & $17,7 \%$ & $10,1 \%$ & $30,4 \%$ & $24,7 \%$ \\
\hline Por menos de 1 ano & $0,5 \%$ & $10,1 \%$ & $13,5 \%$ & $10,4 \%$ & $31,4 \%$ & $34,6 \%$ \\
\hline Entre 1 e 3 anos & $0,4 \%$ & $5,6 \%$ & $10,4 \%$ & $9,0 \%$ & $34,8 \%$ & $40,2 \%$ \\
\hline Entre 3 e 5 anos & $0,4 \%$ & $4,0 \%$ & $7,7 \%$ & $8,1 \%$ & $35,2 \%$ & $45,0 \%$ \\
\hline Entre 5 e 10 anos & $0,3 \%$ & $3,0 \%$ & $6,5 \%$ & $7,4 \%$ & $35,5 \%$ & $47,6 \%$ \\
\hline Mais de 10 anos & $0,3 \%$ & $2,6 \%$ & $5,0 \%$ & $6,3 \%$ & $34,0 \%$ & $52,0 \%$ \\
\hline Gostaria de me aposentar nesta empresa & $0,3 \%$ & $2,6 \%$ & $5,0 \%$ & $5,8 \%$ & $33,1 \%$ & $53,6 \%$ \\
\hline \hline Total de Respostas no item sobre total da amostra & $0,3 \%$ & $4,0 \%$ & $7,1 \%$ & $7,1 \%$ & $33,7 \%$ & $47,7 \%$ \\
\hline Fonte:
\end{tabular}

Fonte: elaborado pela autora 
Tabela 27 - Tabela de Contingência Apr_For_1 e IPO com frequência total de respostas sobre o total de respostas do grupo da variável IPO.

\begin{tabular}{|l|r|r|r|r|r|r|}
\hline Tabela Resumo & \multicolumn{5}{|c|}{ Apr_For_1 } \\
\hline Int_Perm & NS/NR & 1 & 2 & 3 & 4 & 5 \\
\hline Estou procurando outra empresa neste momento & $2,3 \%$ & $22,8 \%$ & $16,1 \%$ & $11,6 \%$ & $23,9 \%$ & $25,5 \%$ \\
\hline Por menos de 1 ano & $2,0 \%$ & $12,0 \%$ & $12,2 \%$ & $10,0 \%$ & $26,1 \%$ & $39,7 \%$ \\
\hline Entre 1 e 3 anos & $1,7 \%$ & $7,1 \%$ & $9,7 \%$ & $8,9 \%$ & $27,3 \%$ & $47,1 \%$ \\
\hline Entre 3 e 5 anos & $1,3 \%$ & $4,2 \%$ & $7,3 \%$ & $7,2 \%$ & $26,4 \%$ & $54,9 \%$ \\
\hline Entre 5 e 10 anos & $1,1 \%$ & $3,0 \%$ & $5,4 \%$ & $5,8 \%$ & $25,5 \%$ & $60,3 \%$ \\
\hline Mais de 10 anos & $0,9 \%$ & $2,2 \%$ & $3,9 \%$ & $4,7 \%$ & $22,0 \%$ & $67,2 \%$ \\
\hline Gostaria de me aposentar nesta empresa & $0,8 \%$ & $2,0 \%$ & $3,3 \%$ & $3,8 \%$ & $19,5 \%$ & $71,4 \%$ \\
\hline \hline Total de Respostas no item sobre total da amostra & $1,1 \%$ & $4,2 \%$ & $5,8 \%$ & $5,8 \%$ & $22,7 \%$ & $60,4 \%$ \\
\hline
\end{tabular}

Fonte: elaborado pela autora

Tabela 28 - Tabela de Contingência Apr_For_2 e IPO com frequência total de respostas sobre o total de respostas do grupo da variável IPO.

\begin{tabular}{|l|r|r|r|r|r|r|}
\hline Tabela Resumo & \multicolumn{7}{|c|}{ Apr_For_2 } \\
\hline Int_Perm & NS/NR & 1 & 2 & 3 & 4 & 5 \\
\hline Estou procurando outra empresa neste momento & $1,7 \%$ & $25,6 \%$ & $18,6 \%$ & $14,7 \%$ & $25,3 \%$ & $15,9 \%$ \\
\hline Por menos de 1 ano & $1,9 \%$ & $13,0 \%$ & $14,3 \%$ & $14,1 \%$ & $29,6 \%$ & $29,1 \%$ \\
\hline Entre 1 e 3 anos & $1,4 \%$ & $7,8 \%$ & $11,2 \%$ & $12,6 \%$ & $33,4 \%$ & $35,0 \%$ \\
\hline Entre 3 e 5 anos & $1,2 \%$ & $4,3 \%$ & $7,8 \%$ & $10,3 \%$ & $33,7 \%$ & $43,9 \%$ \\
\hline Entre 5 e 10 anos & $0,9 \%$ & $2,8 \%$ & $6,2 \%$ & $8,1 \%$ & $32,1 \%$ & $50,9 \%$ \\
\hline Mais de 10 anos & $0,7 \%$ & $2,1 \%$ & $3,9 \%$ & $6,0 \%$ & $28,5 \%$ & $59,5 \%$ \\
\hline Gostaria de me aposentar nesta empresa & $0,7 \%$ & $1,7 \%$ & $3,4 \%$ & $4,9 \%$ & $25,1 \%$ & $64,9 \%$ \\
\hline \hline Total de Respostas no item sobre total da amostra & $1,0 \%$ & $4,3 \%$ & $6,4 \%$ & $7,8 \%$ & $28,6 \%$ & $51,9 \%$ \\
\hline
\end{tabular}

Fonte: elaborado pela autora

Tabela 29 - Tabela de Contingência Apr_Inf_1 e IPO com frequência total de respostas sobre o total de respostas do grupo da variável IPO.

\begin{tabular}{|l|r|r|r|r|r|r|}
\hline Tabela Resumo & \multicolumn{7}{|c|}{ Apr_Inf_1 } \\
\hline Int_Perm & NS/NR & 1 & 2 & 3 & 4 & 5 \\
\hline Estou procurando outra empresa neste momento & $2,4 \%$ & $21,3 \%$ & $12,8 \%$ & $14,8 \%$ & $21,7 \%$ & $29,4 \%$ \\
\hline Por menos de 1 ano & $2,8 \%$ & $11,1 \%$ & $10,0 \%$ & $15,2 \%$ & $27,3 \%$ & $36,4 \%$ \\
\hline Entre 1 e 3 anos & $2,2 \%$ & $5,7 \%$ & $7,9 \%$ & $14,5 \%$ & $31,4 \%$ & $40,6 \%$ \\
\hline Entre 3 e 5 anos & $2,5 \%$ & $3,2 \%$ & $5,2 \%$ & $12,1 \%$ & $31,4 \%$ & $48,1 \%$ \\
\hline Entre 5 e 10 anos & $2,4 \%$ & $2,6 \%$ & $4,2 \%$ & $10,4 \%$ & $30,2 \%$ & $52,5 \%$ \\
\hline Mais de 10 anos & $2,5 \%$ & $2,5 \%$ & $3,3 \%$ & $8,8 \%$ & $26,3 \%$ & $59,1 \%$ \\
\hline Gostaria de me aposentar nesta empresa & $3,2 \%$ & $3,0 \%$ & $3,2 \%$ & $8,6 \%$ & $24,8 \%$ & $60,4 \%$ \\
\hline \hline Total de Respostas no item sobre total da amostra & $2,7 \%$ & $4,1 \%$ & $4,8 \%$ & $10,3 \%$ & $26,7 \%$ & $51,3 \%$ \\
\hline Fonte: elab
\end{tabular}

Fonte: elaborado pela autora 
Tabela 30 - Tabela de Contingência Apr_Inf_2 e IPO com frequência total de respostas sobre o total de respostas do grupo da variável IPO.

\begin{tabular}{|l|r|r|r|r|r|r|}
\hline Tabela Resumo & \multicolumn{7}{|c|}{ Apr_Inf_2 } \\
\hline Int_Perm & NS/NR & 1 & 2 & 3 & 4 & 5 \\
\hline Estou procurando outra empresa neste momento & $1,7 \%$ & $22,4 \%$ & $14,8 \%$ & $15,8 \%$ & $28,5 \%$ & $18,6 \%$ \\
\hline Por menos de 1 ano & $1,6 \%$ & $10,6 \%$ & $11,2 \%$ & $14,4 \%$ & $31,5 \%$ & $32,3 \%$ \\
\hline Entre 1 e 3 anos & $1,1 \%$ & $4,2 \%$ & $6,3 \%$ & $10,6 \%$ & $35,6 \%$ & $43,3 \%$ \\
\hline Entre 3 e 5 anos & $0,9 \%$ & $2,0 \%$ & $3,7 \%$ & $7,2 \%$ & $31,2 \%$ & $55,9 \%$ \\
\hline Entre 5 e 10 anos & $0,8 \%$ & $1,3 \%$ & $2,1 \%$ & $5,2 \%$ & $27,2 \%$ & $64,2 \%$ \\
\hline Mais de 10 anos & $0,6 \%$ & $0,9 \%$ & $1,4 \%$ & $3,7 \%$ & $21,7 \%$ & $72,3 \%$ \\
\hline Gostaria de me aposentar nesta empresa & $0,6 \%$ & $0,9 \%$ & $1,3 \%$ & $3,3 \%$ & $19,0 \%$ & $75,4 \%$ \\
\hline \hline Total de Respostas no item sobre total da amostra & $0,8 \%$ & $2,7 \%$ & $3,3 \%$ & $6,0 \%$ & $24,9 \%$ & $62,4 \%$ \\
\hline Fonte: elaborad
\end{tabular}

Fonte: elaborado pela autora

Tabela 31 - Tabela de Contingência Apr_Exp_1 e IPO com frequência total de respostas sobre o total de respostas do grupo da variável IPO.

\begin{tabular}{|l|r|r|r|r|r|c|}
\hline Tabela Resumo & \multicolumn{7}{|c|}{ Apr_Exp_1 } \\
\hline Int_Perm & NS/NR & 1 & 2 & 3 & 4 & 5 \\
\hline Estou procurando outra empresa neste momento & $1,0 \%$ & $24,9 \%$ & $18,9 \%$ & $15,2 \%$ & $26,0 \%$ & $15,1 \%$ \\
\hline Por menos de 1 ano & $0,9 \%$ & $11,9 \%$ & $13,0 \%$ & $14,0 \%$ & $30,9 \%$ & $30,2 \%$ \\
\hline Entre 1 e 3 anos & $0,7 \%$ & $5,6 \%$ & $9,1 \%$ & $10,5 \%$ & $35,1 \%$ & $39,6 \%$ \\
\hline Entre 3 e 5 anos & $0,6 \%$ & $2,8 \%$ & $5,6 \%$ & $7,9 \%$ & $33,5 \%$ & $50,2 \%$ \\
\hline Entre 5 e 10 anos & $0,4 \%$ & $2,2 \%$ & $4,0 \%$ & $6,5 \%$ & $30,8 \%$ & $56,6 \%$ \\
\hline Mais de 10 anos & $0,5 \%$ & $1,5 \%$ & $2,9 \%$ & $4,8 \%$ & $27,0 \%$ & $63,8 \%$ \\
\hline Gostaria de me aposentar nesta empresa & $0,5 \%$ & $1,6 \%$ & $2,6 \%$ & $4,3 \%$ & $24,6 \%$ & $67,0 \%$ \\
\hline \hline Total de Respostas no item sobre total da amostra & $0,5 \%$ & $3,6 \%$ & $5,1 \%$ & $6,7 \%$ & $28,5 \%$ & $55,7 \%$ \\
\hline
\end{tabular}

Fonte: elaborado pela autora

Tabela 32 - Tabela de Contingência Apr_Exp_2 e IPO com frequência total de respostas sobre o total de respostas do grupo da variável IPO.

\begin{tabular}{|l|r|r|r|r|r|r|}
\hline Tabela Resumo & \multicolumn{5}{|c|}{ Apr_Exp_2 } \\
\hline Int_Perm & NS/NR & 1 & 2 & 3 & 4 & 5 \\
\hline Estou procurando outra empresa neste momento & $2,3 \%$ & $27,6 \%$ & $22,0 \%$ & $17,2 \%$ & $24,5 \%$ & $8,7 \%$ \\
\hline Por menos de 1 ano & $2,6 \%$ & $14,0 \%$ & $16,4 \%$ & $17,0 \%$ & $32,3 \%$ & $20,3 \%$ \\
\hline Entre 1 e 3 anos & $2,2 \%$ & $7,1 \%$ & $11,7 \%$ & $15,9 \%$ & $38,8 \%$ & $26,6 \%$ \\
\hline Entre 3 e 5 anos & $2,0 \%$ & $4,0 \%$ & $7,5 \%$ & $12,4 \%$ & $40,4 \%$ & $35,7 \%$ \\
\hline Entre 5 e 10 anos & $1,5 \%$ & $2,5 \%$ & $5,6 \%$ & $10,4 \%$ & $39,1 \%$ & $42,5 \%$ \\
\hline Mais de 10 anos & $1,3 \%$ & $1,9 \%$ & $4,0 \%$ & $8,0 \%$ & $35,2 \%$ & $50,9 \%$ \\
\hline Gostaria de me aposentar nesta empresa & $1,2 \%$ & $1,8 \%$ & $3,3 \%$ & $6,4 \%$ & $32,7 \%$ & $55,7 \%$ \\
\hline \hline Total de Respostas no item sobre total da amostra & $1,5 \%$ & $4,2 \%$ & $6,5 \%$ & $9,9 \%$ & $34,8 \%$ & $43,1 \%$ \\
\hline \hline
\end{tabular}

Fonte: elaborado pela autora 


\section{Apêndice E: Gráfico de Resultados}

Seguem os gráficos de resultados esperados sem efeito e gráficos de resultados observados por questão que compõe a variável PPAI. Observa-se o mesmo padrão em cada um dos gráficos de resultados observados, demonstrando a associação entre as variáveis.

Os gráficos referentes ao item Apr_Soc_1 foram apresentados no corpo do texto sob a denominação Gráfico 1 e Gráfico 2, mas para uma melhor comparação foram replicados aqui, lado a lado e tratam da pergunta:

Apr_Soc_1 - Meus colegas estão sempre dispostos a dividir comigo o que sabem
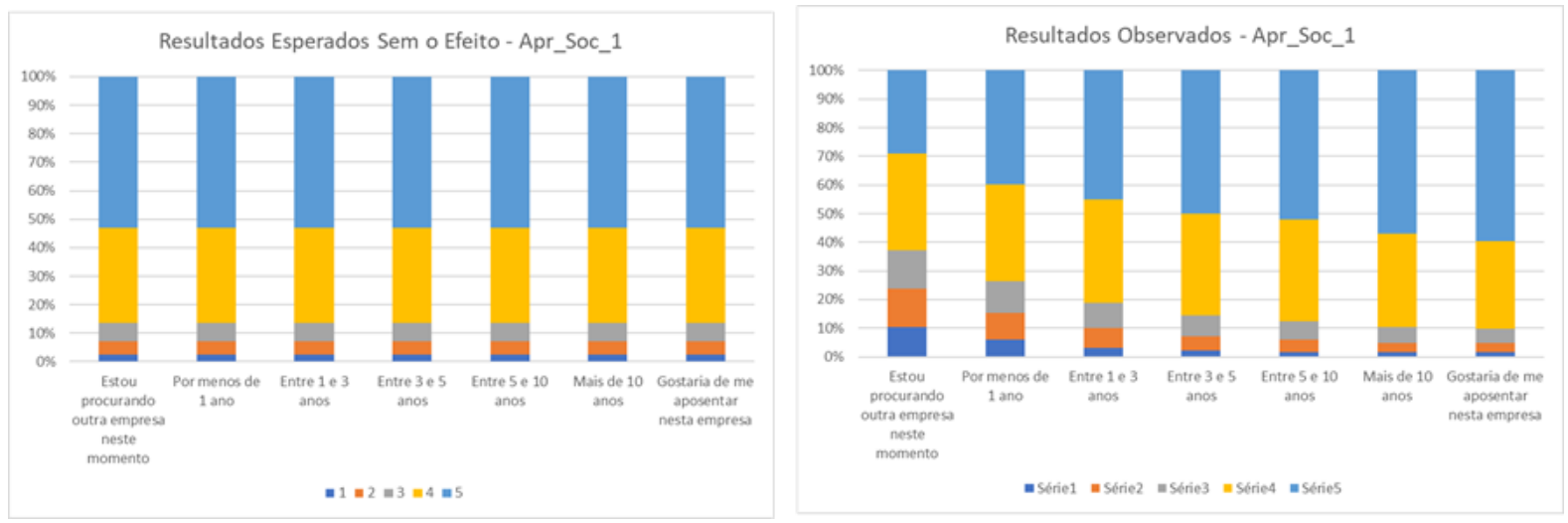

Fonte: elaborado pela autora

Os gráficos deste Apêndice não foram apresentados no corpo do texto, apenas aqui para o esclarecimento de quaisquer dúvidas $\mathrm{O}$ Gráfico 12 se orienta pelo item: $\mathrm{Na}$ minha equipe, as pessoas estão sempre dispostas a ajudar umas às outras (Apr_Soc_2) 
Gráfico 12 - Resultados Esperados sem o Efeito de Associação e Resultados Observados para item Apr_Soc_2 e IPO
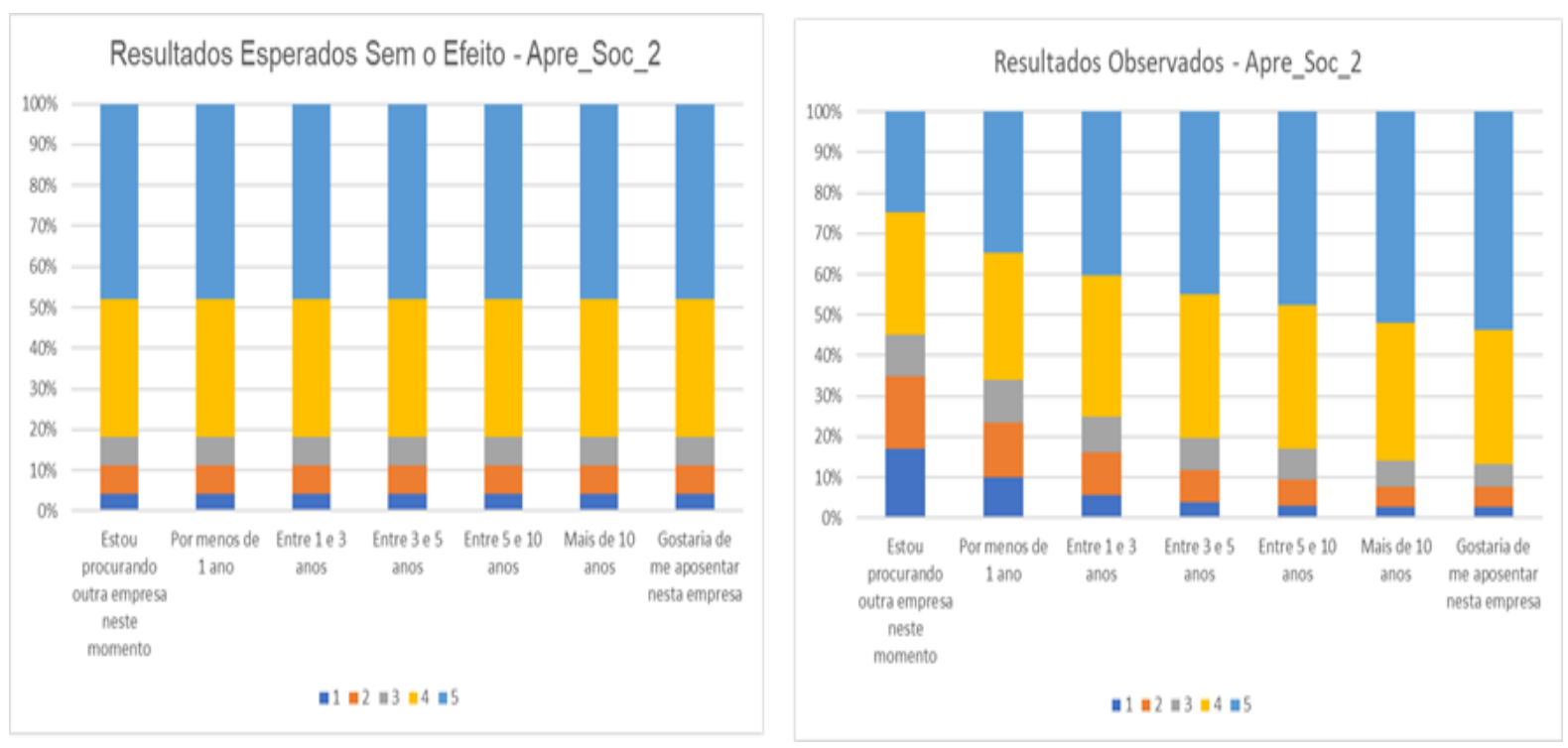

Fonte: elaborado pela autora

O Gráfico 13 se orienta pelo item: Todos têm oportunidade de participar de atividades de treinamento nesta empresa (Apr_For_1)

Gráfico 13 - Resultados Esperados sem o Efeito de Associação e Resultados Observados para item Apr_For_1 e IPO
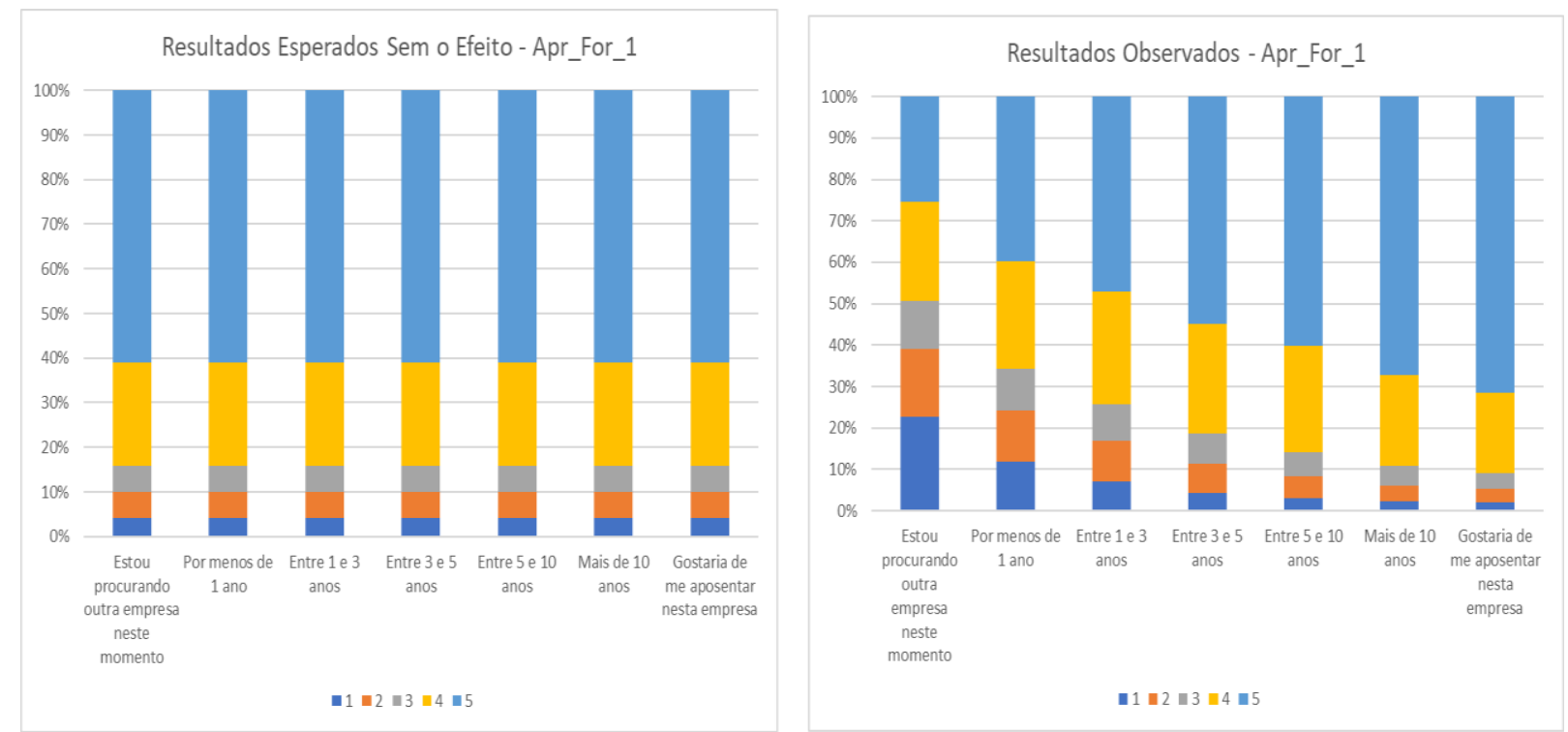

Fonte: elaborado pela autora 
O Gráfico 14 se orienta pelo item: Os treinamentos oferecidos pela empresa atendem adequadamente às necessidades do meu trabalho (Apr_For_2)

Gráfico 14 - Resultados Esperados sem o Efeito de Associação e Resultados Observados para item Apr_For_2 e IPO
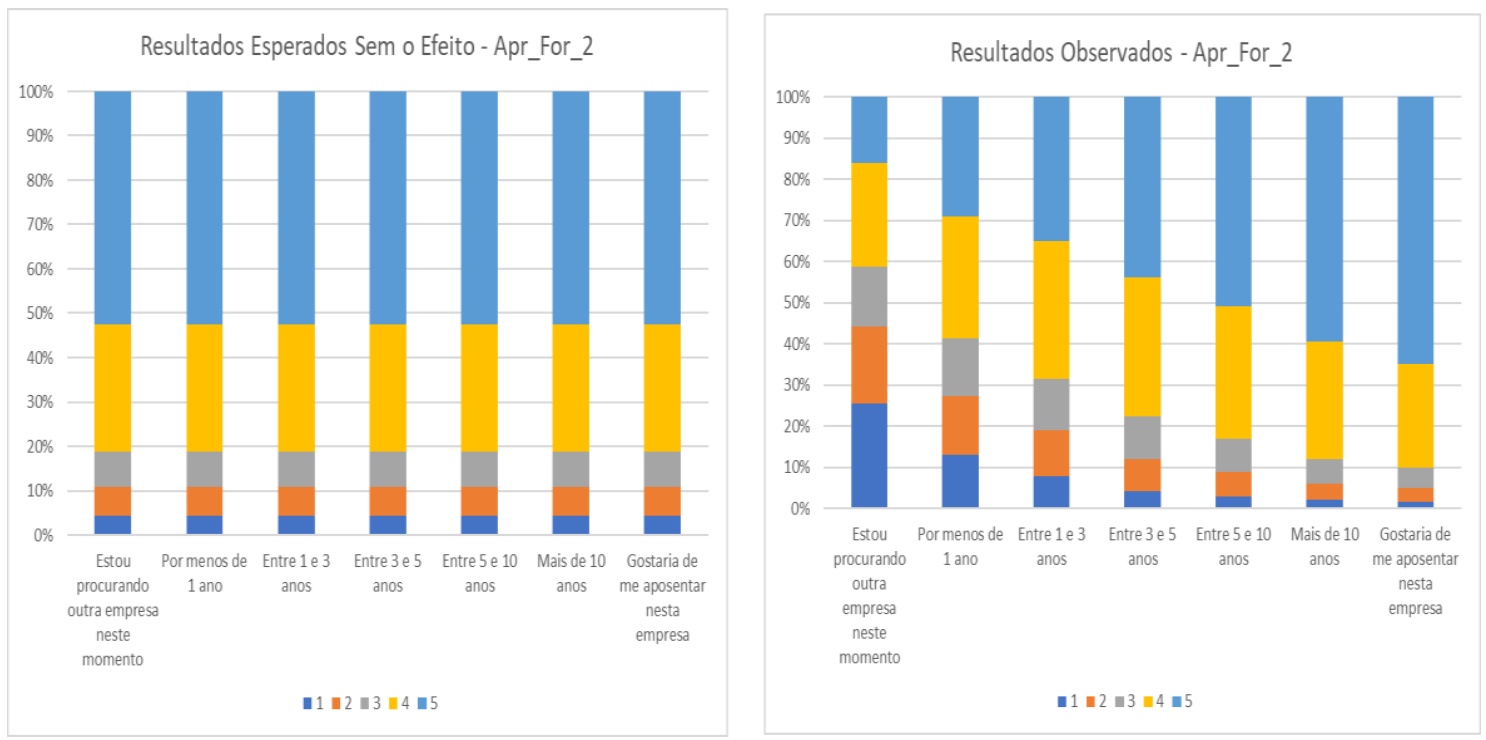

Fonte: elaborado pela autora

O Gráfico 15 se orienta pelo item: Sinto-me estimulado a buscar novos conhecimentos fora da empresa (Apr_Inf_1)

Gráfico 15 - Resultados Esperados sem o Efeito de Associação e Resultados Observados para item Apr_Inf_1 e IPO
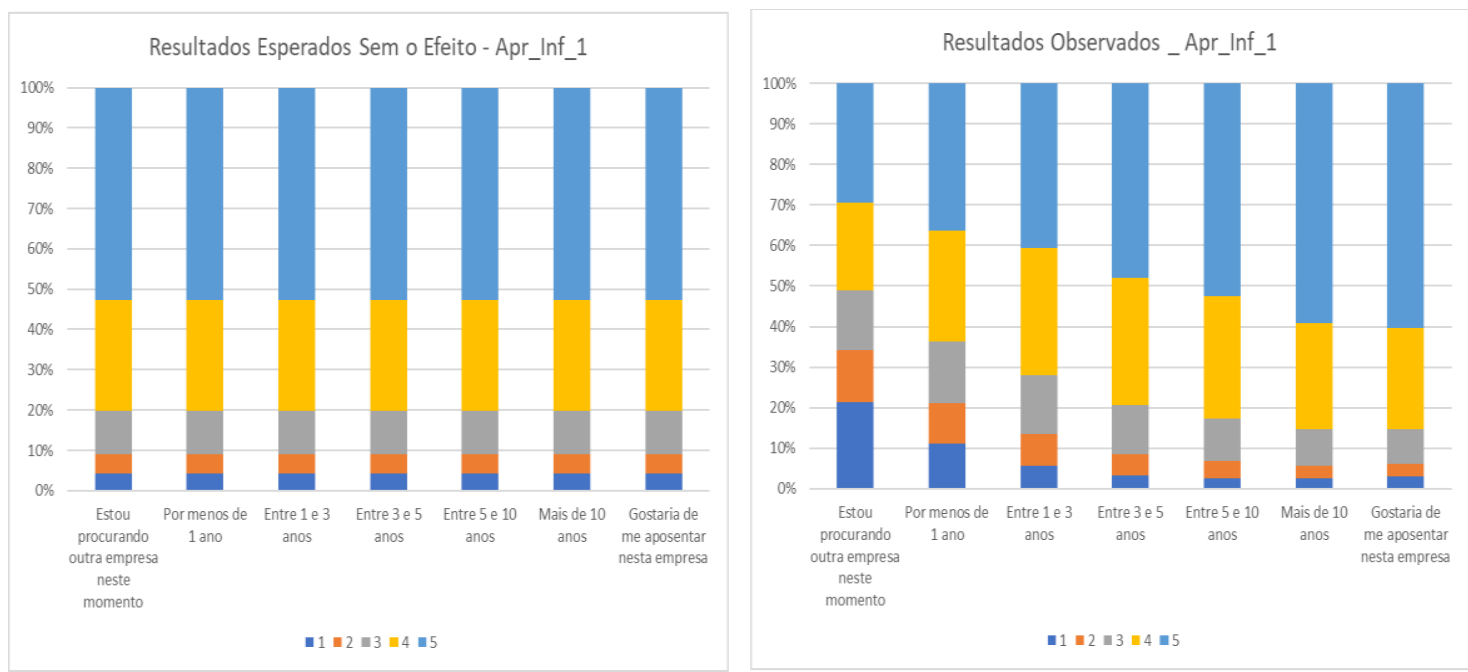

Fonte: elaborado pela autora 
O Gráfico 16 se orienta pelo item: O trabalho que realizo nesta empresa apresenta desafios que estimulam o meu desenvolvimento (Apr_Inf_2)

Gráfico 16 - Resultados Esperados sem o Efeito de Associação e Resultados Observados para item Apr_Inf_2 e IPO
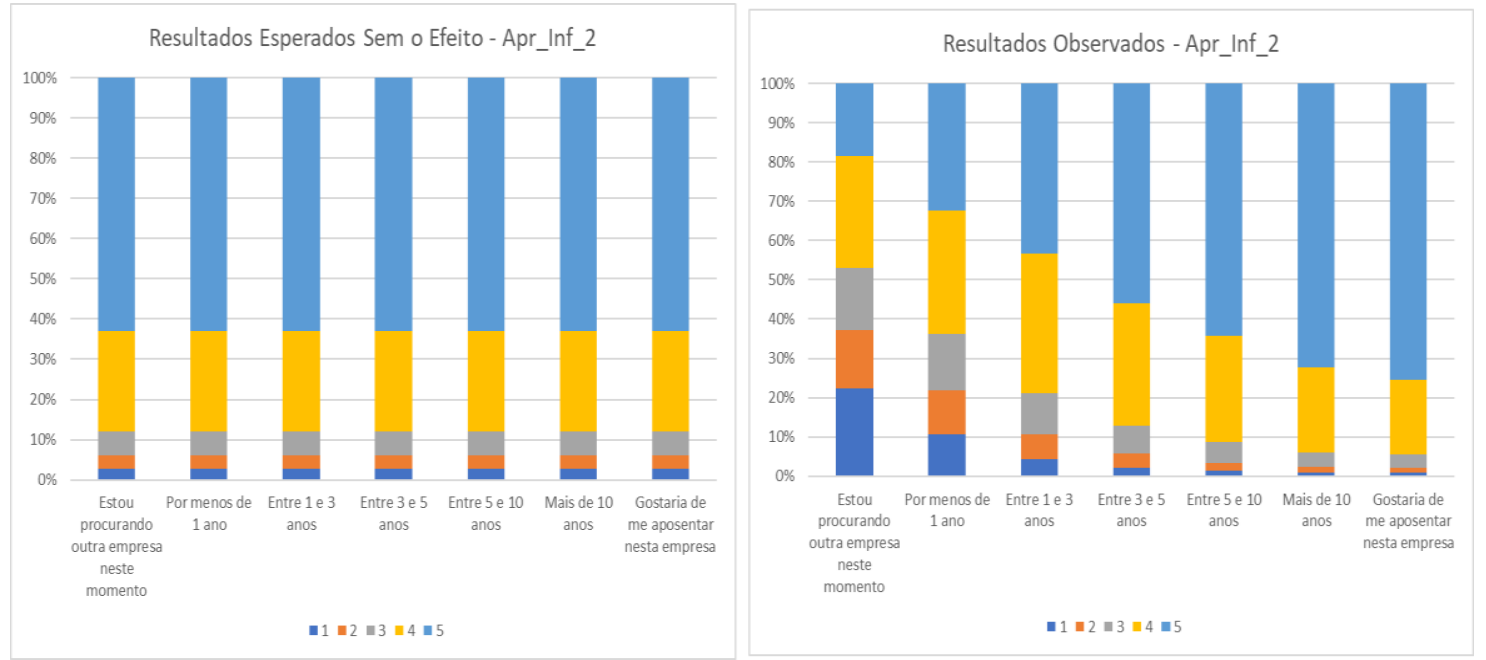

Fonte: elaborado pela autora

O Gráfico 17 se orienta pelo item: Sou estimulado a contribuir para melhorar a forma como é feito meu trabalho (Apr_Exp_1)

Gráfico 17 - Resultados Esperados sem o Efeito de Associação e Resultados Observados para item Apr_Exp_1 e IPO
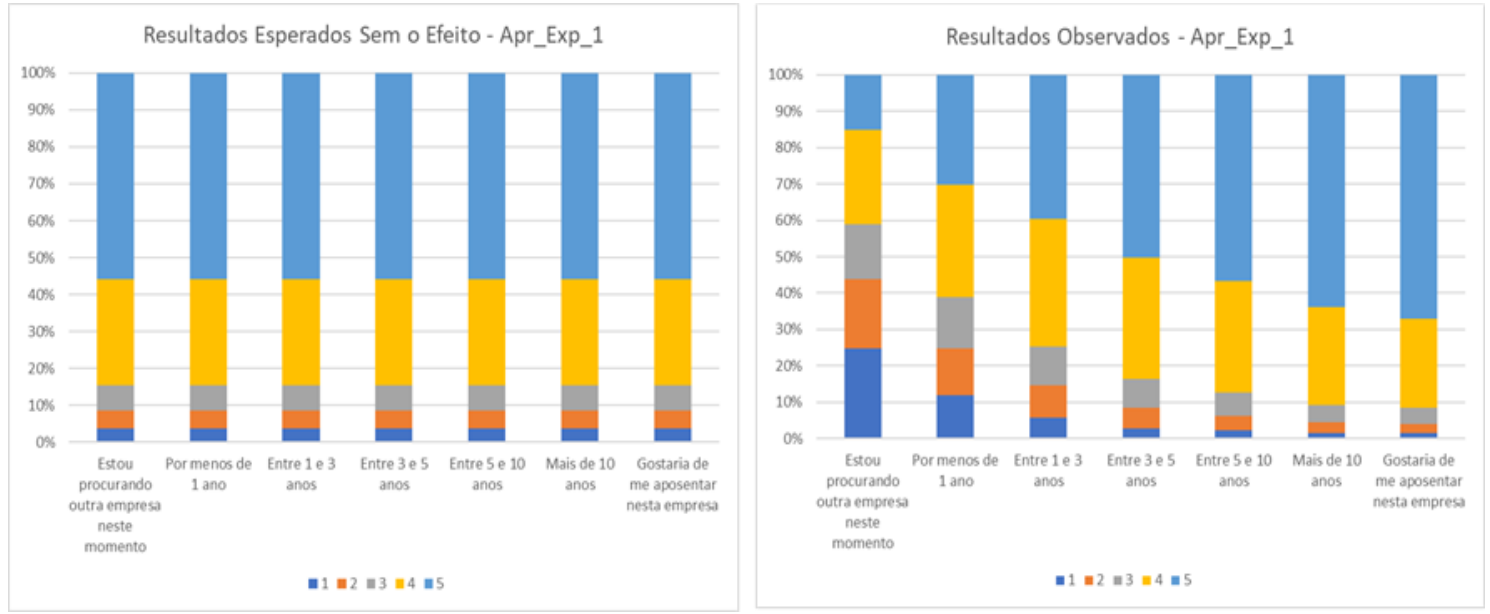

Fonte: elaborado pela autora 
O Gráfico 18 se orienta pelo item: Esta empresa coloca em prática as sugestões de seus funcionários, sempre que possível (Apr_Exp_2)

Gráfico 18 - Resultados Esperados sem o Efeito de Associação e Resultados Observados para item Apr_Exp_2 e IPO
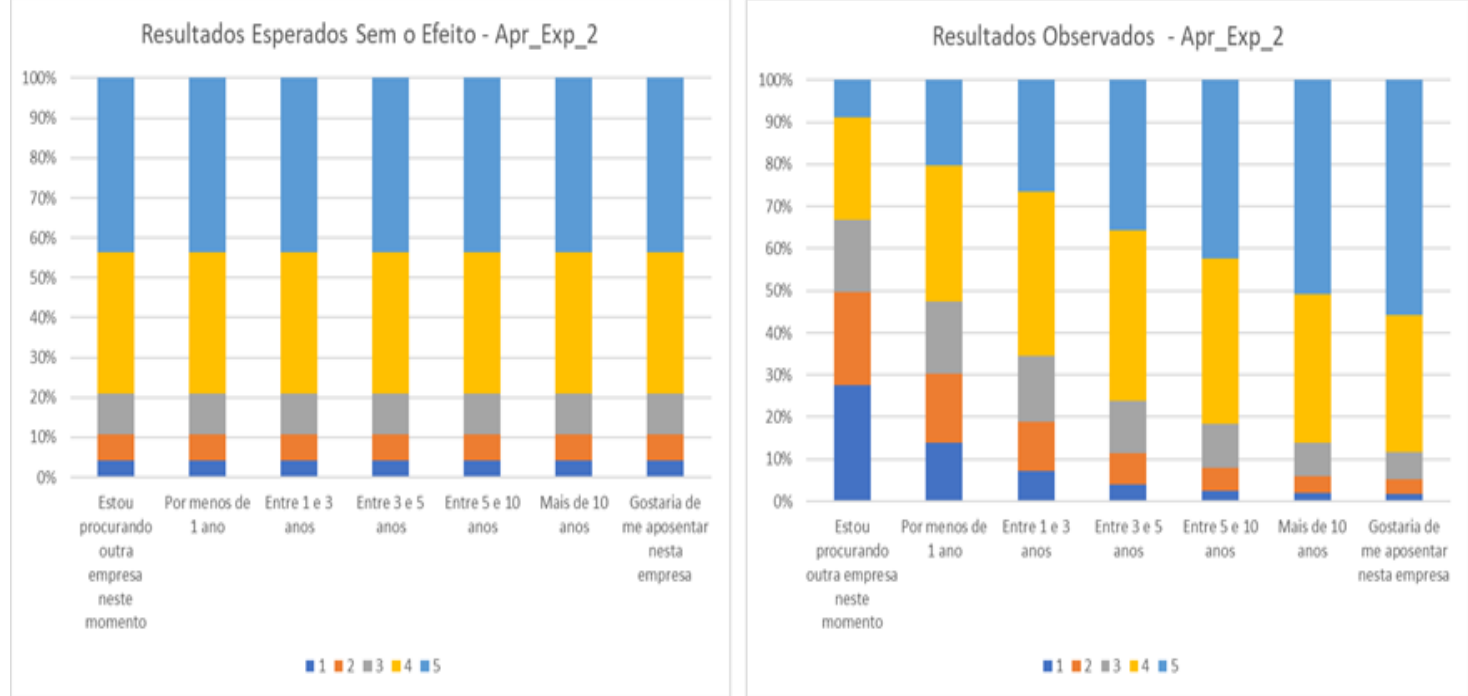

Fonte: elaborado pela autora 